\begin{abstract}
Title of Document:

A STRUCTURED METHODOLOGY FOR IDENTIFYING PERFORMANCE METRICS AND MONITORING MAINTENANCE EFFECTIVENESS

Maria Mercedes Amoedo, Master's, 2005

Directed By:

Professor Mohammad Modarres

Department of Mechanical Engineering

Reliability Engineering Program
\end{abstract}

Most current maintenance programs focus on achieving the main goals of maintenance operations: increasing mean time between failures, reducing time to repair and minimizing costs. Some researchers have focused on optimizing these variables. Detailed analyses have been conducted in the fields of equipment wellness, spares administration, planned maintenance and structured organization. Still, many organizations fail to fulfill today's ambitious objective of guaranteeing operations while achieving high reliability and maintaining safety. A comprehensive method of maintenance assessment that considers key factors and indicators that influence the main goals of maintenance is still sought after.

This paper discusses a new approach to performance-based maintenance management. The objective is to determine an integrated reliability management system that provides a method of aligning maintenance operations with the business strategy and monitoring performance of key technical, human and organization goals over time. 


\section{A STRUCTURED METHODOLOGY FOR IDENTIFYING PERFORMANCE METRICS AND MONITORING MAINTENANCE EFFECTIVENESS}

By

Maria Mercedes Amoedo

Thesis submitted to the Faculty of the Graduate School of the University of Maryland, College Park, in partial fulfillment of the requirements for the degree of

Master of Science

2005

Advisory Committee:

Professor Mohammad Modarres, Chair

Professor Ali Mosleh

Professor Joseph Bernstein 
(C) Copyright by

Maria Mercedes Amoedo

2005 


\section{Acknowledgements}

I would like to thank the Ford Argentina Stamping and Body Maintenance staff for providing valuable information to this research. I specially thank Mr. Osvaldo Lerose for his helpful feedback on the trees development.

I am also grateful to my parents that always helped me achieve my ambitions and my husband Jan whose unconditional support has always been the foundation to my career and academic success. 


\section{Table of Contents}

Acknowledgements ........................................................................................... ii

Table of Contents .................................................................................................ii

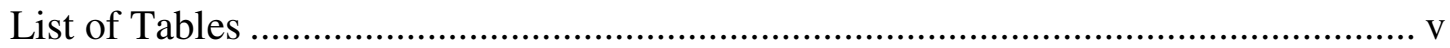

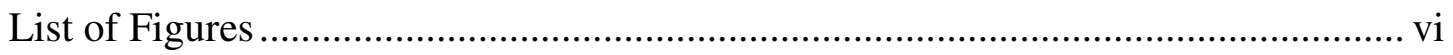

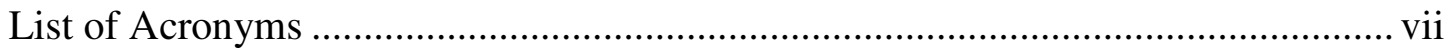

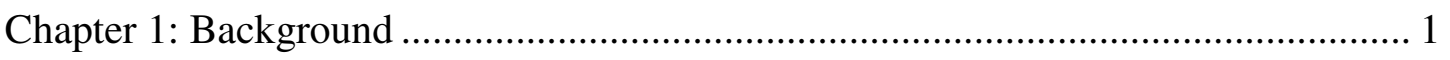

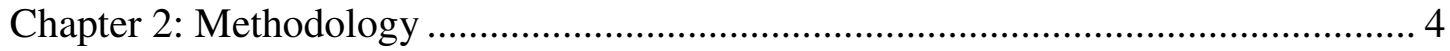

2.1 Overview .............................................................................................. 4

2.2 The Balanced Scorecard ...................................................................... 4

2.3 Hierarchical Decomposition Using Goal Tree Analysis................................ 7

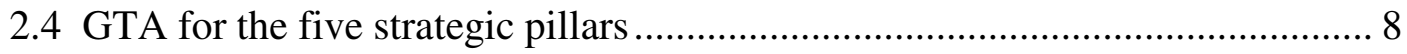

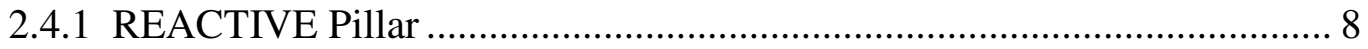

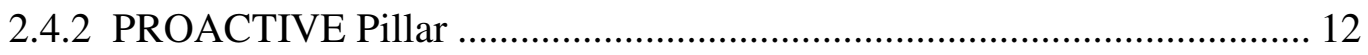

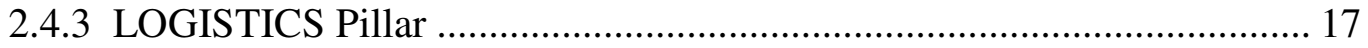

2.4.4 TRAINING Pillar............................................................................ 23

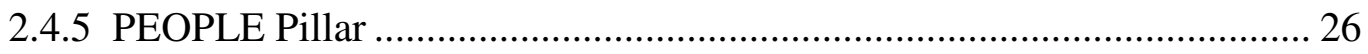

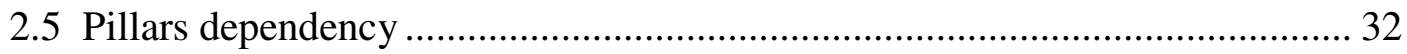

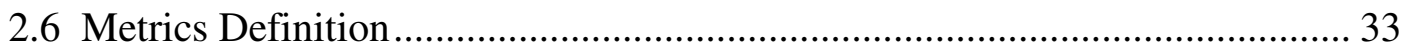

2.7 Weighting Metrics Using the Analytic Hierarchy Process ............................ 35

2.8 Considerations of Feedback ..................................................................... 39

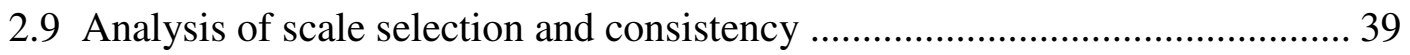


Chapter 3: Case Study: Automotive Manufacturing .............................................. 43

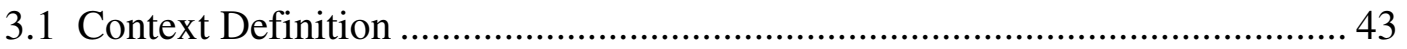

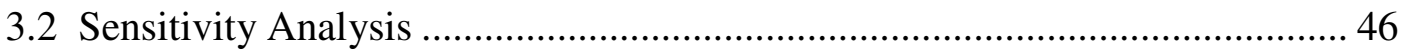

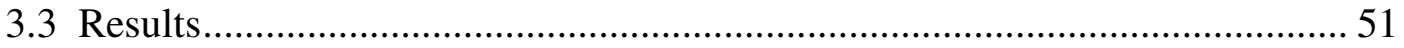

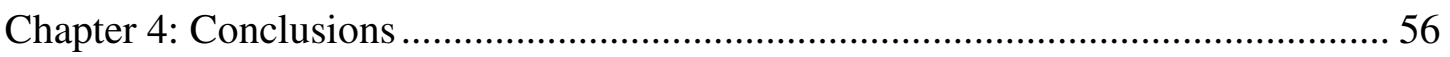

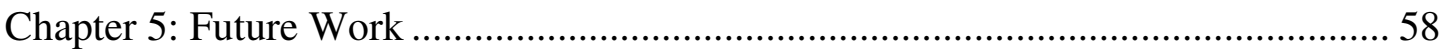

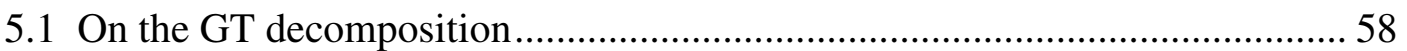

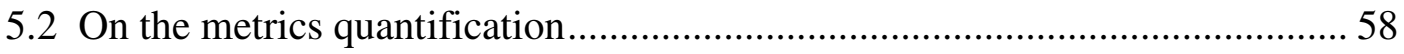

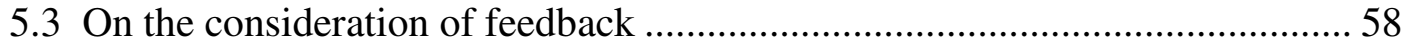

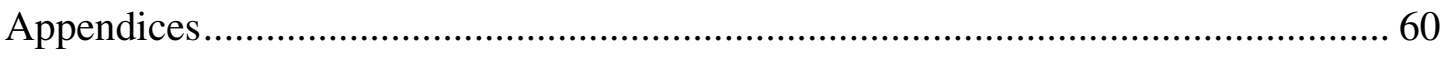

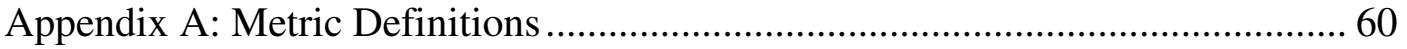

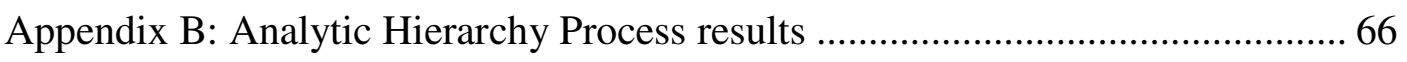

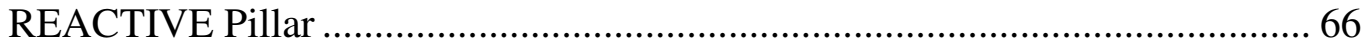

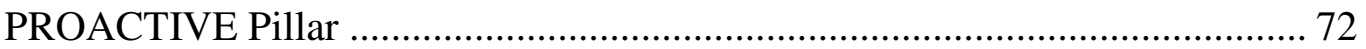

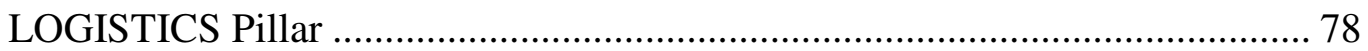

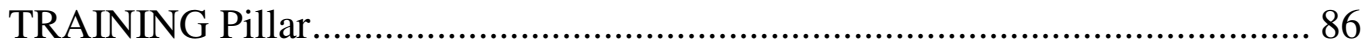

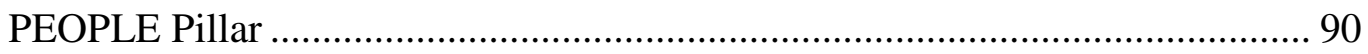

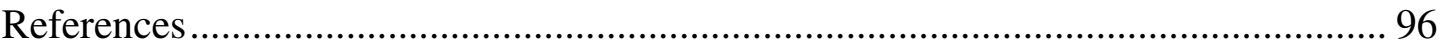




\section{List of Tables}

Table 1: Fundamental pillars of the strategy.............................................................6

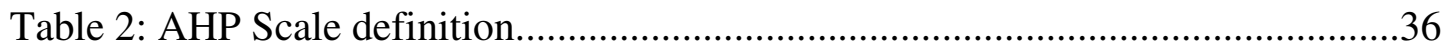

Table 3: AHP results for the simplified example on the correct diagnosis attribute...38

Table 4: Automotive industry case study results..................................................45

Table 5: Observations derived from the attribute sensitivity analysis conducted

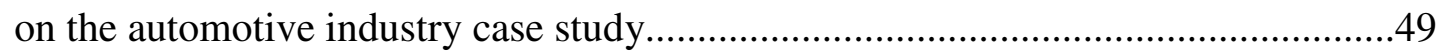




\section{List of Figures}

Figure 1: Goal tree hierarchy decomposition...........................................................

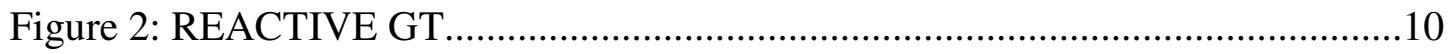

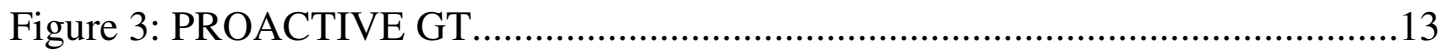

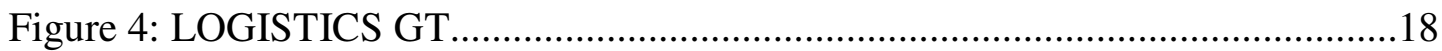

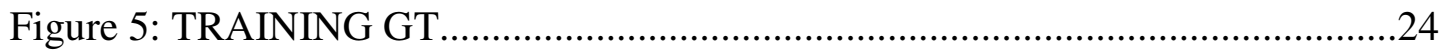

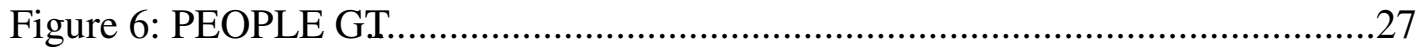

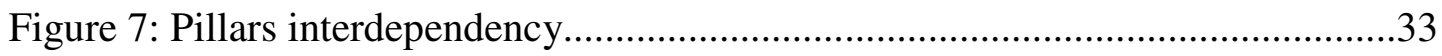

Figure 8: Application of the AHP in metric weighting ..........................................

Figure 9: AHP matrices for "Perform correct diagnosis" simplified example............37

Figure 10: Consistency as a function of the order of the matrix..............................41

Figure 11: Attributes with high contribution to the TRAINING GT goal..................46

Figure 12: Attributes sensitive in the automotive industry case study.....................48

Figure 13: Metrics and Pillars dependency for the automotive case study.................52

Figure 14: Relative influence of the resulting metrics over each pillar......................53

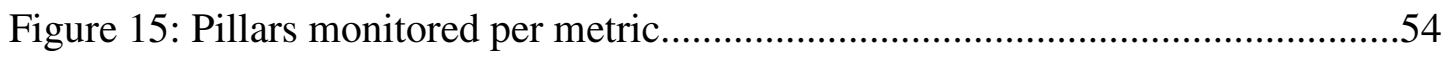

Figure 16: Resulting metrics with their relative weights per Pillar...........................55 


\section{List of Acronyms}

AHP: Analytic Hierarchy Process

BTS: Built To Schedule

CMMS: Computerized Maintenance Management System

CSI: Customer Satisfaction Index

DFM: Design F or Maintainability

FMECA: Failure Mode and Effect Criticality Analysis

FTT: First Time Through

GT: Goal Tree

GTA: Goal Tree Analysis

MSI: Maintenance Satisfaction Index

MTBF: Mean Time Between Failures

MTTR: Mean Time To Repair

OEE: Overall Equipment Effectiveness

PM: Preventive Maintenance

RCM: Reliability Centered Maintenance

TPM: Total Productive Maintenance

VF: Visual Factory

WG: Work Group

WO: Work Order 


\section{Chapter 1: Background}

Over the past hundred years maintenance management had to rapidly change to keep pace with the increase of complexity in manufacturing processes. In the beginning, equipment maintenance was reduced to optimize the corrective activities in order to minimize downtime. Good performance was dictated by the ability to reduce time to repair. Therefore, the main focus was put on improving human technical skills as well as troubleshooting effectiveness.

When reactive maintenance was organized in such a way that failures were immediately found and solved, the need for availability improvement led to preventing failures to occur. The concept of preventive maintenance changes the way of managing maintenance. The objective moves from reactive to proactive maintenance. This means staying ahead of the problem through programmed inspections to find potential failures and eliminate them before they manifest.

Different preventive maintenance programs have been implemented. Initially, fixed schedules were developed. These methods did not consider the equipment usage pattern. Consequently, frequent interventions in low utilization equipment represented a waste of resources, while failures still occurred in equipment with higher utilization.

In order to develop a customized plan a more careful analysis was needed. This analysis should define the optimum maintenance schedule for each equipment. With customized planning, resources were allocated more efficiently. This led to significant cost reduction and availability improvement.

The significant increase in competitive products generated the need to reduce costs and increase quality and reliability. Old techniques were no longer suitable in 
the new continuous improvement era. One of the initiatives that arose was the Total Productive Maintenance (TPM) ${ }^{[1]}$.

TPM has the objective to prevent failures and quality defects, minimize equipment losses and improve equipment cycle life. The active participation of every part of the organization is the key ingredient for TPM success. Consequently, production personnel participate by conducting inspections and minor interventions on their own equipment. This self-directed maintenance helps detecting equipment malfunctioning in an early stage and provides with important information to maintenance department. Additionally, maintenance force can be assigned to more critical tasks now that minor repairs are handled by production personnel.

This innovative approach to maintenance management was a breakthrough. Still, there was a sustained increase in automation and therefore the need for more skilled technicians to ensure equipment performance. Clearly, organizational goals included the reduction of product indirect costs and in most cases hiring was unaffordable so new alternatives in maintenance operations had to be studied.

The most recent advances in maintenance management include Design for Maintainability $(\mathrm{DFM})^{[2]}$ and Reliability Centered Maintenance $(\mathrm{RCM})^{[2]}$. DFM is a proactive approach that aims at reducing the frequency of required repairs, the time to repair and the amount of preventive maintenance interventions. The goal of Design for Maintainability is maintenance prevention.

RCM started from the aeronautical industry. Thorough analysis conducted on a group of aircrafts under different maintenance schedules concluded that increasing the frequency of inspection does not necessarily reduce the number of failures. On the 
contrary, after overhaul the aircrafts would show an increase in the probability of failure due to infant mortality. Additionally, it was found that most failures are related to random events such as poor maintenance practices, overload or improper equipment operation.

RCM methodology is based on choosing the most important systems and determining their potential functional failures. With the aid of Failure Mode and Effect Criticality Analysis (FMECA) the most critical causes of failure are identified and an appropriate maintenance plan is developed to control them. This approach admits the "run to failure" option for those equipment failures that will not represent a significant safety or economical concern on production.

The previous discussion shows that maintenance practices evolved to a focus oriented approach where resources are put were they are more needed. Still these initiatives are being implemented among many industries with different levels of success. Evidently, there are other factors making the results widely vary not always properly considered.

Success or failure in maintenance management depends on how technical, human and organizational factors are considered. This study will focus on how to integrate these factors and methodically define a set of performance indicators to monitor maintenance operations effectiveness. 


\section{Chapter 2: Methodology}

\subsection{Overview}

The Balanced Scorecard concept ${ }^{[3]}$ will be used to determine the maintenance strategies. This concept will help define the fundamental pillars upon which the overall maintenance operation rests. From these basic pillars, a group of attributes will be derived using a hierarchical decomposition such as the Goal Tree Analysis ${ }^{\text {[4]. }}$ Successful implementation and monitoring of these few attributes will lead to more effective management of maintenance operations.

A set of metrics must be selected to lead the attributes implementation. These indicators need to monitor the maintenance strategies in such a way that any deviation from the objectives can be detected and immediately corrected.

The problem resides in that no attribute can be fully monitored by an isolated metric. As such, a set of indicators would be needed for this purpose. The assignment of each metric to an attribute must be determined through expert judgment. The Analytic Hierarchy Process (AHP) ${ }^{[5]}$ is a powerful tool to formally bring expert judgment to define relevance and importance of each metric to the fulfillment of the attribute.

\subsection{The Balanced Scorecard}

The Balanced Scorecard is a management system that enables the organization to align their vision with the strategy and translate it into action. Its main purpose is to define a set of metrics that will closely monitor the organization performance. The 
structured methodology allows us to understand the key aspects in maintenance operations preventing the uncontrolled and unfocused selection of performance indicators ${ }^{[6]}$.

In this thesis a model of the Balanced Scorecard has been developed in context of a complex manufacturing plant. The first step in developing the Balanced Scorecard is to define the vision of maintenance operations. This is defined as: Attainment of high performance of people, equipment and processes in maintenance. This ultimate goal is to be accomplished through a methodical strategy that must consider all different aspects of the organization. Therefore, the strategy will be decomposed into fundamental pillars.

When selecting the pillars, the first and basic aspect to consider is repairs management. Once a failure occurred the cause must be effectively found and solved. Therefore, the REACTIVE pillar goal must focus on reducing the downtime through minimizing the time to repair. In order to prevent failures to occur in the first place, the focus must change from a reactive to a proactive approach. The PROACTIVE pillar will aim at reducing the amount of failures through appropriate maintenance planning. The goal is to maximize the time between failures.

Having good reactive response and effective preventive maintenance (PM) plan is not sufficient without the necessary tools and spares. The LOGISTICS pillar must ensure resource administration including materials, equipment, spares and energy consumption. Therefore this fourth pillar goal is to guarantee resource availability with minimum cost. Even with good planning and having the necessary tools and spares, maintenance personnel must have the appropriate skills to do a 
quality job. The goal for the TRAINING pillar is to prepare personnel for their job requirements.

Finally, it is important to keep in mind that all maintenance related activities are planned, performed or controlled by individuals. Without personnel motivation maintenance results are in jeopardy. PEOPLE pillar is probably the most critical because it is present in all other pillars. Its goal is to increase personnel motivation and performance in order to get the best out of each employee.

Table 1 shows the scope of each pillar with its goal definition. Detailed analysis of each pillar will be discussed in the following section.

Table 1. Fundamental pillars of the strategy

\begin{tabular}{lll}
\hline \multicolumn{1}{c}{ PILLAR } & \multicolumn{1}{c}{ SCOPE } & \multicolumn{1}{c}{ GOAL } \\
\hline REACTIVE & $\begin{array}{l}\text { Repair action after the failure } \\
\text { occurs }\end{array}$ & Minimize time to repair \\
PROACTIVE & $\begin{array}{l}\text { Planning and monitoring actions } \\
\text { to prevent failures }\end{array}$ & $\begin{array}{l}\text { Maximize time between } \\
\text { failures }\end{array}$ \\
LOGISTICS & $\begin{array}{l}\text { Tools, spares and equipment and } \\
\text { their availability }\end{array}$ & $\begin{array}{l}\text { Guarantee resources } \\
\text { availability with minimum } \\
\text { TRAINING }\end{array}$ \\
Pechnical and interpersonal & Prepare personnel for their \\
& training & job requirements \\
PePLE & Personnel involvement, human & Get the best performance \\
performance, safety and & out of each employee \\
& workforce planning & \\
\hline
\end{tabular}


In order to fulfill the overall vision each of the five goals must be realized. It w1l be considered that each pillar has the same relative importance with respect to the vision accomplishment.

\subsection{Hierarchical Decomposition Using Goal Tree Analysis}

The next step in the balanced scorecard definition is to translate the strategy into action. Goal Tree Analysis (GTA) ${ }^{[4]}$ is the means used in this thesis to perform a hierarchical decomposition of each of the strategic goals. The purpose of the decomposition is to arrive to the lowest measurable function, whereby obtaining the fundamental attributes. In this way, each general goal can be easily managed through the analysis of this few attributes. This simplification is valid given that GTA carefully breaks down the high level goal into subsequent sub goals so that success of all sub goals will guarantee the main goal accomplishment.

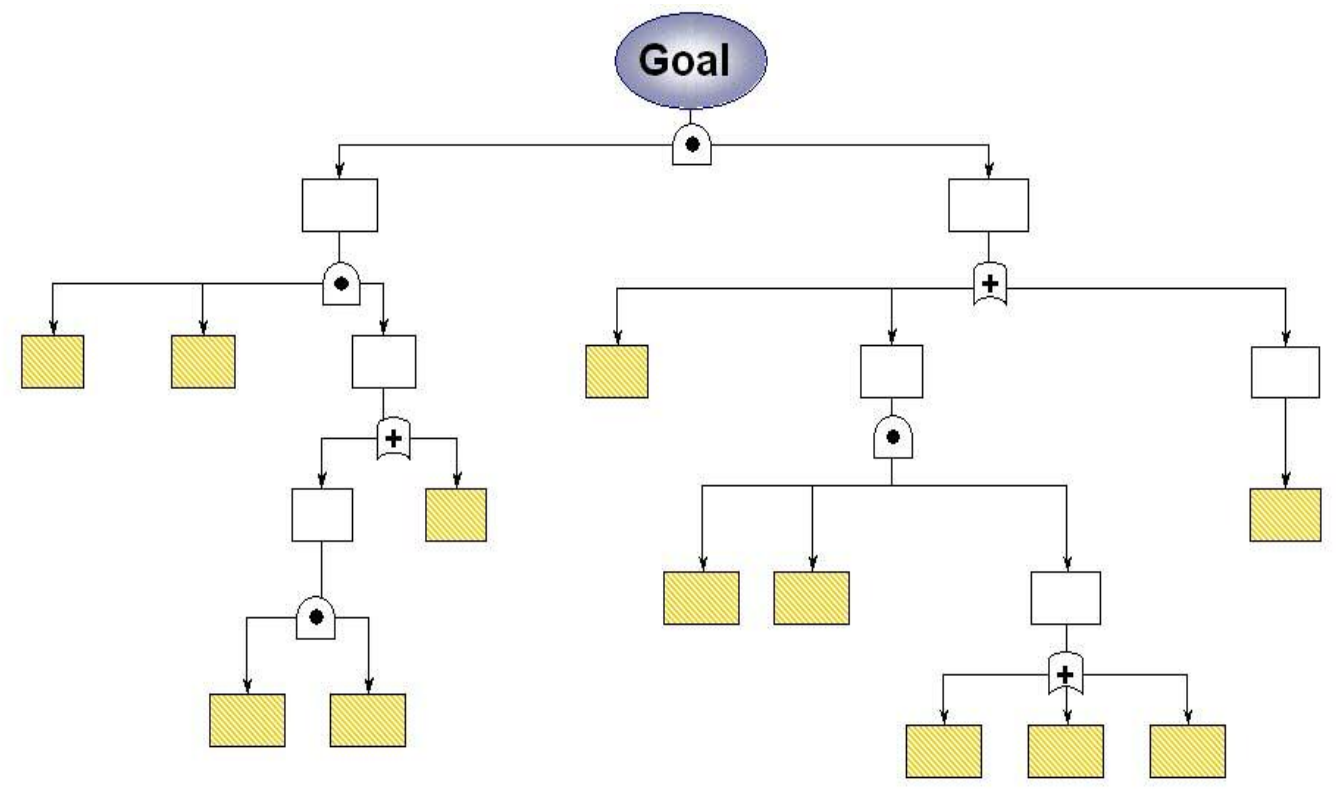

Figure 1. Goal tree hierarchy decomposition 
It is important to mention that every subgoal can be eventually decomposed into lower level subgoals. The level of decomposition will be defined intuitively and will mainly depend on the degree to which the attribute can be measured. Therefore, paths that will result from the decomposition may vary in level depth.

Figure 1 shows a conceptual diagram of the goal tree (GT). The higher level represented by an oval is the ultimate goal which is decomposed in lower level subgoals until the lowest possible decomposition is met. The shaded blocks represent these fundamental attributes.

Note that logical connectors are used to show in which way the combination of various attributes will lead to the goal accomplishment ${ }^{[7]}$. The AND gate implies that all attributes must be satisfied in order to guarantee the goal success. On the other hand, OR gates indicate that the goal can be met if at least one of the success paths underneath is achieved. Considering this, we must refer to "alternatives" rather than subgoals given that not all the attributes need to be necessarily met to ensure success at a higher level.

The complete decomposition has been conducted considering maintenance operations and management literature and was also based on the authors' judgment. Figures 2 to Figure 6 in the following section show the GTs for each pillar.

\subsection{GTA for the five strategic pillars}

\subsubsection{REACTIVE Pillar}

Figure 2 shows the hierarchical decomposition for the REACTIVE pillar. There are two possible alternatives to manage a failure depending on the availability 
of an alternative process. These processes include, backup systems, redundancy, standby equipment and bypass procedures ${ }^{[8]}$. The OR gate shows that success of either path will lead to the top goal accomplishment.

The decision to launch the alternative process will be based on the repair time estimate, the time to switch from normal to alternate operation and the potential loss of production the alternative process represents. Therefore, good communication between maintenance and production personnel is essential to make the best decision. At the same time, clear procedure must be in place to perform a quick change over.

An important part of having an effective alternative process in place is its reliability. Stand by and redundant equipment must be in good condition when needed. Even though these installations are rarely used, it is important to have them under planned maintenance. Note that in order to have a good maintenance plan the REACTIVE goal must be satisfied. Figure 2 shows this dependency between REACTIVE and PROACTIVE GTs.

The repair path is followed when no alternative process is available or a decision to conduct the repair facing the down time is made. In this case a correct diagnosis followed by an effective repair action is needed.

Many variables must work together in order to perform a correct diagnosis. A complete and reliable monitoring system together with appropriate troubleshooting procedures will help detect the failure promptly. Additionally, the technician must have the appropriate knowledge through previous experience or training. As mentioned earlier, good performance also depends on personnel morale and therefore this subgoal will be repeatedly seen throughout the GT. 


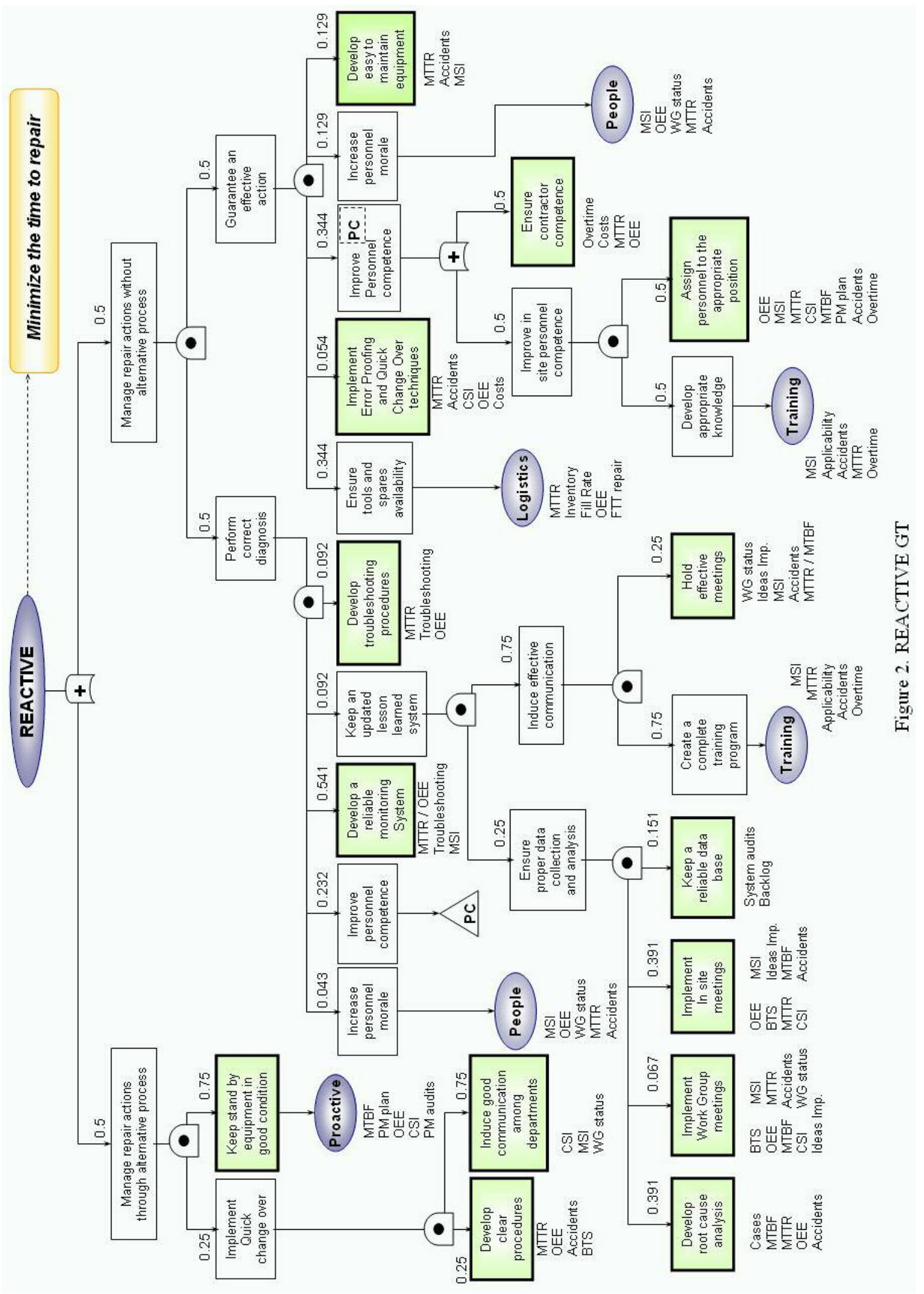


Conducting an effective action mainly depends on the technician knowledge and skills. Still, having the ability to conduct the repair is not enough if the proper tools and materials are not available. And even with the skills and resources, the optimum repair action would be carried out if the equipment is easy to maintain. Hard to reach spaces will make the job more difficult, thus increasing the time to repair. Some design approaches such as design for maintainability ${ }^{[2]}$ have this into consideration and provide error proof devices. Having these convenient tools already in the equipment and quick change over procedures can expedite the repair process.

The REACTIVE GT shows a detailed decomposition of these many goals in lower level attributes. Some of these attributes deserve a comment. Doc Palmer ${ }^{[8]}$ emphasizes the importance of assigning personnel by skill. Those individuals that are prone to easily find a root cause and promptly implement a solution should be available for production support where time to repair is critical. Generally, these containment actions are highly effective but many lack of quality work given the nature of the repair. On the other hand, preventive and predictive activities should be conducted more carefully. For these interventions, troubleshooting ability is not required but skilled work with high quality finish is essential. Therefore, meticulous technicians should be assigned to planned maintenance tasks.

Another important aspect to consider is the work group activities. There are different kinds of meetings that will be explained in more detail when discussing the PEOPLE pillar. The importance of these meetings for the REACTIVE pillar is that they are a source of data analysis and lesson learned communication. 


\subsubsection{PROACTIVE Pillar}

Figures $3 \mathrm{a}$ and $3 \mathrm{~b}$ show the PROACTIVE pillar decomposition. All planned activities are considered including preventive, predictive and self-directed maintenance, programmed replacements and projects implementation. The latest refers to improvement modifications conducted with maintenance department budget.

Preventive, predictive and replacement programs are effective if there is a dynamic schedule, oriented to prevent the loss of the system function. This is the objective of Reliability Centered Maintenance $(\mathrm{RCM})^{[2]}$. The plan must be routinely evaluated and adjusted based on failure history, condition-based techniques and root cause analysis among other reliability tools. This resource optimization needs appropriate data collection and analysis so having a reliable Computerized Maintenance Management System (CMMS) is essential. Similarly to most management tools, the critical part is not putting the system in place, but maintaining it up to date with all equipment information and analyzing this information routinely. Terry Wireman ${ }^{[9]}$ reinforces the need to have a complete and accurate data in order to support maintenance decisions making process. Therefore, when implementing a CMMS it is important to design an easy to use system, promote personnel involvement and provide necessary resources such as computers and time to enter the data. Optimally, the CMMS will be integrated with other systems in the organization 


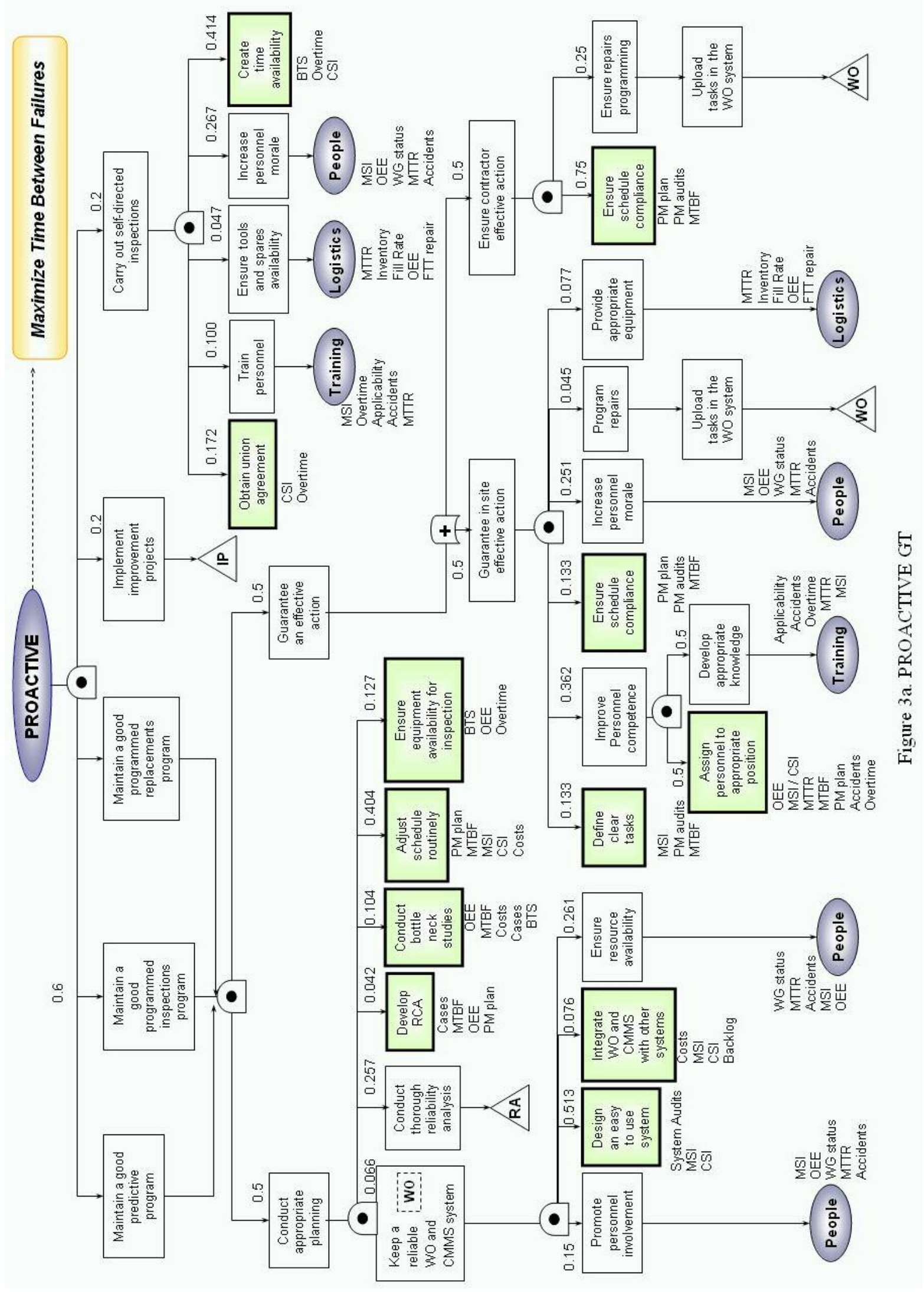




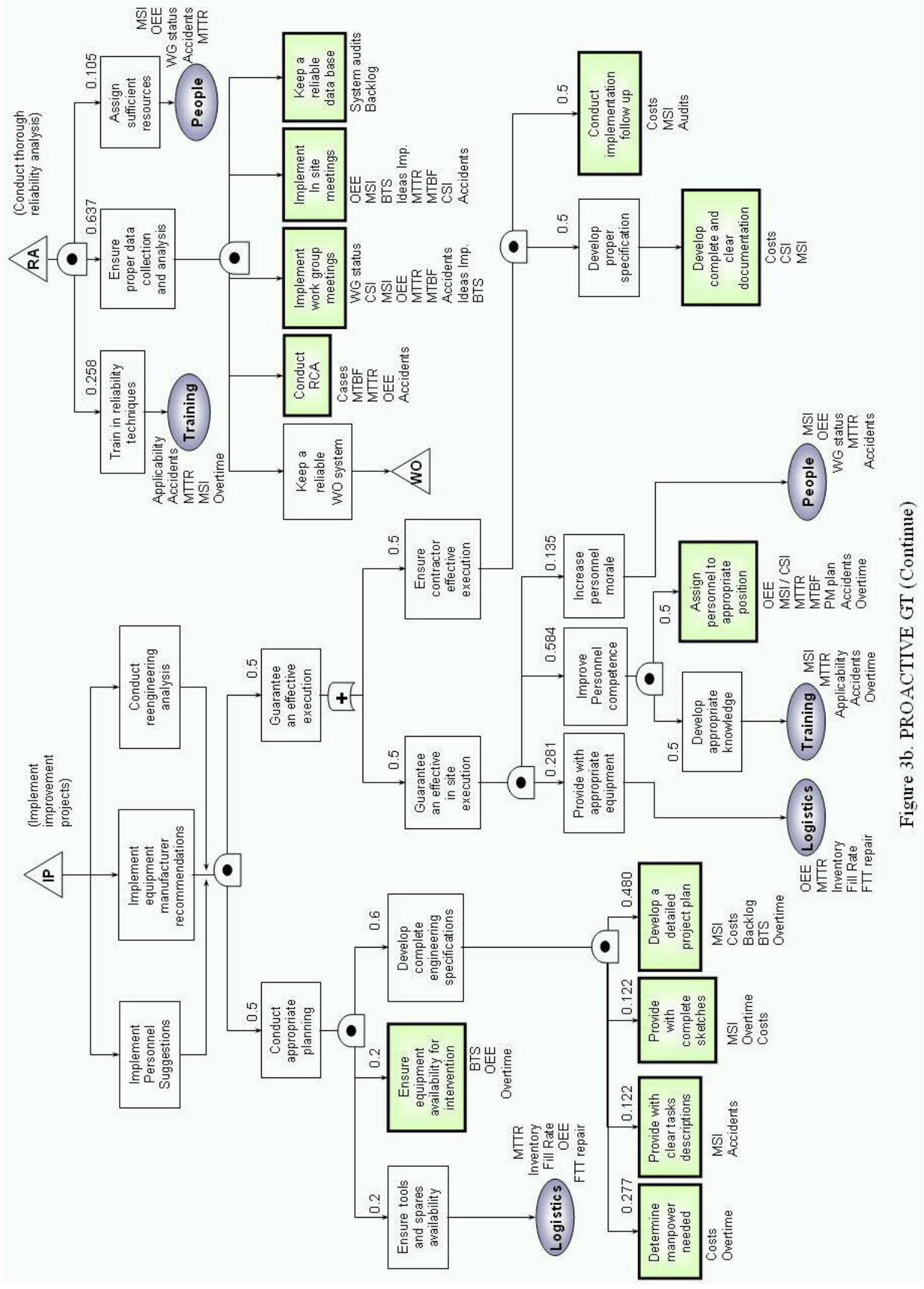


Planned interventions also need to consider equipment availability. This is especially important when production systems are in continuous operation. In many cases production patterns must be adjusted to support the PM down time. Planning ahead of time production department will ensure an effective intervention without significant production loss.

Preventive or predictive activities can be performed by the on site personnel or by a contractor. As discussed in the REACTIVE pillar, the quality of the intervention will depend on the technician skill and morale as well as having the appropriate tools and spares. Additionally, structured procedures must ensure the schedule compliance and also inspection tasks must be clearly defined. This includes not only what to inspect, but also what is considered substandard conditions. This is particularly important for predictive inspections where the variables analyzed increase as the equipments degrade and a threshold value will define the need for replacement.

Another important aspect in maintenance inspections is the repair scheduling. For processes that allow short periods of down time it is common to conduct the planned maintenance in two phases. First, the entire equipment is inspected following a detailed checklist. If a substandard condition is found, the technician must decide whether to repair it or program the repair in the near future. This decision will depend on the time needed to conduct the repair, the equipment availability and the tools and spares availability. If the repair is not conducted immediately, the task should be entered in the Work Order (WO) system. This is a very important part of the process that requires discipline. Without proper repair scheduling, the substandard condition 
can worsen significantly leading to equipment failure before the next PM inspection.

The improvement projects include personnel recommendations that can reduce the time to repair, increase the time between failures or reduce the risk of personal injury or property damage. Other projects are derived from manufacturer recommendations or process modifications. For all projects complete engineering specifications must be developed. Additionally, if the project implementation is to be conducted with maintenance workforce, detailed sketches and a list of resources (parts, tools, materials, and manpower) must be prepared. On the other hand, when contractors are involved the implementation plan must be closely followed in order to verify compliance with the specifications.

The third type of planned maintenance tasks are the inspections and minor repairs conducted by the operator. This self-directed maintenance approach provides the benefit of discovering equipment problems in an early stage. In order to commit production personnel to add this task to their routine there must be agreement from the union. This step is fundamental when implementing self-directed maintenance. Then, operators must be trained in the inspection checklists as well as in some basic skills to perform minor repairs.

An important aspect that is usually overlooked is that conducting daily inspections is time demanding, especially if subsequent interventions are required. Therefore, self-directed activities must be included in production planning. Considering these activities as part of the daily tasks will prevent loss of motivation and operators performance. 


\subsubsection{LOGISTICS Pillar}

Figures $4 \mathrm{a}$ and $4 \mathrm{~b}$ show the LOGISTICS GT. This pillar focuses mainly on materials, parts and tools availability but it also includes energy as a resource to be administrated. As mentioned earlier, the objective is to ensure resource availability with minimum cost. The latest is the actual challenge. Benjamin W. Niebel ${ }^{[10]}$ defines one of his five primary pillars as "Cost Reduction" and parts and tools administration is one of many activities to fulfill this goal.

In the presented approach, LOGISTICS pillar goal will be accomplished by ensuring equipment, parts and tools availability, optimizing energy consumption and minimizing maintenance inventory. The first condition can be satisfied not only by guaranteeing the part is in stock, but also weather this part is available immediately. Having the part somewhere in a chaotic store will make the repair ineffective and increase the mean time to repair (MTTR). Therefore, great effort should be invested keeping a clear and properly identified storage area. This may include the development of equipment drawings / sketches and a reliable inventory system, as well as applying Visual Factory (VF) procedures. Lack of proper stores administration result in parts unavailability. If storages do not provide with the necessary parts, technicians would start keeping basic spares at hand leading to personal storages generation .

Nevertheless, the concept of personal storages should not always be rejected. For large installations where distances are important it would be wise to have materials 


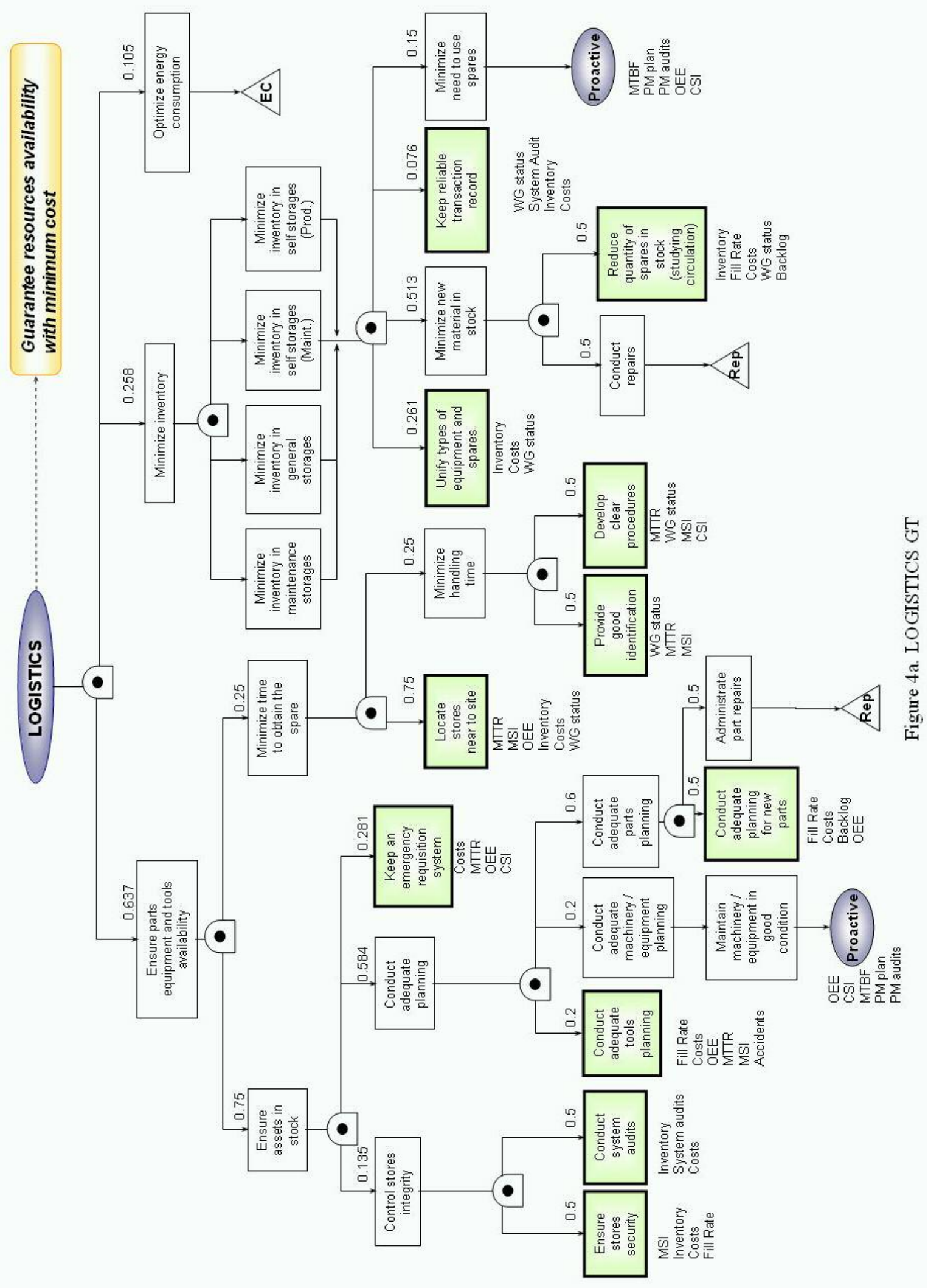




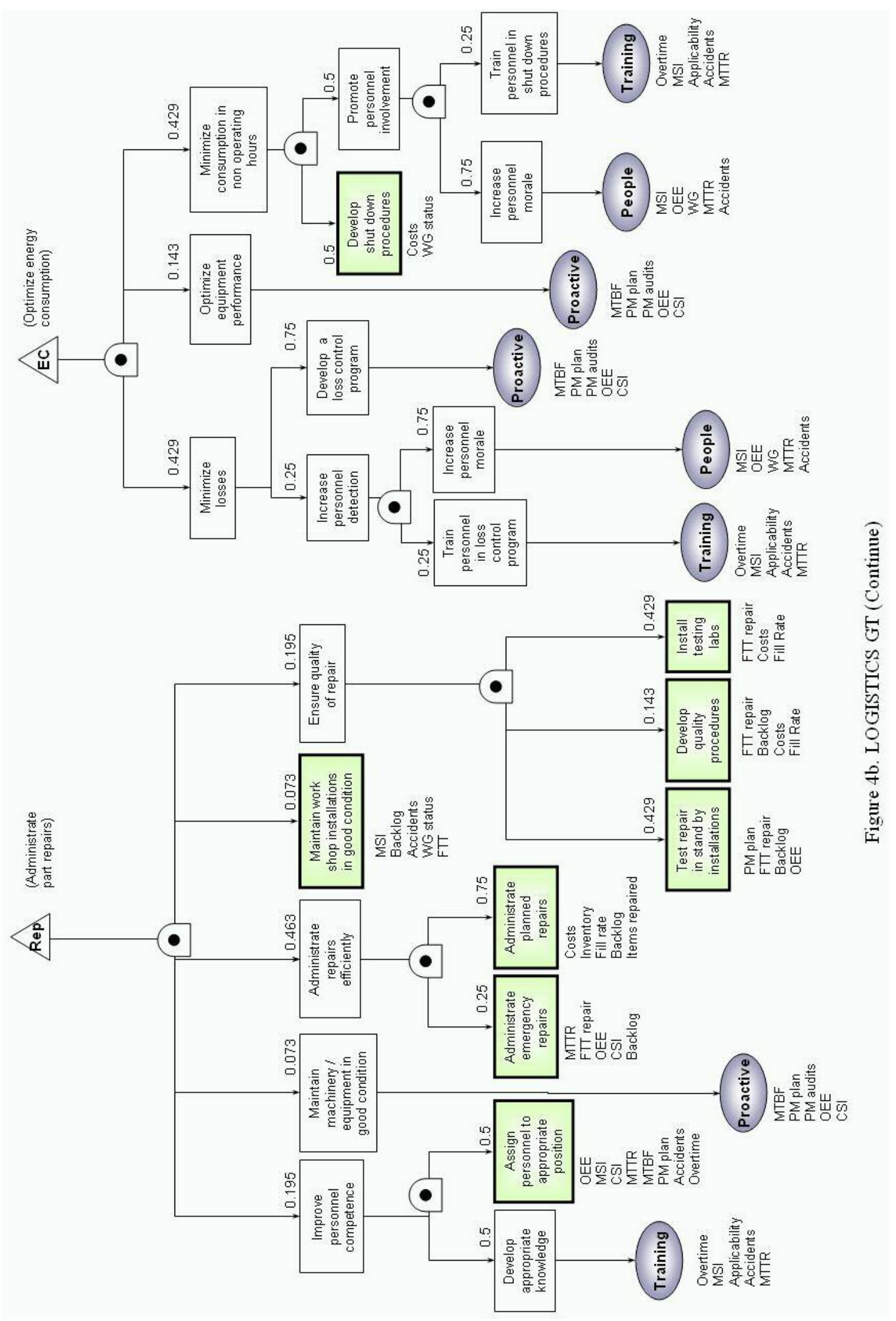


near to site. But parts and their quantity must be carefully selected to prevent high inventory. Materials with high circulation and low cost are prone to be in the selfstorages. Additionally, spares specified for one particular equipment can also be stored near to site.

Even though having parts at hand may significantly reduce the time to repair, multiple storage places may be complex to maintain and control. The lack of organization is a menace for parts administration and it is the main cause of inventory multiplication and high maintenance costs. Therefore, proper analysis of advantages and disadvantages is needed when making the decision to have multiple storage places.

In order to ensure the part is in stock when needed, it is essential to conduct adequate planning. Basically, this includes the part list derived from a close analysis conducted in the early design and installation phases. Additionally, one interesting approach that Niebel reinforces is having a parts salvage program ${ }^{[1 \Phi}$. By repairing malfunctioning parts the cost of inventory decreases since a new part is not required. In order to implement a salvage program there must be workshops with the appropriate equipment, sufficient technical skills and clear procedures for repair administration and repair quality assurance. Clearly, the repair would worth the investment if the total repair cost is less than the actual cost of the new part. It is important to notice that the total repair cost not only refers to manpower, parts and materials but there are also hidden costs that usually exceed these tangible values such as opportunity costs. For example, it may take considerable time, skills and resources to repair a failed servomotor from a welding robot. The repair cost can 
easily surpass the cost of a new servomotor. But if this spare part is not in stock and the arrival time takes weeks, the down time cost generated may be unacceptable given the significant production loss.

Planned repairs can represent a great benefit, but it can also increase failure risk considering that the repair does not always leave the part "as good as new". Therefore good quality procedures that include testing of the repair of parts must be established. Once the part is certified it can enter the storages and become part of the inventory.

But spare parts are one of the three resources that must be administrated. Other important assets that should be controlled are tools and special equipment. Some examples of special equipment include measurement and test equipment, notebooks used for PLC and SLC program access or portable welders. Generally, these types of equipment are expensive and maintenance department own a few. Therefore they deserve special control of their uses and storage. Additionally, they must be under PM schedule.

Now that parts, tools and equipment availability was discussed, focus must be on the inventory reduction. It was mentioned that repairing faulty parts helps reduce the amount of parts in stock. Another way to minimize the inventory is by studying parts circulation (for example, how many electrodes are used per week). For this purpose the equipment history must be studied in detail. With this information and the spare acquisition time, a minimum limit is set for that particular part so that when reaching that value a purchase order must be filled.

An important cause of high inventory is the multiple types of equipment and 
vendors. This is common for facilities in expansion where new systems are installed and old equipments are improved. Equipment form vendors that are not certified by the company will certainly have parts list that greatly differs from those that are already specified. Therefore, parts with identical specification but from different suppliers will be duplicated in maintenance stores. Having a list of selected and certified vendors will help minimize this spare parts multiplication reducing the inventory.

The final condition for reducing the spare costs is minimizing the need to use them. Well maintained installations will have higher performance and lower failure probability. Consequently the need to replace a defective part will be minimized through proper planned maintenance.

As mentioned before, energy consumption will also be treated as a resource to be optimized. This goal will be attained by minimizing energy losses, improving the equipment performance and reducing energy consumption in non operating hours. Some sources of energy loss are water leakage from defective pipe lines, air loss from pneumatic devices, unnecessary power consumption for stand by equipment, etc. One approach for loss control is conducting regular inspections under the preventive maintenance schedule. It is also helpful to have personnel involved in loss detection and reporting.

Regarding the non operating hours, a detailed study needs to be conducted to identify the equipment that need to be continuously energized and those that can be powered down. Once the list of equipment to be powered down is defined, clear shut down procedures must be established per equipment. 


\subsubsection{TRAINING Pillar}

Training is a highly important activity that is usually underestimated. The general believe is that time spent for training is time lost, given that many courses are ineffective and after some weeks the student would probably forget what he was taught. The problem is that this statement is generally true because of the lack of proper planning. Training must be a "just in time" activity. This means that the person should receive the course when he or she would get the best out of it. Figure 5 shows that training planning should consider the right course for the person. For this purpose, a tool known as training matrix is used. This matrix will relate each employee with the skills and training needed for their job positions. Having defined the matrix, a customized training plan is easily constructed considering not only the courses applicable to the position, but also the adequate level according to the employee's expertise.

Training courses are grouped in four different categories: knowledge base, on the job training, attitudinal and lessons learned. On the job training focuses on skills and tasks directly related to the person's daily activities. Generally, these courses are taught by more experienced co-workers and are carried out in site. This type of training is especially applicable for new employees or when the person is assigned to a new position.

Lessons learned courses are designed to expand individual experiences to the rest of the workforce. The objective is to prevent errors experienced in one application to occur in another one as well as share the best practices among the department. 


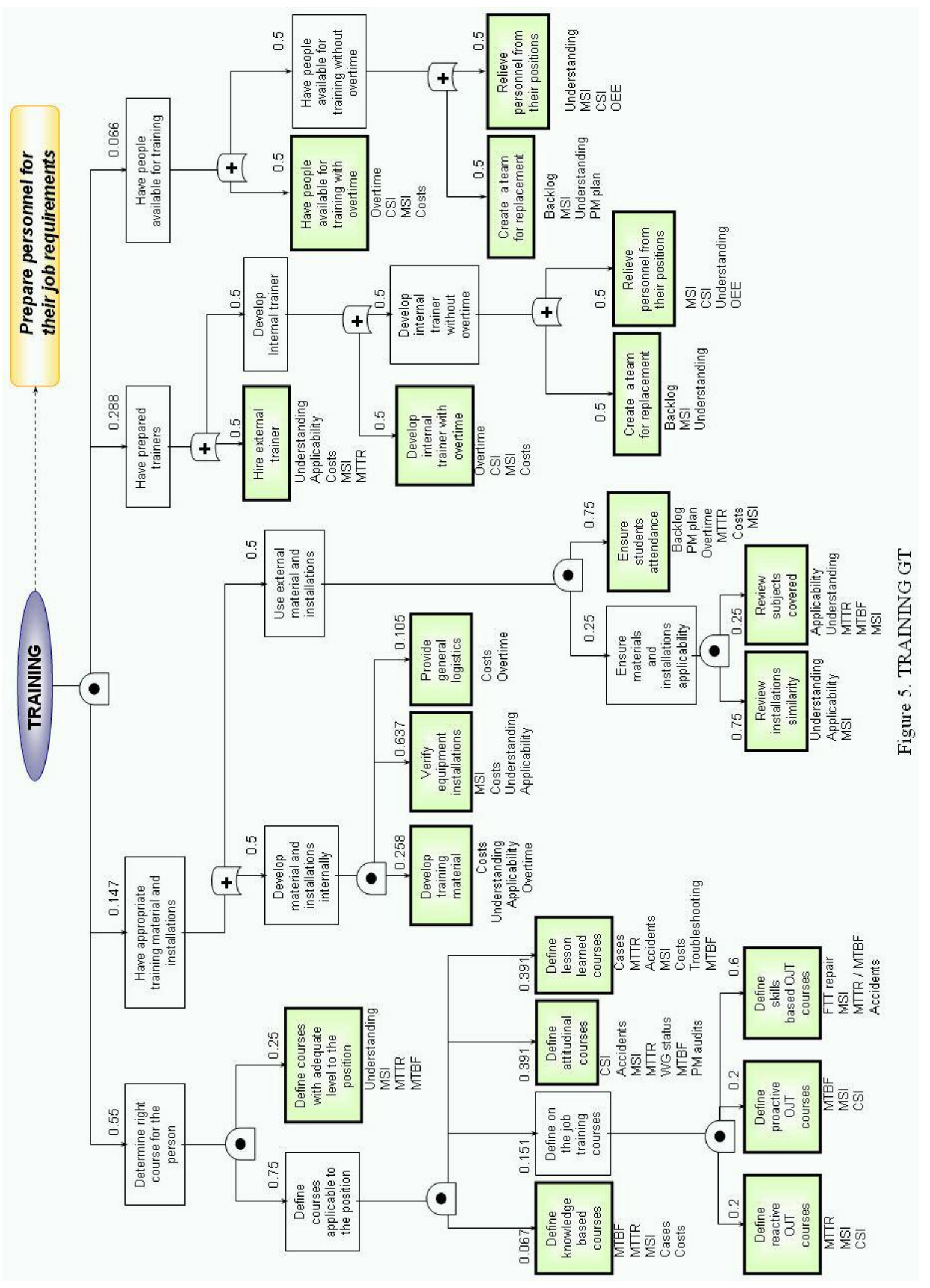


Together with the course definition, there must be material preparation and people organization. The course can be prepared within the organization or it can be outsourced. There are advantages and disadvantages in both approaches. Internally designed courses are generally more applicable to the organization needs given that they are customized. But a lot of effort is demanded to prepare the material and installation and usually lack of quality and proper learning methods. On the other hand, external courses are designed by qualified training groups. Additionally, given that many agencies and most manufacturers provide with a set of courses for different customers, they already have the materials and installations ready to use so the course is available immediately. Yet, these courses not always fit the organization particular needs, are less applicable and many times useless. Another disadvantage of external course is that when there are budget cuts, the organization cannot afford contracting external training. Moreover, considering that it is common that the students must attend classes off site overtime is a must which is usually unaffordable in times of recess.

These conditions discussed are considered in Figure 5. A similar approach is made when selecting the trainer. Most maintenance management literature reinforces the value of developing interpersonal training. For these cases having internal trainers is the most effective. Proper planning is needed to take the person away from the operation to prepare him as a trainer. For this purpose some maintenance departments have a special team for replacement. These technicians will normally be assigned to improvement tasks such as spare parts repair, equipment testing or projects implementation and will cover the person to be trained up when needed. This same 
methodology can be seen for "have people available for training" subgoal.

\subsubsection{PEOPLE Pillar}

As discussed in the previous sections, people morale is a critical aspect that affects most attributes. PEOPLE pillar focuses on getting the best out of every employee. The way to achieve this goal is depicted in Figures $6 a$ and $6 \mathrm{~b}$. The first sub

goal is to increase employee's motivation. R.F. Pagano ${ }^{[11]}$ indicates that a person is mainly concerned about self-esteem, independence, self-actualization, and recognition. From this perspective, defining challenging objectives is an important aspect for self-esteem. Additionally, good communication of these objectives as well as departamental and organizational objectives is essential to make the employee understand and become part of the company's vision. But sharing the goals with the employees will make no difference if there is not an established recognition plan that would reward the individual that actively participates in the results improvement.

Independence and self-actualization are two parameters that must be analized when assigning roles and responsabilities. Individuals that are overqualified for their job position will find it difficult to learn something new leading to loss of motivation. But if they are underqulified, they will feel frustrated also leading to motivation problems. In conclusion, the supervisor must ensure that the person is comfortable in his position.

Last but not least, there ust be a propert benefits and compensation plan that would be suitable for each employee's experience and expectations. The program must be aligned with the employee development plan. 


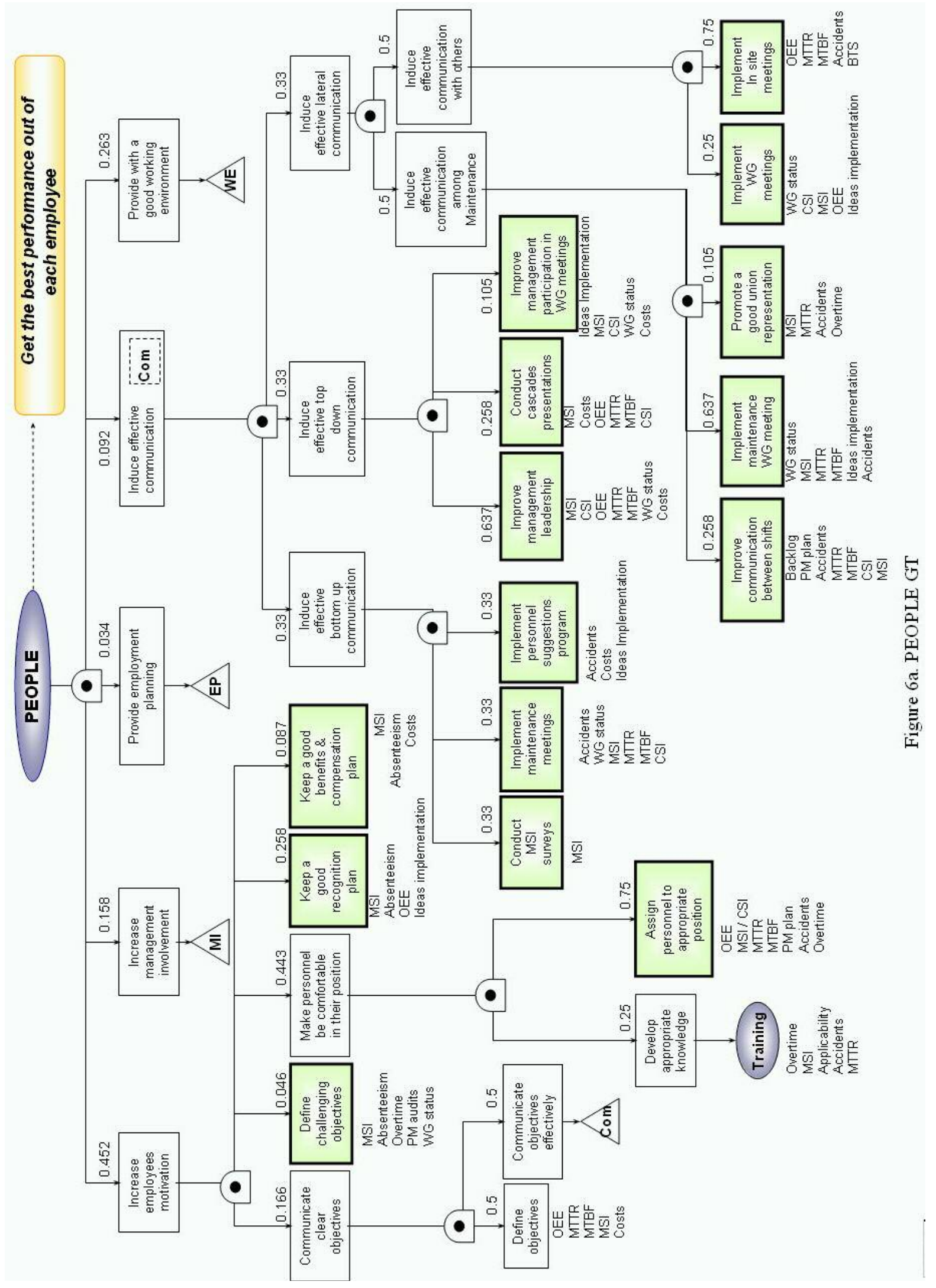




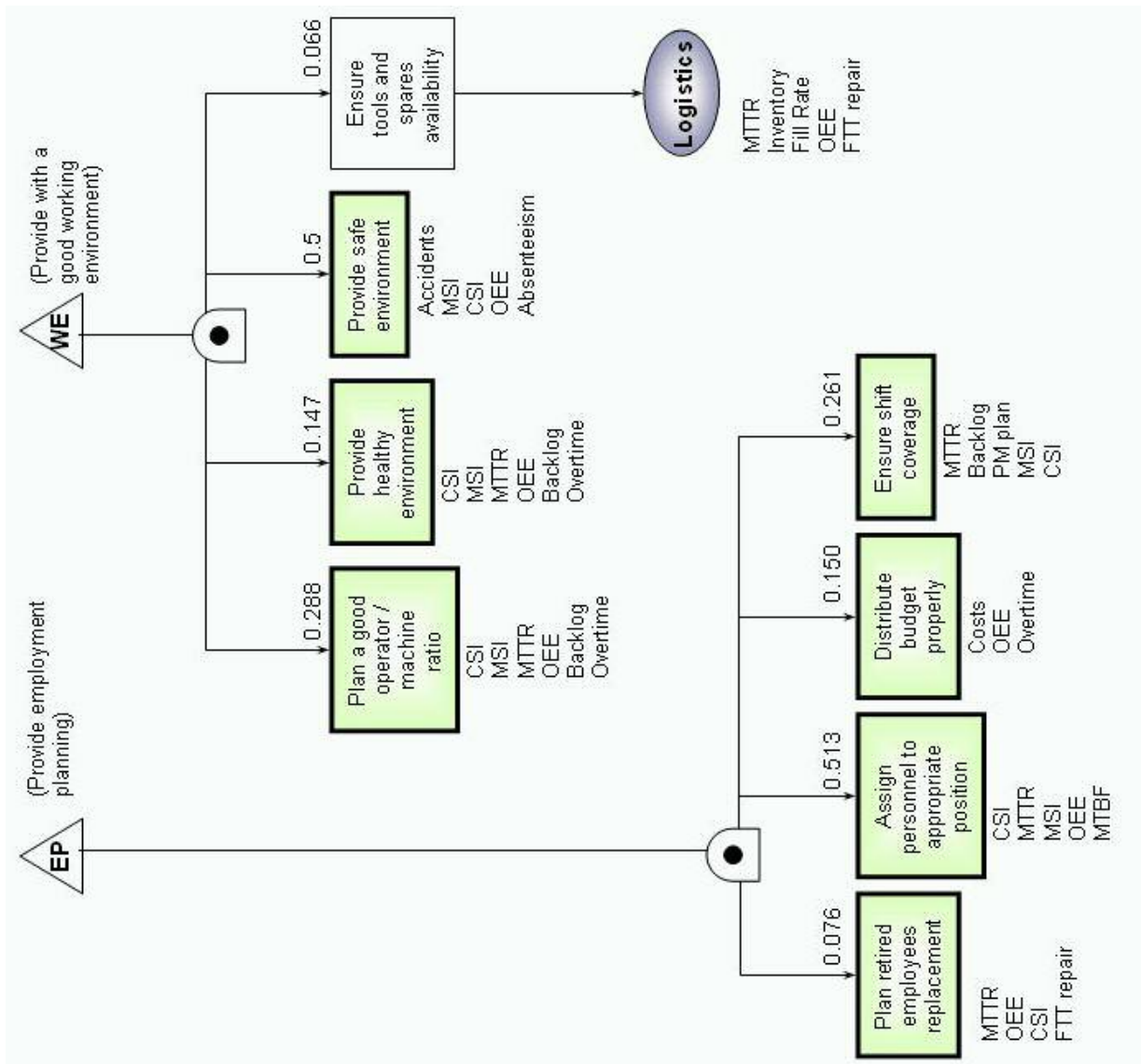

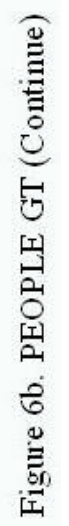

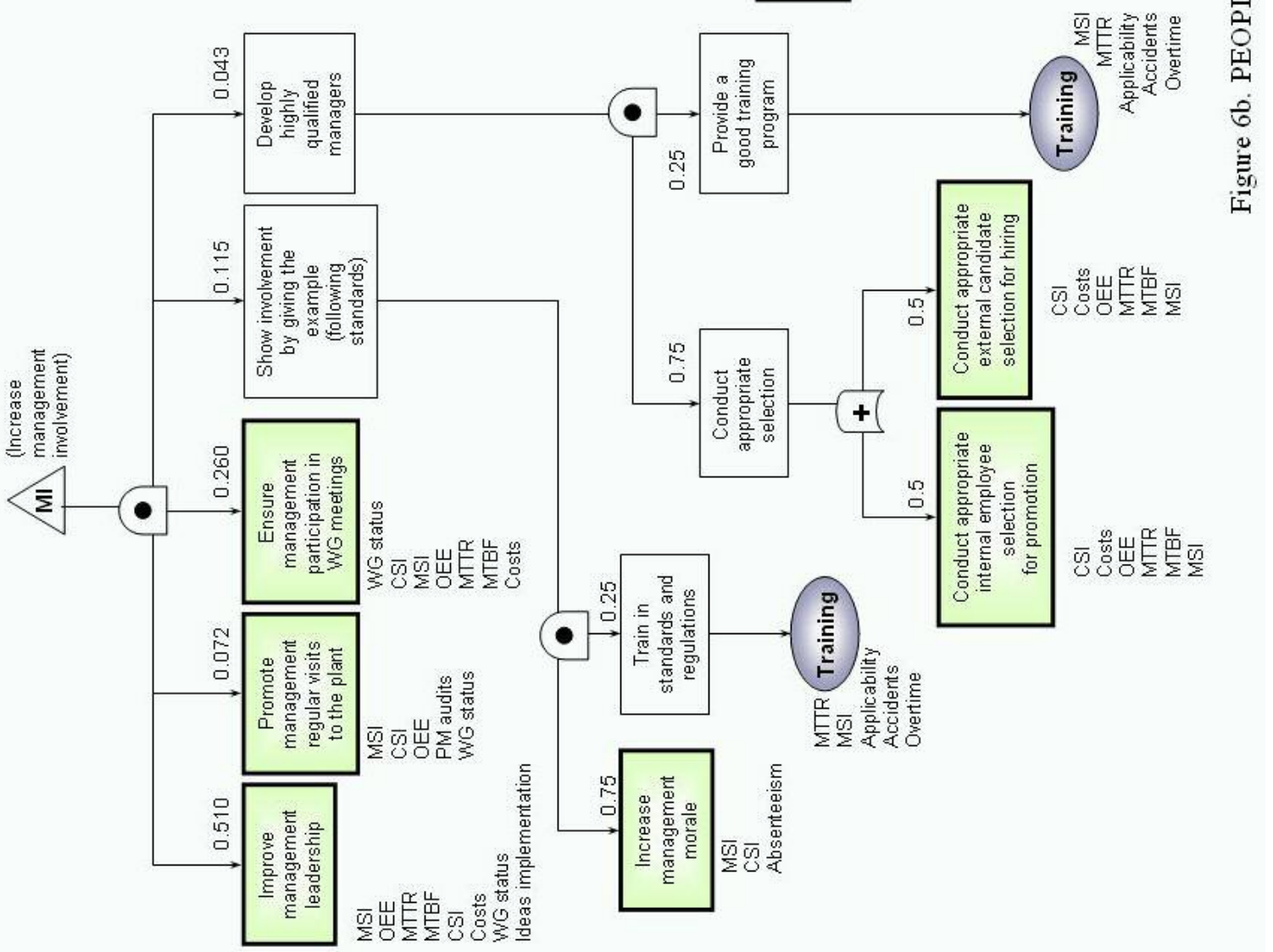


Another sub goal in the PEOPLE GT is increase management involvement Note that the term involvement was chosen instead of commitment. Managers can be fully committed to the Organization's objectives but they need to communicate this commitment to his subordinates in a clear and consistent way. To be consistent, they must give the example by following the standards and procedures established. Also, managers must actively participate in work group meetings. They must understand what the team's needs are and offer support in order for them to succeed. Additionally, it is important for people to realize that the manager and other supervisors are concerned about day to day activities, so it is important to promote regular visits of managers to the plant. In addition to employees increased motivation, plant touring would allow the managers to get in touch with real problems that are being experienced.

The last item in management involvement is to develop highly qualified managers. A proper selection needs to be done from the very beginning, based on the applicant experience and leadership skills. The person to be assigned to this position can be either promoted or hired. Either way, a thorough training program must be provided to enhance technical and personal skills.

Employment planning is another activity to consider. It was already mentioned the importance of assigning each employee to the appropriate position. Another important task is to distribute the personnel in order to ensure shift coverage. This is a complex analysis that must balance the need for reactive maintenance technicians in the productive shift with a group of serviceman that will work on 
pending work orders and the proactive team that will perform preventive and predictive activities.

The fact that people will retire some day is commonly neglected. Given that these people are generally highly experienced employees their separation from the organization generates an important knowledge drain. To prevent this situation, an early plan must be developed to prepare new employees for the future vacant position.

Based on the previous parameters, the human resources budget should be assigned properly. For example, most organizations have a higher compensation for people that work the night shift. Imagine that the night shift will perform the preventive and predictive tasks. If the strategy is to have $70 \%$ of the workforce in proactive activities, therefore this percentage of technicians will be in the night shift. Therefore, enough budget must be assigned to cover the excess of salary compensation for night shift personnel.

When discussing motivation it was mentioned the need of proper objectives communication. Communication is a primary subgoal of the PEOPLE pillar decomposition and that is why the "Communicate objectives effectively" attribute is addressed to "Induce effective communication" subgoal. Communication must be established bottom up, top down and also laterally. This means that superiors must communicate with their subordinates as well as subordinates need a means to communicate with their superiors. Additionally, communication among co-workers must also be excelled. 
Work group activities are a good environment to share opinions and discuss problems as well as are suitable to cascade high level objectives. That is why it is essential that these teams are conformed by cross-functional individuals as well as different hierarchies. Three types of meetings are considered. Work group meetings refer to cellular manufacturing teams. These meetings are usually held on a weekly basis. Most participants are from production department with one or two representatives from the supportive areas (maintenance and logistics). People from other areas of interest such as safety, quality or manufacturing are requested to participate if needed. These meeting are always programmed since operations must be stopped in order to gather all the production team. Therefore they have a specific agenda that includes different issues of the area performance (volume, quality, ergonomics, safety, down time, etc.)

The second type of meeting is the in site meeting. These are held daily and last only a few minutes. They are conducted in the site while the area is in operation and only a couple of production operators participate together with the maintenance technician and generally the maintenance supervisor and engineer. The main objective is to discuss equipment and installation maintenance issues. Therefore the focus is on reviewing the production log in order to improve the system performance.

Communication must be very precise between shifts. Detailed description of the problems faced during the shift of operation must be delivered to the corrective and preventive teams. Similarly, the shift responsible for the PM and system start up must inform any modifications performed in the equipment or anomalies found during setup procedures to the operations shift. 
The last but probably most important aspect to analyze is the work environment. Safety and health are two conditions that must be guaranteed to every employee. Most organizations have a specific safety department that exclusively focuses on ensuring safe and healthy working conditions. Safety practices are an extensive field of study and will not be explained in detail in this work. For further information please refer to reference [12].

Another important component in a good work environment is resources availability. Both time and tools and spares are considered in Figure 6b. Assigning technicians to different areas is a critical task that must always consider the optimum operator / machine ratio. The analysis must relate the level of complexity of the area with technician skills and familiarity with the equipment. For example, for automatic lines that share electrical and mechanical equipment, at least two technicians must be assigned (one electrical and one mechanical). If it is a complex installation with several equipment, it might be needed to assign more maintenance people, especially if it is a critical system in the process.

\subsection{Pillars dependency}

One important characteristic is that most trees end with fundamental attributes that are common among pillar GTs. The REACTIVE pillar in Figure 2 shows that in order to ensure an effective action, tools and spares must be available. This can only be done through the LOGISTICS pillar. Similarly, personnel competence will be enhanced through proper TRAINING as well as personnel morale will depend on the success of the PEOPLE pillar. This means that the achievement of REACTIVE pillar is directly dependent on LOGISTICS, TRAINING and PEOPLE pillars. This 
dependency is repeatedly seen in most pillars as represented in Figure 7, showing a feedback process. Note that REACTIVE depends on all other pillars, while TRAINING is completely independent. The evident interdependency among five pillars determines the importance of achieving all the goals simultaneously. This conceptual result reinforces the assumption of assigning equal importance to each pillar.

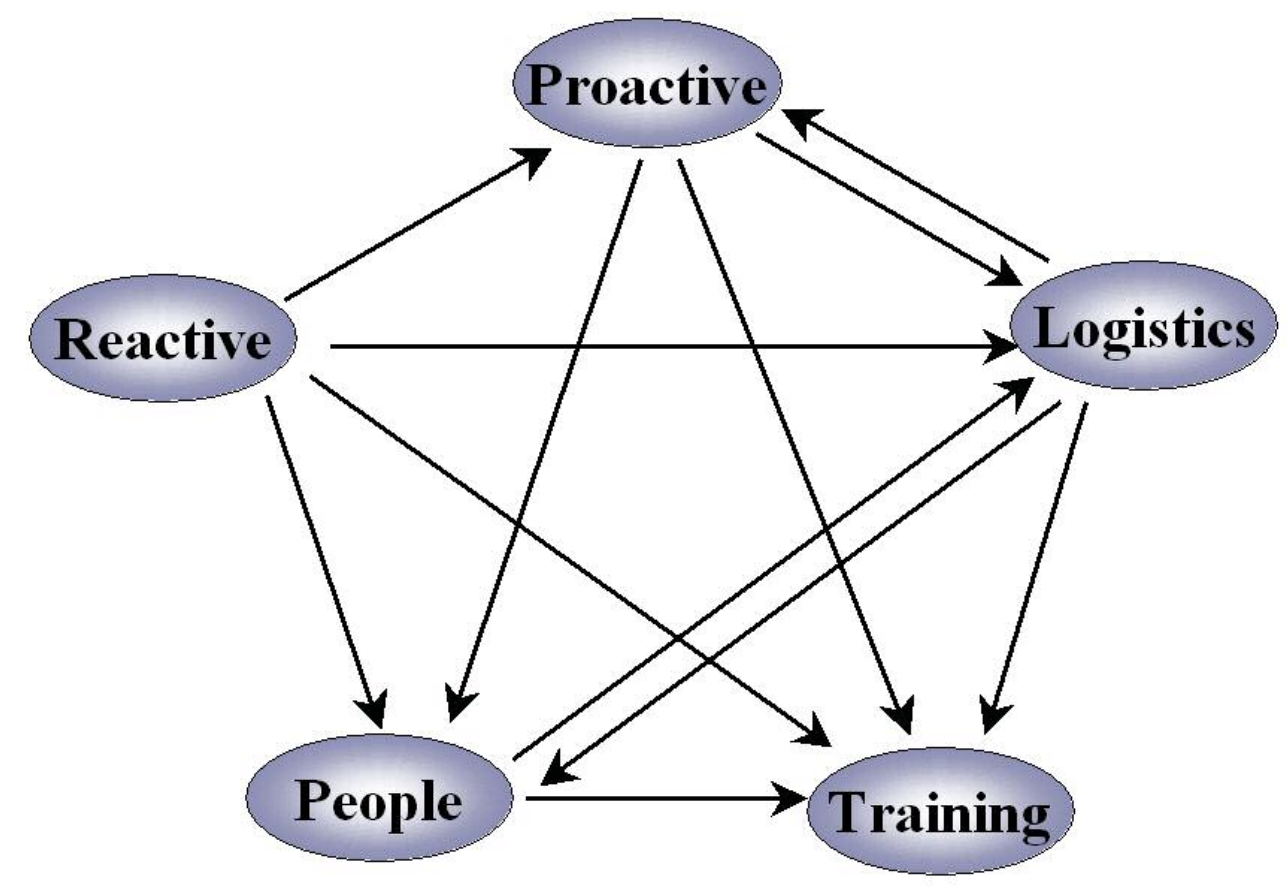

Figure 7. Pillars interdependency

\subsection{Metrics Definition}

Having developed the GTs, the focus shifts to the metric selection. In Figures 2 through 6 all fundamental attributes (shaded boxes) have a set of metrics assigned. There are few cases in which a specific performance indicator can fully monitor a particular attribute. On the contrary, it is more likely that several metrics would be 
needed to describe a behavior. For example for the "Develop easy to maintain equipment" attribute in the REACTIVE tree (Figure 2) three metrics are considered: Mean Time To Repair (MTTR), Number of Accidents or incidents, and Maintenance Satisfaction Index (MSI). It is expected that as the equipment becomes easier to maintain, both the time to repair and number of accidents or incidents decrease, while the satisfaction index increases. But there is one question that still remains: In what proportion does each metric represent the attribute fulfillment?

This question cannot be answered in a generic way. There are several context dependent situations that vary from application to application. Additionally, even though some aspects of maintenance practices are shared among different industries, there are some characteristics that differ considerably. For example, safety factors are probably the most critical in nuclear industry while reliability without regular inspections is essential for aerospace projects.

The GTs resulted in a total of 22 metrics that are seen simultaneously in the five pillars and in different levels of decomposition. Appendix A lists these metrics with their definition.

The GTs are developed considering all important aspects of maintenance practices. This general model is later customized to suit particular applications. The customization process will be carried out by assigning relative weights to each metric with respect to the attribute it monitors and also through weighting of the different alternative paths to achieving the pillars. 


\subsection{Weighting Metrics Using the Analytic Hierarchy Process}

Assigning weight to the metrics is based on expert judgment. It is context dependent and thus depends on the industry for which the trees are being used. When analyzing the context one must understand the economical, social, political and cultural background as well as personnel competence, resource availability and equipment conditions. After considering all these variables, the Analytic Hierarchy Process (AHP) ${ }^{[5]}$ can be used to determine the relative weight of the metrics.

The AHP is a decision making process to set priorities and to make the best decision when qualitative aspects of a decision must be considered. It is a systematic method for comparing a list of objectives or alternatives that reduces complex decisions to a series of one-to-one comparisons.

The first step of the process is to determine the relative strengths of the metrics in monitoring the attribute. The process consists of conducting a pairwise comparison of the metrics by posing the following question: Is $\mathrm{M}_{1}$ metric preferred (or more important) over $\mathrm{M}_{2}$ metric in measuring the attribute? At what level of intensity? The level of intensity can be subjectively assigned through a numeric scale ranging from 1 to 9 , where 1 indicates equal importance and 9 absolute importance of $\mathrm{M}_{1}$ over $\mathrm{M}_{2}$. Table 2 shows the scale definition proposed by Saaty ${ }^{[5]}$.

There is also a need to make a comparison among all associated attributes in meeting the higher-level goals. Figure 8 visualizes the comparison procedure. This block diagram shows a simplified example from the REACTIVE pillar. In order to perform a correct diagnosis of a failure, four conditions must be satisfied: increase 
Table 2. AHP Scale definition

\begin{tabular}{|c|c|c|}
\hline $\begin{array}{l}\text { Intensity of } \\
\text { importance }\end{array}$ & Definition & Explanation \\
\hline 1 & $\begin{array}{l}\text { Equally importance of both } \\
\text { elements }\end{array}$ & $\begin{array}{l}\text { Two elements contribute } \\
\text { equally to the attribute }\end{array}$ \\
\hline 3 & $\begin{array}{l}\text { Weak importance of one } \\
\text { element over another }\end{array}$ & $\begin{array}{l}\text { Experience and judgment } \\
\text { slightly favor on element over } \\
\text { another }\end{array}$ \\
\hline 5 & $\begin{array}{l}\text { Essential or strong importance } \\
\text { of one element over another }\end{array}$ & $\begin{array}{l}\text { Experience and judgment } \\
\text { strongly favor on element over } \\
\text { another }\end{array}$ \\
\hline 7 & $\begin{array}{l}\text { Demonstrated importance of } \\
\text { one element over another }\end{array}$ & $\begin{array}{l}\text { An element is strongly } \\
\text { favored and its dominance is } \\
\text { demonstrated in practice }\end{array}$ \\
\hline 9 & $\begin{array}{l}\text { Absolute importance of one } \\
\text { element over another }\end{array}$ & $\begin{array}{l}\text { The evidence favoring one } \\
\text { element over another is of the } \\
\text { highest possible order of } \\
\text { affirmation }\end{array}$ \\
\hline
\end{tabular}

personnel morale, improve personnel competence, develop a reliable monitoring system and implement troubleshooting procedures. Each of these attributes can be measured by one or more of the following metrics: Mean Time To Repair (MTTR), Maintenance Satisfaction Index (MSI), Overall Equipment Effectiveness (OEE), and Maintenance Costs.

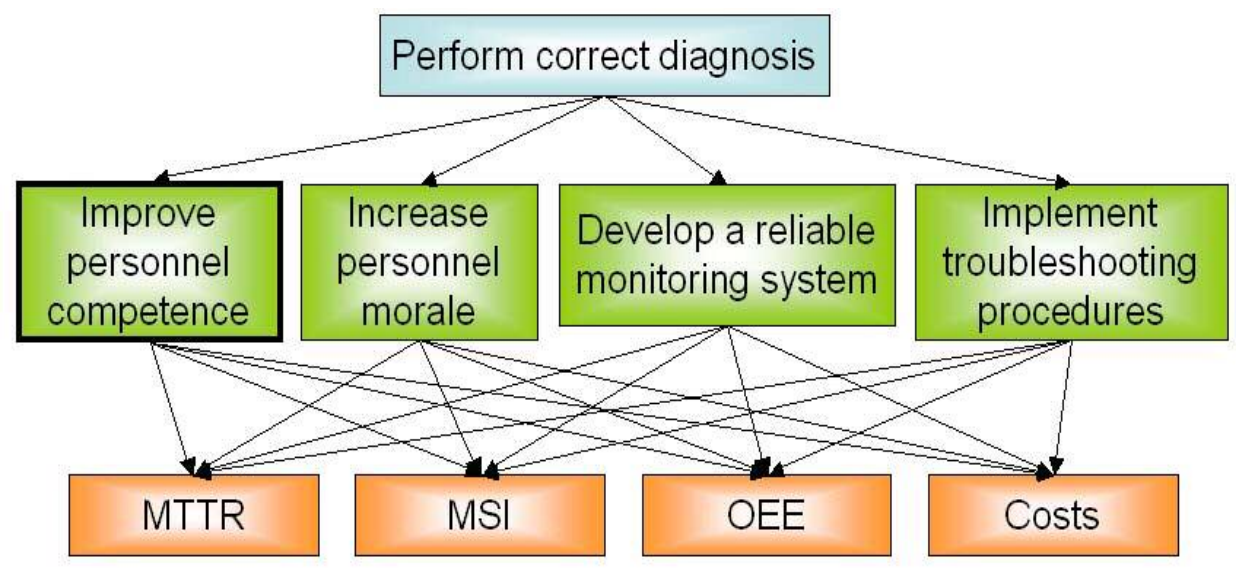

Figure 8. Application of the AHP in metric weighting 
The methodology consists of evaluating the strength of the metrics in monitoring each of the four attributes with respect to "Perform correct diagnosis". One matrix per attribute is constructed as shown in Figure 9. Likewise, a criteria matrix is built to determine the attribute relative importance with respect to the goal.
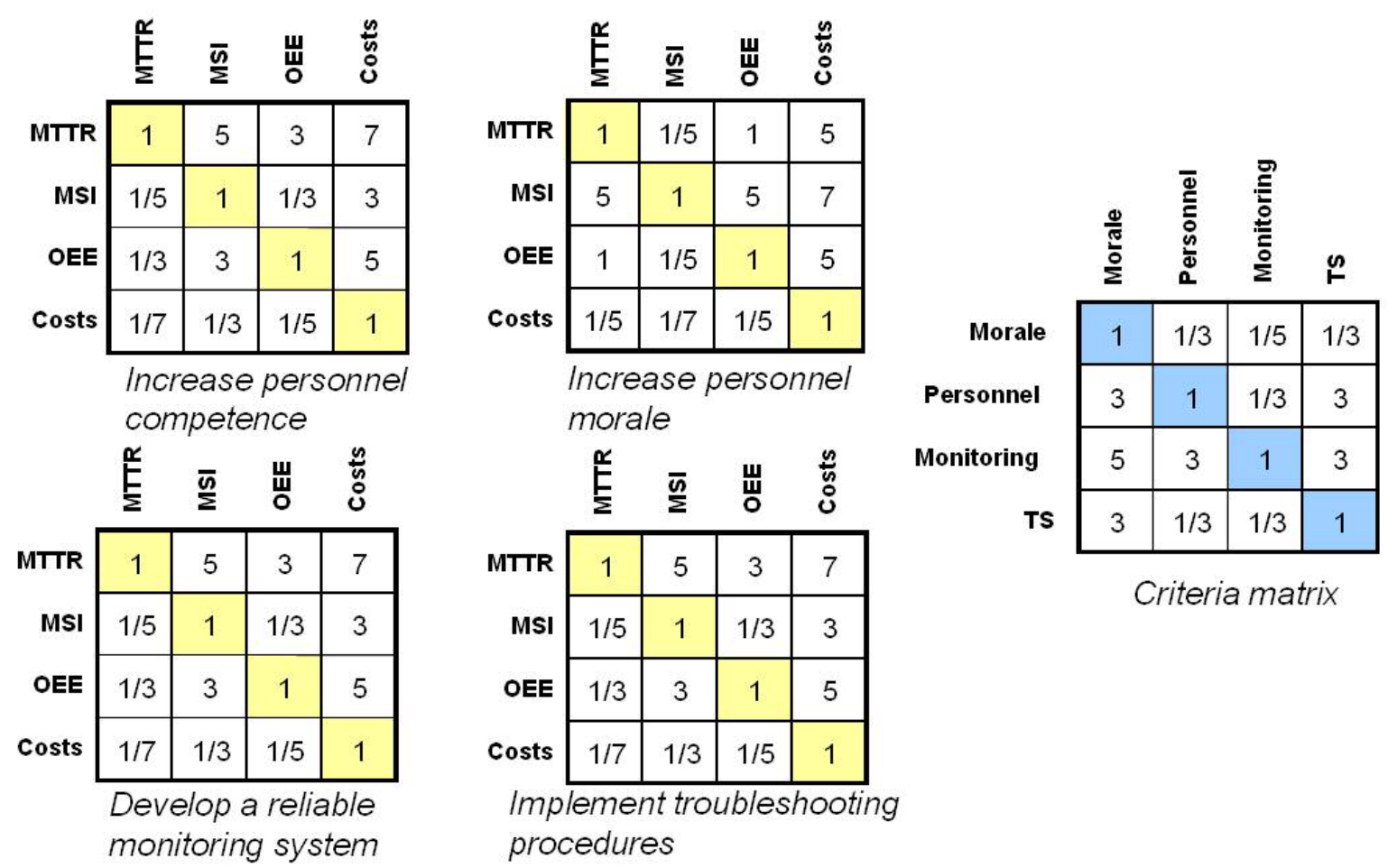

Figure 9. AHP matrices for "Perform correct diagnosis" simplified example

The complete solution will determine the metrics ranking with respect to the "Perform correct diagnosis" goal as summarized in Table 3. The attributes ranking appears in the first column while the metric ranking is indicated in each corresponding row. The overall ranking will be determined by combining each metric weight with the respective attribute weight. The AHP result for this example 
shows that MTTR is the most representative metric in measuring "Perform correct diagnosis" attribute, followed by OEE, then MSI and finally Maintenance Costs. Having these weights assigned, the problem is reduced by one level of decomposition and we move one step upward in the AHP analysis.

Table 3. AHP results for the simplified example on the correct diagnosis attribute

\begin{tabular}{lcccc}
\hline & MTTR & MSI & OEE & Costs \\
\hline 0.076 Morale & 0.169 & 0.615 & 0.169 & 0.047 \\
0.261 Personnel & 0.564 & 0.118 & 0.263 & 0.055 \\
0.513 Monitoring & 0.564 & 0.118 & 0.263 & 0.055 \\
0.150 Troubleshooting & 0.564 & 0.118 & 0.263 & 0.055 \\
\hline \multicolumn{1}{c}{ Final Result } & $\mathbf{0 . 5 3 4}$ & $\mathbf{0 . 1 5 6}$ & $\mathbf{0 . 2 5 6}$ & $\mathbf{0 . 0 5 4}$ \\
\hline
\end{tabular}

It is important to mention that there are generally too many metrics involved in the comparison. In order to transfer a limited set of metrics to the upper level, only those with high contribution are selected. The limit is imposed considering the Pareto rule of $80-20$. For the analyzed example, the sum of MTTR, OEE and MSI contribution is $94.6 \%$ and therefore "Costs" metric is not considered further.

The procedure is carried out starting from the lowest level attributes. The set of metrics and their ranking derived in this level will serve as the starting point for the next level comparison and this methodology will continue until reaching the pillar goal. Thus, the final indicators will closely reflect the pillar performance. 


\subsection{Considerations of Feedback}

It was noted that feedback will be present in the GT model due to the dependency of the pillars. Such dependency leads to the existence of fundamental attributes that correspond to the main goal of a number of trees. For these attributes no metric can be effectively selected given that they will most likely differ in each tree.

In order to solve this recursive loop problem, a first set of estimated metrics will be considered for the attributes in question. Once the whole process has been conducted in the five pillars, the resulting indicators will now serve as an input for the second round of calculation. The iterative recalculation continues until no variation is observed in any of the five pillars resulting metrics.

Another approach to solve the pillars dependency is to use the Analytic Network Process (ANP) ${ }^{[13]}$. ANP is an enhanced approach to the AHP that supports dependencies and feedback. This theory adds networks to model dependencies among elements under the comparison process. This methodology was not applied in this study. It is left for future studies the application of the ANP and the analysis of how much the results differ from those obtained by the iteration process.

\subsection{Analysis of scale selection and consistency}

There are two aspects in the methodology that deserve detailed analysis: the scale selection and the level of consistency. Both concepts are closely related.

The scale proposed by Saaty ranges from 1 to 9 with clear qualitative definitions for the odd values as shown in Table 2. The intermediate values $(2,4,6$ 
and 8) are used when slight distinction is needed. There are several studies that provide different alternatives in the scale selection ${ }^{[14]}$. Some suggest quadratic and root square scales while others argue that the geometric scale is preferable. But integer scales yield to unevenly dispersed weights and therefore there is the alternative of a balanced scale where the local weights are evenly dispersed over the weight range $[0.1,0.9]$.

Clearly, the scale selection is highly subjective. For the purpose of this study, the linear 1-9 scale is chosen given that it is an easy way to represent the common verbal statements that the decision maker utilizes when making the metrics comparison. Nevertheless, this scale intransitive behavior must not be overlooked and the consistency results must be analyzed carefully.

Consistency is driven mainly by three factors. First, there must be a transitivity consistency. This means that if $\mathrm{A}$ is preferred over B and B is preferred over C, therefore A should be preferred over C. If this relation is not sustained, inconsistency will be generated. Nevertheless, there are real life cases where these types of inconsistencies are present. Such is the case of sport teams. It is not uncommon to see that $\mathrm{A}$ defeats $\mathrm{B}, \mathrm{B}$ defeats $\mathrm{C}$ and $\mathrm{C}$ defeats $\mathrm{A}$. This is a clear example that shows that inconsistency values must be analyzed carefully before assuming that there is judgment error.

The second factor affecting consistency is the numerical weights. If $\mathrm{A}$ is 3 times preferred over B and B is 3 times preferred over $C$, then, A should be $3 \times 3=9$ times preferred over C. Any value that does not arithmetically match this result will generate inconsistencies. This condition can represent an important source of 
uncertainty particularly for qualitative comparisons (the most commonly used in decision making). For this case, it is important to mention that the scale limit of 9 can also compromise the comparison process consistency. For example, if A is 3 times preferred over B and B is 5 times preferred over $\mathrm{C}$, then A should be $3 \times 5=15$ times preferred over C. This value exceeds the upper limit of 9.

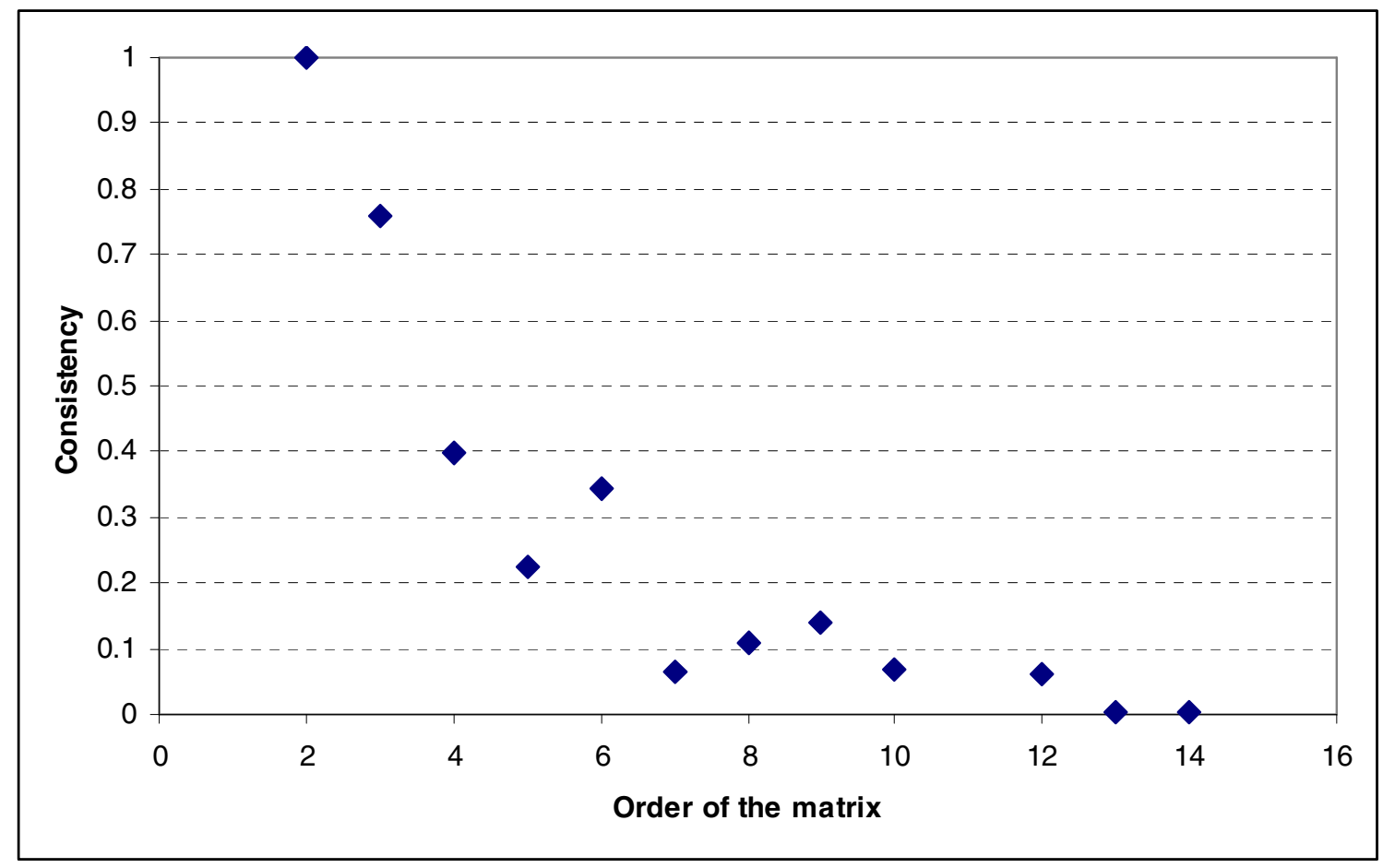

Figure 10. Consistency as a function of the order of the matrix

The third important factor is the size of the comparison matrix. The more elements being compared the greater the inconsistency. Figure 10 shows how the size of the matrix affects the consistency ${ }^{[5]}$. Note that as the number of elements to be compared increase the consistency value decrease. The problem becomes more complex for larger matrices. There is a psychological limit defined by the human 
capability of managing a certain amount of elements at the same time. The working memory capacity has been experimentally evaluated and it ranges from 5 to 9 items when full attention is deployed ${ }^{[15]}$.

Having all these aspects into consideration, an acceptable level of consistency has to be defined. The consistency ratio $(\mathbf{R})$ is determined by a consistency index CI and a random index RI through the following expression:

$$
\begin{gathered}
\mathrm{CR}=\mathrm{CI} / \mathrm{RI} \\
\mathrm{CI}=\left(\lambda_{\max }-\mathrm{n}\right) / \mathrm{n}-1
\end{gathered}
$$

The random index RI is tabulated and depends on the number of elements in the matrix:

\begin{tabular}{c|ccccccccccccccc}
$\mathrm{n}$ & 1 & 2 & 3 & 4 & 5 & 6 & 7 & 8 & 9 & 10 & 11 & 12 & 13 & 14 & 15 \\
\hline $\mathrm{RI}$ & 0.0 & 0.0 & 0.58 & 0.9 & 1.12 & 1.24 & 1.32 & 1.41 & 1.45 & 1.49 & 1.51 & 1.48 & 1.56 & 1.57 & 1.59
\end{tabular}

T.L Saaty ${ }^{[5]}$ suggests that a consistency ratio CR smaller than 0.1 or $10 \%$ is acceptable and for greater values a matrix revision should be made.

In this study, all matrices with CR greater than $10 \%$ have been carefully reviewed for transitivity and numerical inconsistencies. But given the important amount of high order matrices and significant metrics differences, there are several cases were the value of $\mathrm{CR}$ is greater than $10 \%$. These values of inconsistency are acceptable especially in those cases were mainly a rank order is sought after. 


\section{Chapter 3: Case Study: Automotive Manufacturing}

A particular case study was selected in order to put the proposed methodology into practice. The study determined the preferred metrics to monitor Maintenance Operations in Automotive Industries under a complex socio-economical environment.

\section{$\underline{3.1 \text { Context Definition }}$}

This case study presents some particular characteristics that define the boundary conditions of the analysis. The following list summarizes these conditions:

- Stamping and Body Plant

- One shift of production

- Equipment in poor operating conditions

- Annual budget cut

- Annual head count reduction

- Minimum overtime

- Limited parts in stock

- Strong union representation

- Extreme currency devaluation making spare parts prices exceed the assigned maintenance budget

- There is a gap of knowledge between technicians and new technologies installed

- There is no economical aid from the Company Headquarters or from the Government due to global financial difficulties

- No budget is assigned for training. There is little or no external training 
- High backlog due to poor equipment conditions and high amount of failures

- Morale: Due to difficult social and economic situation, people in all hierarchy levels are working under great pressure with low motivation

The consideration of these conditions will affect the pairwise comparison of the metrics, but will mostly alter the attributes importance. GTs in Figures 2 to 6 include the results from the attributes weight matrices. For example, in Figure 2 it can be seen that "Ensure tools and spares availability" together with "Improve personnel competence" are the most important attributes that must be satisfied to guarantee an effective repair. On the contrary, "Implement Quick Change Over and Error Proofing techniques" is the least significant.

Detailed results from the AHP can be found in Appendix B. Note that the previously mentioned iterative process leads to different results depending on the round of iteration. Additionally, the results are listed from higher to lower resulting weights and only those metrics with higher influence are selected. These most representative metrics are highlighted in the resulting tables.

The analysis result for this case study is summarized in Table 4. The metrics for PROACTIVE and LOGISTICS were selected using engineering judgment for the first iteration. From this selection the complete process was repeated deriving the set of leading indicators in the "2nd iteration". The highlighted metrics are new in the pillar. 
Table 4. Automotive industry case study results

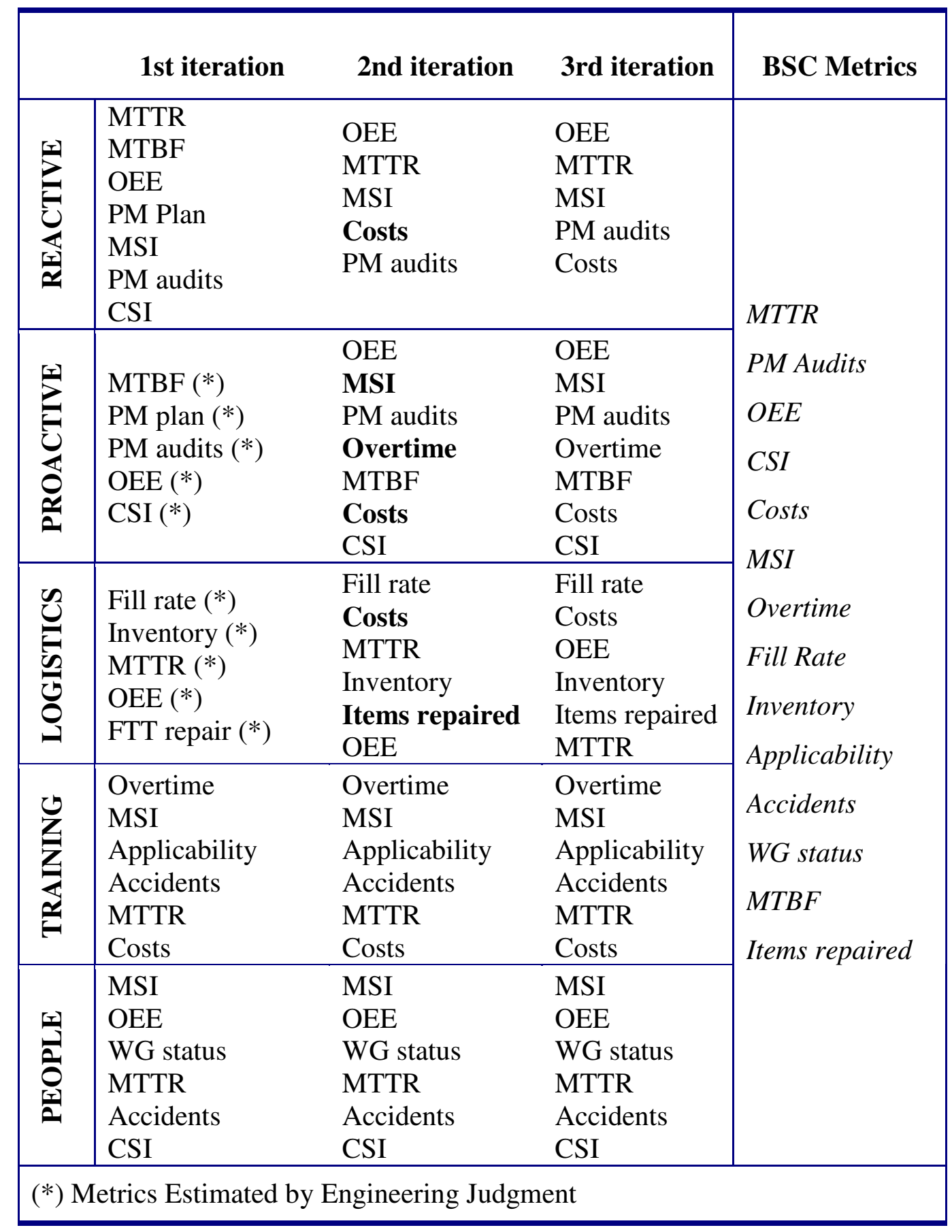

After three iterations, there were no further changes in the ranking and the final Balanced Scorecard metrics were obtained. 


\section{$\underline{3.2 \text { Sensitivity Analysis }}$}

Given the high number of fundamental attributes estimated and some complexity of comparison matrices, two different approaches have been selected to conduct a sensitivity analysis. One will focus on the importance of metrics weight and the other one on the importance of attributes weight.

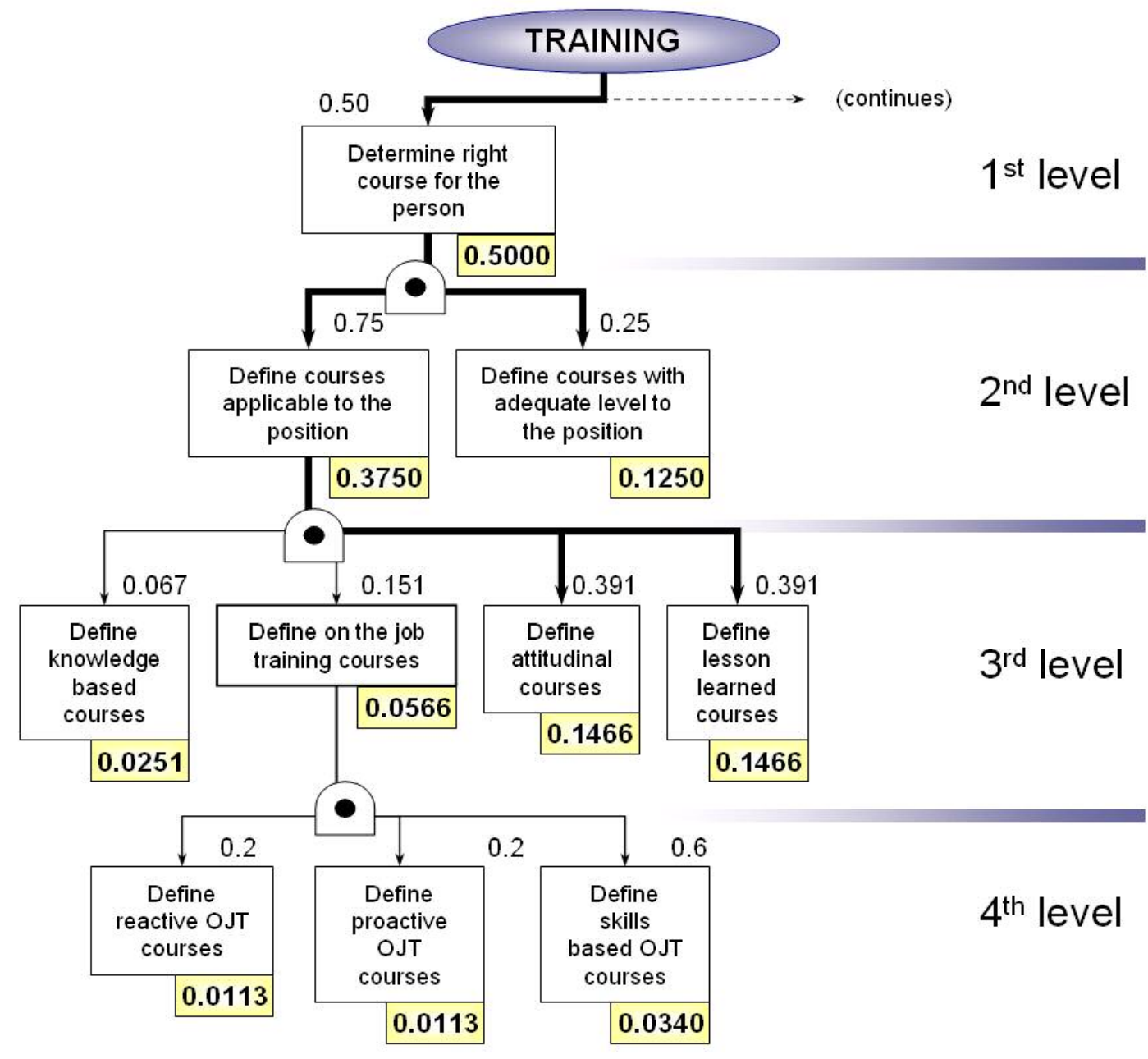

Figure 11. Attributes with high contribution to the TRAINING GT goal

For the metric sensitivity analysis, the attributes weights are kept constant throughout the tree decomposition. With these values, we will identify the most 
critical paths in each pillar. These can be calculated by multiplying each attribute weight at the different tree levels. The metrics to be evaluated will be those whose attributes weights are larger than $10 \%$ contribution to the main goal.

To help visualize this condition the path weights for "Determine right course for the person" from TRAINING Pillar are calculated. Figure 11 summarizes all resulting weights from this path. In addition to the individual attribute weights, each attribute's contribution to the TRAINING goal is shown. It is expected that attributes in higher levels have a higher contribution to the goal success. Thicker arrows in Figure 12 indicate those attributes that contribute in more than $10 \%$ to the main goal and whose metrics will be considered for the sensitivity analysis.

This methodology will lead to a limited set of attributes per pillar. Figure 12 lists the resulting attributes with their absolute influence over the goal and the level at which each attribute belongs. This representation shows that higher-level attributes have a greater influence on the pillar goal, which reinforces the conclusion that the metrics comparisons will be more critical as we move to the upper levels.

For each of these attributes, the metric sensitivity will be conducted. The procedure consists of varying the metric weight in one level of importance, for example from 3 to 5 in case of increasing relevance or from 9 to 7 for decreasing weight, given that the applied scale uses five absolute measures of importance $(1,3,5,7$ and 9$)$. These sensible variations may result in metrics rank modification as well as new weight assignments. The resulting observations derived a group of high sensitive metrics and the corresponding AHP matrices were revised. 

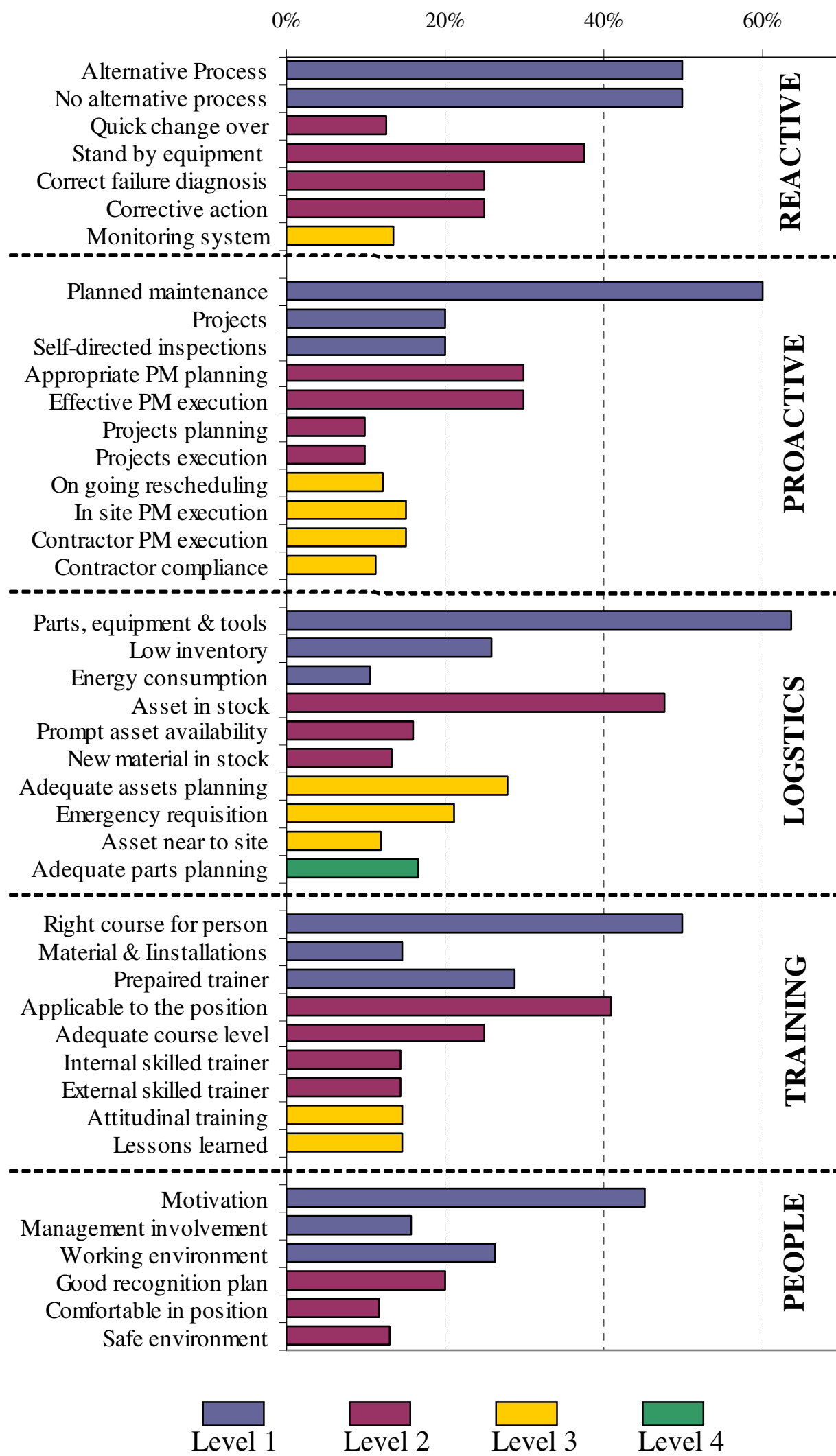

Figure 12. Attributes sensitive in the automotive industry case study 
The second approach considers constant metric weights and varies the attribute relative values. The criteria immediately below the goal will be subjected to analysis given its dominance in the final result. The objective is to determine how minimum variations in criteria weighting will affect the resulting metrics. All attributes from the first level of decomposition are subjected to individual increased and decreased weights. Observations derived from this sensitivity analysis are listed per attribute within each of the five pillars in Table 5.

Table 5. Observations derived from the attribute sensitivity analysis conducted on the automotive industry case study

\begin{tabular}{|c|c|c|c|}
\hline PILLAR & CRITERIA & INCREASING & DECREASING \\
\hline REACTIVE & $\begin{array}{l}\text { Manage repair } \\
\text { actions through } \\
\text { alternative } \\
\text { process }\end{array}$ & $\begin{array}{l}\text { - OEE remains the most } \\
\text { relevant metric } \\
\text { - Maintenance costs is no } \\
\text { more representative of this } \\
\text { pillar giving place to } \\
\text { Overtime } \\
\text { - MTTR decreases } 45 \% \\
\text { moving from the second to } \\
\text { the fourth place }\end{array}$ & $\begin{array}{l}\text { - OEE remains the most relevant } \\
\text { metric } \\
\text { - } M T T R \text { remains the second indicator } \\
\text { but increases its relevance in } 45 \%\end{array}$ \\
\hline \multirow[t]{3}{*}{ PROACTIVE } & $\begin{array}{l}\text { Maintain a good } \\
\text { planned } \\
\text { maintenance } \\
\text { program }\end{array}$ & $\begin{array}{l}\text { - OEE remains the most } \\
\text { relevant metric } \\
\text { - One metric less to measure } \\
\text { the pillar since CSI is } \\
\text { excluded } \\
\text { - New } P M \text { plan metric is } \\
\text { considered while Costs is no } \\
\text { longer relevant }\end{array}$ & $\begin{array}{l}\text { - MSI becomes the most important } \\
\text { metric with a } 14 \% \text { increase followed } \\
\text { by Overtime } \\
\text { - OEE is reduced in } 27 \% \text { moving to } \\
\text { the third place } \\
\text { - } M T B F \text { is no longer considered giving } \\
\text { place to BTS performance indicator } \\
\text { - PM audits falls } 40 \% \text { moving to the } \\
\text { last place }\end{array}$ \\
\hline & $\begin{array}{l}\text { Implement } \\
\text { improvement } \\
\text { projects }\end{array}$ & $\begin{array}{l}\text { - MSI becomes the higher } \\
\text { influence metric moving } \\
O E E \text { to the second place } \\
\text { - } C S I \text { is excluded giving place } \\
\text { to } B T S\end{array}$ & $\begin{array}{l}\text { - OEE remains the most relevant } \\
\text { metric } \\
\text { - Costs is excluded giving place to } \\
\text { BTS }\end{array}$ \\
\hline & $\begin{array}{l}\text { Carry out self- } \\
\text { directed } \\
\text { maintenance }\end{array}$ & $\begin{array}{l}\text { - } O E E \text { remains the most } \\
\text { relevant metric } \\
\text { - There is a significant } \\
\text { increase in CSI relevance } \\
(65 \%) \\
\text { - Costs is excluded giving } \\
\text { place to BTS }\end{array}$ & $\begin{array}{l}\text { - There is no change in the first three } \\
\text { metrics (OEE, MSI and PM audits) } \\
\text { - CSI is no longer considered reducing } \\
\text { the total amount of used metrics }\end{array}$ \\
\hline
\end{tabular}




\begin{tabular}{|c|c|c|c|}
\hline PILLAR & CRITERIA & INCREASING & DECREASING \\
\hline \multirow[t]{3}{*}{ LOGISTICS } & $\begin{array}{l}\text { Ensure parts, } \\
\text { equipment \& } \\
\text { tools availability }\end{array}$ & $\begin{array}{l}\text { - There is no change in the } \\
\text { first three metrics (Fill rate, } \\
\text { Cost and OEE) } \\
\text { - Items repaired is no longer } \\
\text { considered reducing the } \\
\text { total amount of used metrics } \\
\text { from six to five }\end{array}$ & $\begin{array}{l}\text { - Costs becomes the most important } \\
\text { metric due to a } 15 \% \text { decrease in the } \\
\text { Fill Rate metric relevance } \\
\text { - MTTR is no longer considered giving } \\
\text { place to } M S I\end{array}$ \\
\hline & $\begin{array}{l}\text { Minimize } \\
\text { inventory }\end{array}$ & $\begin{array}{l}\text { - There is no change in the } \\
\text { first two metrics (Fill Rate } \\
\text { and Costs) } \\
\text { - MTTR is no longer } \\
\text { considered reducing the } \\
\text { total amount of used metrics } \\
\text { from six to five }\end{array}$ & $\begin{array}{l}\text { - There is no change in the first three } \\
\text { metrics (Fill Rate, Costs and } O E E \text { ) } \\
\text { - Inventory drops } 67 \% \text { and is no longer } \\
\text { considered giving place to } M S I\end{array}$ \\
\hline & $\begin{array}{l}\text { Optimize } \\
\text { energy } \\
\text { consumption }\end{array}$ & $\begin{array}{l}\text { - There is no change in the } \\
\text { first three metrics (Fill Rate, } \\
\text { Costs and OEE) } \\
\text { - Even though there is no } \\
\text { significant variation in the } \\
\text { metrics results, Items } \\
\text { repaired gives place to MSI }\end{array}$ & $\begin{array}{l}\text { - There is no change in the metrics } \\
\text { ranking but the higher significance of } \\
\text { the primary indicators results in one } \\
\text { less metric needed (MTTR) }\end{array}$ \\
\hline \multirow[t]{4}{*}{ TRAINING } & $\begin{array}{l}\text { Determine right } \\
\text { courses for the } \\
\text { person }\end{array}$ & $\begin{array}{l}\text { - Given the close final result } \\
\text { weights, a slight variation of } \\
\text { the attribute weight easily } \\
\text { changes the metrics ranking } \\
\text { - Overtime moves from first } \\
\text { to fifth place } \\
\text { - Costs is no longer } \\
\text { considered giving place to } \\
\text { Understanding metric }\end{array}$ & $\begin{array}{l}\text { - There is no change in the first two } \\
\text { metrics (Overtime and MSI) } \\
\text { - Accidents drops } 36 \% \text { and is no } \\
\text { longer considered giving place to } \\
\text { Backload metric } \\
\text { - Costs increases } 27 \% \text { moving from } \\
\text { the sixth to the third place }\end{array}$ \\
\hline & $\begin{array}{l}\text { Have } \\
\text { appropriate } \\
\text { training material } \\
\text { and installations }\end{array}$ & $\begin{array}{l}\text { - Overtime remains the most } \\
\text { important metric } \\
\text { - MSI decreases } 15 \% \text { falling } \\
\text { from second to fifth place }\end{array}$ & $\begin{array}{l}\text { - Overtime and MSI switch first and } \\
\text { second places }\end{array}$ \\
\hline & $\begin{array}{l}\text { Have prepared } \\
\text { trainers }\end{array}$ & $\begin{array}{l}\text { - No significant change in } \\
\text { ranking or weights }\end{array}$ & $\begin{array}{l}\text { - No significant change in ranking or } \\
\text { weights }\end{array}$ \\
\hline & $\begin{array}{l}\text { Have people } \\
\text { available for } \\
\text { training }\end{array}$ & $\begin{array}{l}\text { - There is no change in the } \\
\text { first two metrics (Overtime } \\
\text { and } M S I \text { ) } \\
\text { - It is observed a higher } \\
\text { predominance of the first } \\
\text { two metrics with respect to } \\
\text { the rest of the set }\end{array}$ & $\begin{array}{l}\text { - Overtime moves from first to third } \\
\text { place after decreasing } 13 \% \\
\text { - Applicability increases } 13 \% \text { moving } \\
\text { from third to first place } \\
\text { - MSI moves from second to fifth } \\
\text { place after decreasing } 12 \%\end{array}$ \\
\hline
\end{tabular}




\begin{tabular}{|c|c|c|c|}
\hline PILLAR & CRITERIA & INCREASING & DECREASING \\
\hline \multirow[t]{5}{*}{ PEOPLE } & $\begin{array}{l}\text { Increase } \\
\text { employees } \\
\text { motivation }\end{array}$ & $\begin{array}{l}\text { - Even though there is no } \\
\text { significant variation in the } \\
\text { metrics results, CSI is no } \\
\text { longer considered giving } \\
\text { place to Ideas } \\
\text { implementation } \\
\text { - The main performance } \\
\text { indicators gain more } \\
\text { relevance }\end{array}$ & $\begin{array}{l}\text { - } M S I \text { and } O E E \text { remain the first two } \\
\text { metrics } \\
\text { - WG status decreases } 22 \% \text { falling } \\
\text { from the third to the sixth place } \\
\text { - Absenteeism is added to the set of } \\
\text { metrics }\end{array}$ \\
\hline & $\begin{array}{l}\text { Increase } \\
\text { management } \\
\text { involvement }\end{array}$ & $\begin{array}{l}\text { - MSI remains the dominant } \\
\text { metric } \\
\text { - There is no significant } \\
\text { variation in the final } \\
\text { weights but some slight } \\
\text { changes in ranking appear }\end{array}$ & - No significant variation is perceived \\
\hline & $\begin{array}{l}\text { Provide } \\
\text { Employment } \\
\text { planning }\end{array}$ & $\begin{array}{l}\text { - No significant variation is } \\
\text { perceived }\end{array}$ & - No significant variation is perceived \\
\hline & $\begin{array}{l}\text { Induce effective } \\
\text { communication }\end{array}$ & $\begin{array}{l}\text { - Even though there is no } \\
\text { significant variation in the } \\
\text { metrics results, Accidents is } \\
\text { no longer considered giving } \\
\text { place to Ideas } \\
\text { implementation }\end{array}$ & - No significant variation is perceived \\
\hline & $\begin{array}{l}\text { Provide with a } \\
\text { good work } \\
\text { environment }\end{array}$ & $\begin{array}{l}\text { - There is no change in the } \\
\text { first two metrics (MSI and } \\
\text { OEE) } \\
\text { - WG status decreases in } 20 \% \\
\text { falling from third to sixth } \\
\text { place }\end{array}$ & $\begin{array}{l}\text { Even though there is no significant } \\
\text { variation in the metrics results, CSI } \\
\text { is no longer considered giving place } \\
\text { to Ideas implementation }\end{array}$ \\
\hline
\end{tabular}

Similar to the metric sensitivity analysis discussed earlier, the result from the attribute sensitivity analysis indicated particular matrices to be carefully reviewed.

\subsection{Results}

The application of the methodology to the automotive industry resulted in a small set of metrics to monitor and effectively manage maintenance operations. These metrics listed in Table 4 resulted from the systematic decompositions of some pillars of effective maintenance along with AHP ranking. 


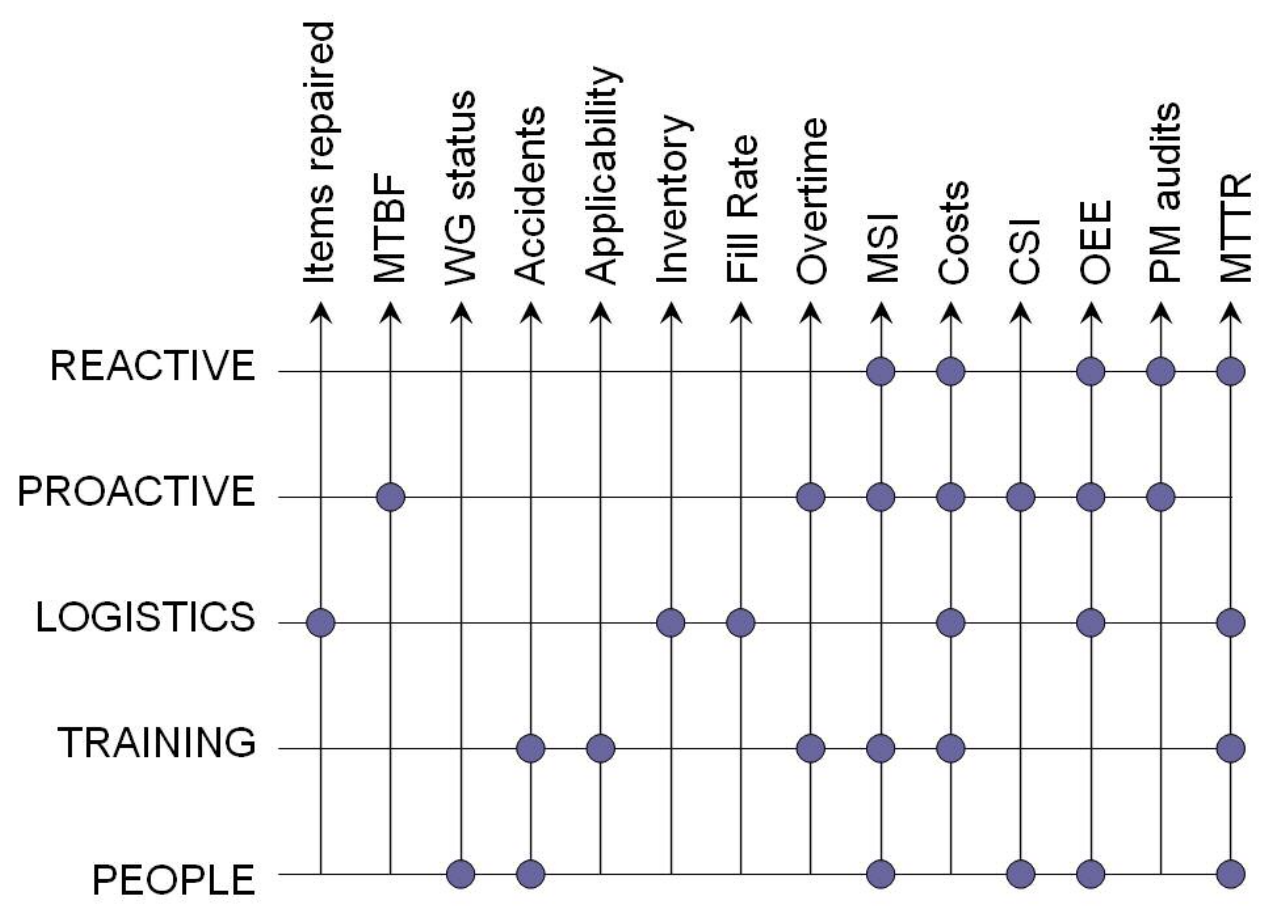

Figure 13. Metrics and Pillars dependency for the automotive case study

Figure 13 helps visualize the dependencies of the resulting metrics with the pillars. For example, CSI will monitor both PROACTIVE and PEOPLE pillars. Similarly, indicators such as Items Repaired, Inventory and Fill Rate will only monitor LOGISTICS pillar. We can also use Figure 13 to depict which metric will reveal a particular pillar performance. Additionally, Figure 14 details the relative importance of each metric to the pillar goal. Note that in Figure 14 a there is a strong dominance of OEE over the other performance indicators. This means that for this particular case study, the REACTIVE pillar can be primarily monitored by the OEE metric. From a management point of view, focusing on improving OEE will result in an important improvement of the REACTIVE pillar. 


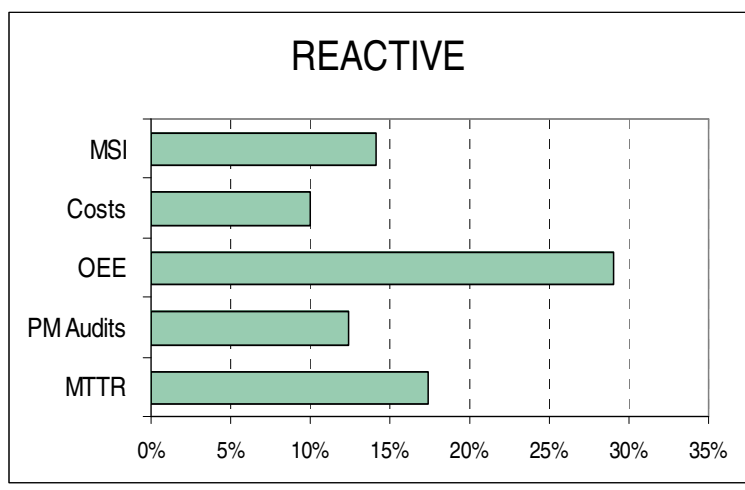

a

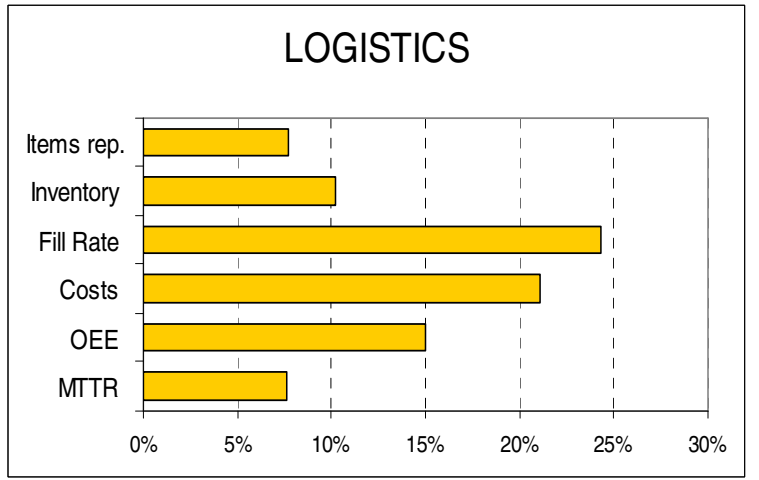

c

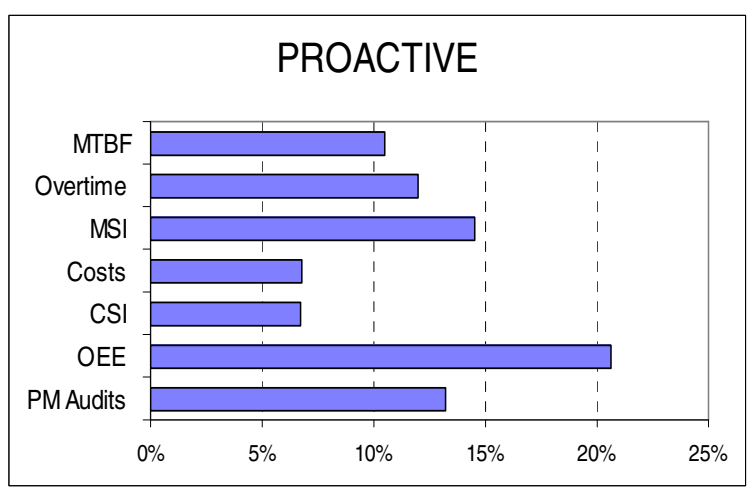

b

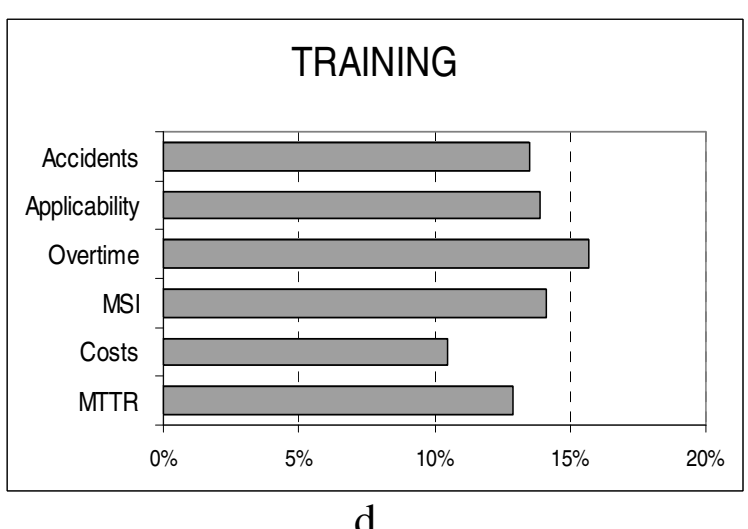

d

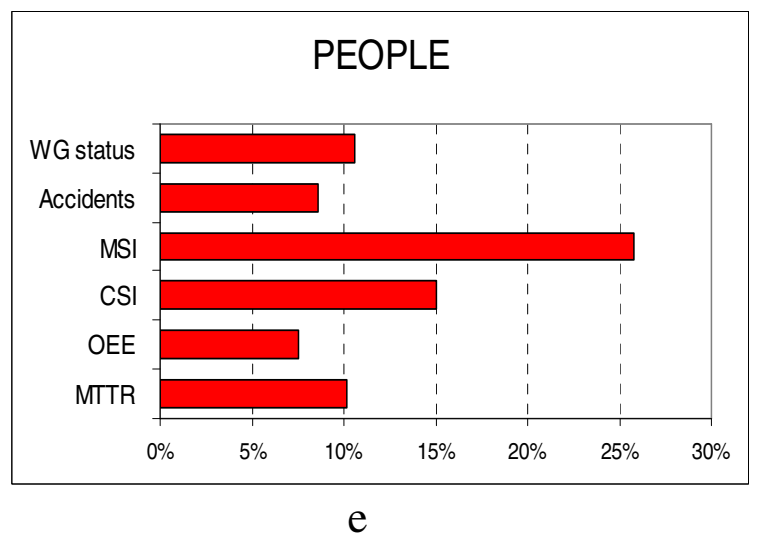

e

Figure 14. Relative influence of the resulting metrics over each pillar

This same analysis can easily be derived from Figure 15. In this figure we can see the how each metric can monitor different pillars. As an example let us focus on 
Accidents. This metric is shown to monitor both PEOPLE and TRAINING pillars. In order to reduce the number of accidents, the resources should be invested in these two pillars with a slight preference on TRAINING.

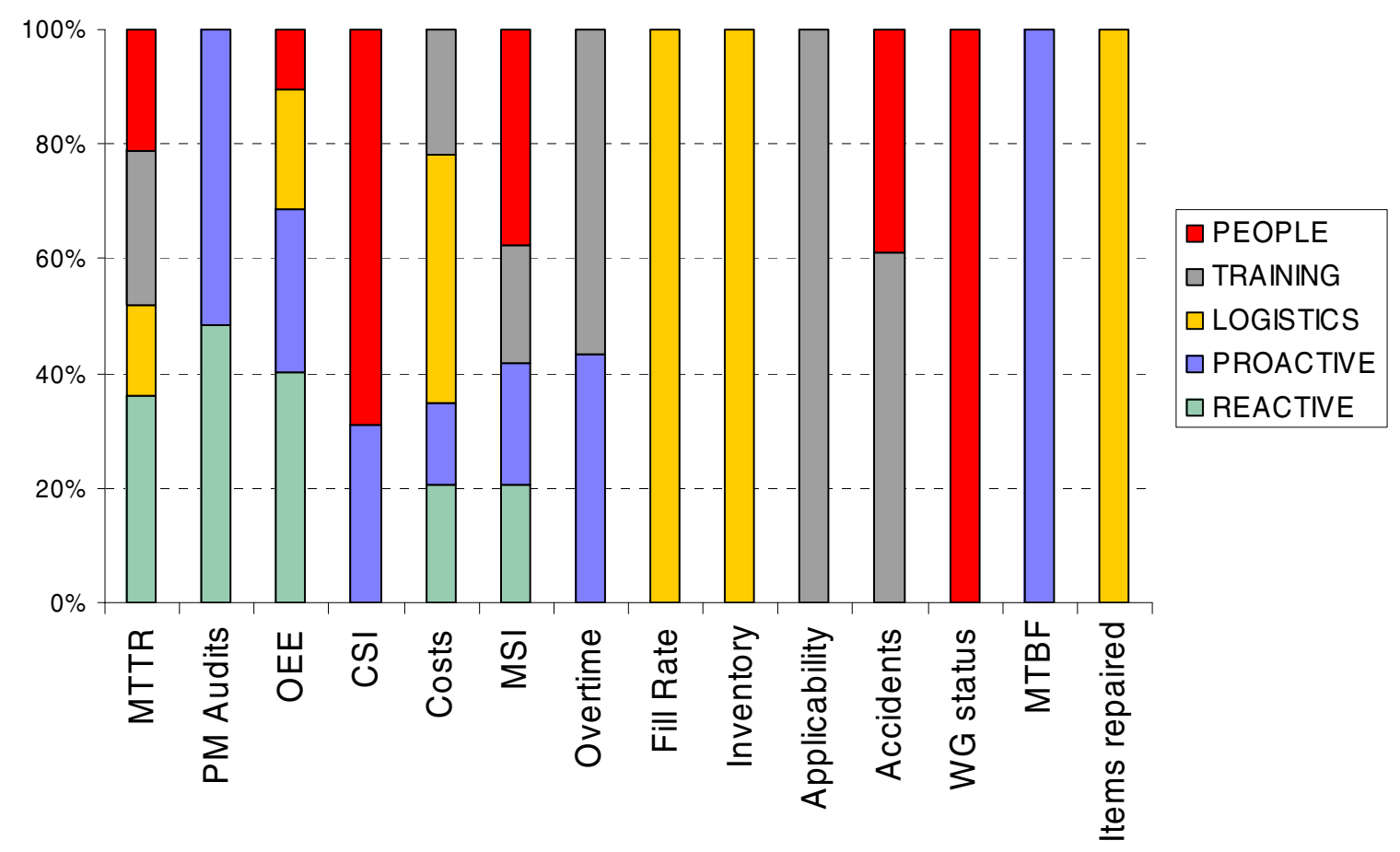

Figure15. Pillars monitored per metric

Similarly, transposing this chart we can obtain the resulting performance indicators that will monitor each pillar as shown in Figure 16. This representation is particularly useful for management decision making since it clearly shows the relative importance each metric has in monitoring a particular pillar.

Again, the dominance of $\mathrm{OEE}$ as the strongest metric for measuring the REACTIVE pillar can easily be seen. Similarly, this figure also shows that MSI metric is the most relevant metric for measuring PEOPLE pillar. 


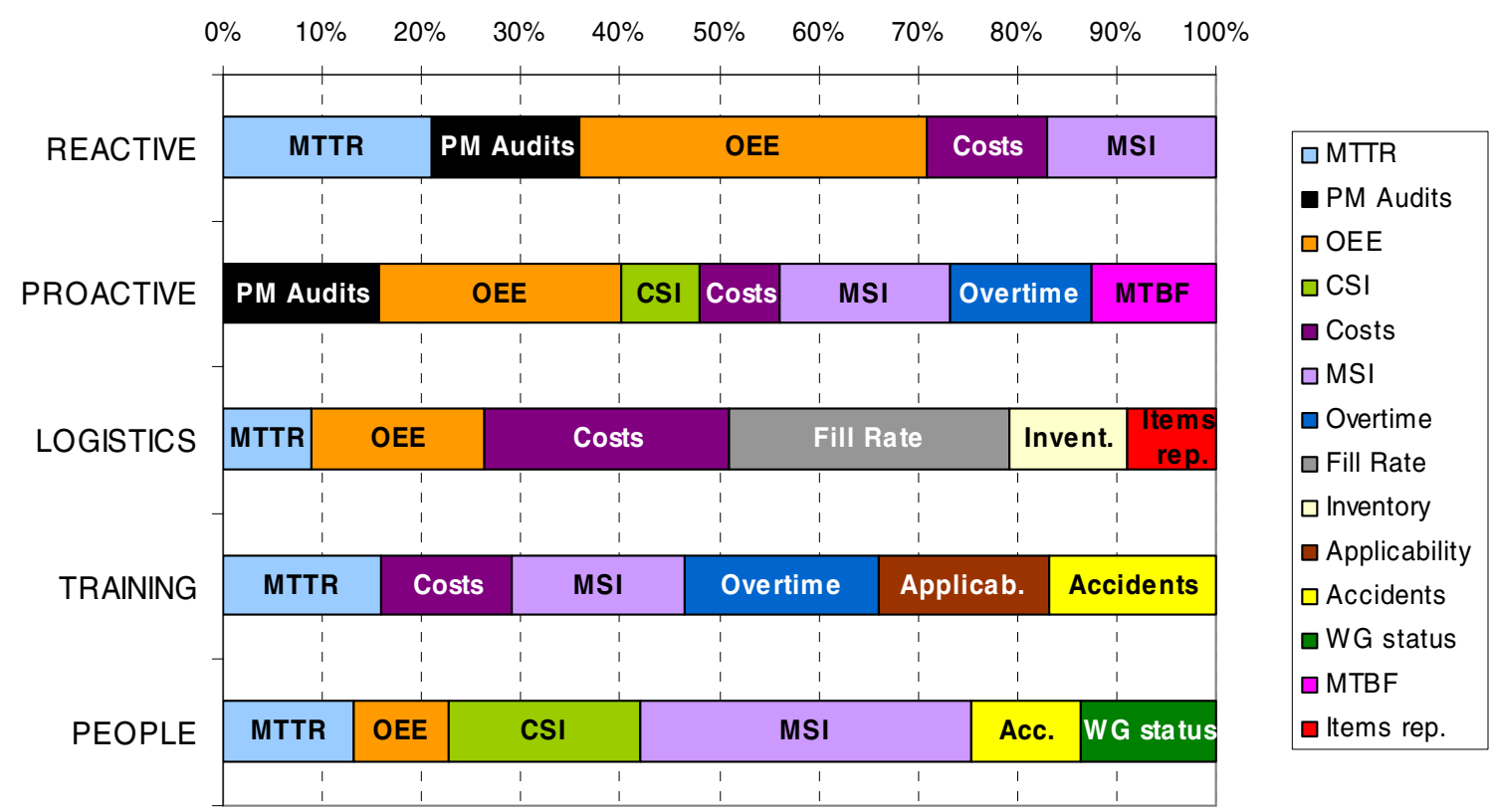

Figure 16. Resulting metrics with their relative weights per Pillar

The proposed method shows what should be monitored to maximize performance of maintenance operations. It also provides the fundamentals to a structured and result-oriented management planning.

The sensitivity analysis reinforces the importance of the higher-level attributes in the final results indicating that the metric weighting should be conducted more carefully as we approach the top level. Additionally, those metrics that are sensitive for each critical path are identified so that judgments regarding ranking of the metrics can be modified, if necessary. 


\section{Chapter 4: Conclusions}

After developing the GTs for each of the five fundamental pillars a group of attributes was derived. Many of these attributes are replicated in more than one pillar showing that there is a close interdependency among the pillars. Moreover, the presence of closed feedback loops indicates the importance of focusing on all pillars simultaneously in order to ensure optimal maintenance performance.

It is observed that most attributes share the same indicators. This means that a variation in a single attribute can modify more than one performance indicators. Also, each metric depends on the success of a number of attributes from different pillars. Therefore, the metrics and attributes show a many-to-many relationship. Decision makers are encountered with this complex model often. The GT decomposition followed by the application of the AHP helped clarify the model dependencies.

An important advantage of this methodology is that GT decomposition provided with a general model for maintenance operations. The model can be further customized by applying the AHP to fit particular applications.

This study provides a complete and integrated methodology for maintenance related activities. The systematic development of the goal trees allows identification of all the main attributes that should be in place for reliable and safe operations. At the same time, the qualitative hierarchical arrangement of the metrics provides a means of selecting those that will better monitor maintenance performance.

A case study was performed and results are consistent with expectation. Most of the resulting metrics are suggested by maintenance management literature. This 
practical application derived these metrics in a methodic way and at the same time provided with relative weights for each of the five pillars of the strategy. 


\section{Chapter 5: Future Work}

\subsection{On the GT decomposition}

The hierarchical decomposition has been conducted by the author and has been reviewed by another maintenance management expert. Given the complexity of different maintenance practices and the diverse industries and applications, future improvement can be made in the GT development. A team of maintenance experts from different industries can be built in order to conduct a thorough revision of the decomposition and ensure it is applicable to all kind of industries.

Additionally, a similar group analysis can be conducted by a cross functional team integrated by experts from the fields of Human Resources, Personnel Development and Training and Logistics and Material Handling.

\subsection{On the metrics quantification}

Given that the AHP quantification is performed by expert judgment it tends to be subjective and dependent on the analyst personal experience. In this work the metric and attribute comparison was conducted only by the author to show the methodology. In order to obtain a more objective result an expert elicitation process should be conducted. Similar to the GT decomposition, this team should involve experts in the maintenance field as well as other cross functional areas.

\subsection{On the consideration of feedback}

In the present work the presence of feedback among pillars was solved using an iterative process. Three iterations have been conducted to obtain the resulting 
performance indicators. The use of $\mathrm{ANP}^{[13]}$ has only been mentioned as an alternative to this problem. Future work should focus on implementing the ANP to address feedback and compare these results with those presented in this study. 


\section{Appendices}

\section{$\underline{\text { Appendix A: Metric Definitions }}$}

Accidents: Defines the number of accidents and incidents per period of time. It is usually monthly kept and includes the year accumulate. This metric focuses on human injury. Some organizations also include property damage as part of this report. An incident is an event that has the potential to cause damage to personnel. Accidents are usually divided by severity into mayor accidents and minor accidents. Therefore, three values are represented:

Applicability: As a training metric, it measures how applicable the course is to the student's job position. It is usually a qualitative indicator. In order to measure the complete training program the average applicability for all the courses on the period is calculated. Numeric applicability values can be assigned to the qualitative statement to facilitate the graphic representation. Then, the sum of these applicability values over the number of courses in the time period is plotted.

Backlog: The backlog can be measured with the work order system by keeping appropriate record of the work order status. This metric measures the amount of work orders (WO) opened and pending for the time period and the ratio of closed WO vs. total WO. In order to see if the backlog is increasing or decreasing, the cumulative values are also represented. 
BTS: BTS stands for Build To Schedule. It is an operational metric that represent how well the plant produced the correct volume, mix, and sequence according to customer requirements.

Cases: "Case" is the name given to a complete failure analysis that includes the study of why the failure happened (MTBF analysis) and why it took that amount of time to implement the corrective action (MTTR analysis). Additionally, one "case" includes the containment and definitive corrective actions with the corresponding implementation plan. A case is to be close when the root cause was determined and the definitive corrective actions were implemented.

This metric shows the number of opened cases versus the total number of failures occurred as well as the ratio of opened versus closed cases.

Costs: There are several ways to measure maintenance costs. Two of the most common are Maintenance cost per unit manufactured and Maintenance cost per total manufacturing costs. It is common to see maintenance costs split in materials costs and manpower costs. The latest also includes over time.

CSI: CSI stands for Customer Satisfaction Index. This metric will represent how satisfied Production department is with maintenance performance. In order to gather this information, surveys are commonly used. 
Fill rate: Fill rate is a material flow performance indicator that represents the ratio of parts provided versus parts requested.

FTT repair: FTT stands for First Time Through. This metric is usually used in manufacturing to measure the percentage of good units manufactured in the first round. It is calculated by dividing the number of units minus any defects by the total number of units.

This concept can be used for repaired items to measure the quality of the repair. In this case, the metrics will represent the ratio of working repaired units divided by the total units that have been repaired.

Ideas Implementation: This metric will measure how many improvement ideas have been proposed by the organization personnel and also the percentage of those that were effectively implemented.

Items repaired: This is a simple indication of total items repaired over the total items failed.

Inventory: There are to variables that must be considered when measuring inventory. The first one is the total number of items in stock and the second one is the total cost of these items. Generally both values are indicated. The stock inactivity can also be included in this metric computing the inactive stock items divided the total stock items. 
MSI: Maintenance Satisfaction Index (MSI) represents the moral of maintenance employees. Similar to the Customer Satisfaction Index, this indicator is derived from appropriate surveys.

MTBF: Mean Time Between Failure measures the breakdown frequency. It is computed as the considered time period divided by the number of breakdowns.

MTTR: Mean Time To Repair as its name clearly indicates, shows the average time to repair. It is computed as the total downtime divided by the number of breakdowns.

OEE: The Overall Equipment Effectiveness combines three different measures as follows:

$$
\text { OEE = Availability } \mathrm{x} \text { Performance } \mathrm{x} \text { Quality }
$$

Where

$$
\begin{gathered}
\text { Availability = Operating Time / Planned Production Time } \\
\text { Performance }=\text { Ideal Cycle Time } / \text { (Operating Time } / \text { Total Pieces) } \\
\text { Quality = Good Pieces / Total Pieces }
\end{gathered}
$$

Overtime: Overtime is the amount of time someone works beyond normal working hours. This metric can be represented by total overtime per period of time or by total overtime cost per period of time.

PM audits: In order to improve the preventive maintenance practices, TPM establishes an audit system that consists of randomly select $5 \%$ of the total PM work 
orders and check its compliance and also asses the quality of the work performed. The amount of WO audited with open issues vs. total audited WO is plotted. This performance indicator can help identify training needs as well as the need to rebalance the amount of PM activities.

PM plan: This metric represents the compliance of the PM plan through the plotting of total PM work orders closed versus total planed PM work orders.

System audits: System audit can be performed on computerized maintenance management system, (CMMS) or the material planning system. This performance indicator is similar to PM audits in that $5 \%$ of the items are audited and those with observations are divided by the total of the items audited and the result is then plotted.

Troubleshooting: Troubleshooting provides a systematic means of searching for the source of a problem so that it can be solved. All critical equipment must have a comprehensive documentation that is used to guide the analyst thourgh the troubleshooting process.

This metric shows how many equipment have troubleshooting documentation over the total plant equipment.

Understanding: This training performance indicator measures how effectively the concepts explained in a certain course have been transmitted. In order to measure this 
level of learning it is necessary that all courses include a brief examination to test the participant's learning process.

The average score of the examination is computed per course and the average of the all the courses results per period of time is represented.

WG status or Work Group Status: This indicator only applies to those organizations that have work cells in place. There are many ways to measure how mature the work group is and it is highly related to the type of organization. One example of this technique is using the 10 pillars of Lean Manufacturing and measuring the results in each pillar. The more mature the group is the more advanced Lean manufacturing indicators will be. 
REACTIVE Pillar

ENSURE PROPER DATA COLLECTION AND ANALYSIS

$1^{\text {st }}, 2^{\text {nd }}$ and $3^{\text {rd }}$ iteration:

\begin{tabular}{|c|c|c|c|c|c|}
\hline & $\begin{array}{c}0.067 \\
\text { WG meetings }\end{array}$ & $\begin{array}{c}0.391 \\
\text { In site meetings }\end{array}$ & $\begin{array}{c}0.151 \\
\text { Database }\end{array}$ & $\begin{array}{l}0.391 \\
\text { Cases }\end{array}$ & $\begin{array}{l}\text { Final } \\
\text { Result }\end{array}$ \\
\hline OEE & 0.088 & 0.289 & 0.110 & 0.145 & 0.192 \\
\hline Cases & 0.027 & 0.029 & 0.034 & 0.371 & 0.163 \\
\hline MTTR & 0.088 & 0.160 & 0.110 & 0.145 & 0.142 \\
\hline BTS & 0.034 & 0.210 & 0.015 & 0.081 & 0.118 \\
\hline MTBF & 0.088 & 0.058 & 0.110 & 0.145 & 0.102 \\
\hline MSI & 0.178 & 0.100 & 0.033 & 0.019 & 0.064 \\
\hline $5 \%$ Audits & 0.009 & 0.008 & 0.373 & 0.008 & 0.063 \\
\hline CSI & 0.178 & 0.100 & 0.011 & 0.019 & 0.060 \\
\hline Backload & 0.022 & 0.022 & 0.182 & 0.037 & 0.052 \\
\hline WG & 0.288 & 0.023 & 0.021 & 0.029 & 0.043 \\
\hline
\end{tabular}

\section{INDUCE EFFECTIVE COMMUNICATION}

$1^{\text {st }}, 2^{\text {nd }}$ and $3^{\text {rd }}$ iteration:

\begin{tabular}{|ccc|c|}
\cline { 2 - 4 } \multicolumn{1}{c|}{} & 0.250 & 0.750 & Final \\
Meetings & Training & Result \\
\hline Overtime & 0.014 & 0.302 & 0.230 \\
MSI & 0.160 & 0.224 & 0.208 \\
Applicability & 0.013 & 0.165 & 0.127 \\
Accidents & 0.111 & 0.111 & 0.111 \\
WG & 0.309 & 0.023 & 0.095 \\
MTTR & 0.073 & 0.083 & 0.080 \\
\hline Ideas implementation & 0.222 & 0.012 & 0.064 \\
Costs & 0.027 & 0.049 & 0.044 \\
MTBF & 0.073 & 0.031 & 0.041 \\
\hline
\end{tabular}




\section{KEEP AN UPDATED LESSON LEARNED SYSTEM}

$1^{\text {st }}, 2^{\text {nd }}$ and $3^{\text {rd }}$ iteration:

\begin{tabular}{|ccc|c|}
\cline { 2 - 4 } \multicolumn{1}{c|}{} & $\begin{array}{c}0.250 \\
\text { Data analysis }\end{array}$ & $\begin{array}{c}0.750 \\
\text { Communication }\end{array}$ & $\begin{array}{c}\text { Final } \\
\text { Result }\end{array}$ \\
\hline Overtime & 0.010 & 0.281 & 0.214 \\
MSI & 0.065 & 0.215 & 0.177 \\
Applicability & 0.010 & 0.158 & 0.121 \\
Accidents & 0.023 & 0.115 & 0.092 \\
OEE & 0.280 & 0.025 & 0.089 \\
MTTR & 0.163 & 0.056 & 0.083 \\
WG status & 0.036 & 0.085 & 0.072 \\
Cases & 0.214 & 0.010 & 0.061 \\
MTBF & 0.085 & 0.036 & 0.048 \\
BTS & 0.115 & 0.019 & 0.043 \\
\hline
\end{tabular}

$1^{\text {st }}, 2^{\text {nd }}$ and $3^{\text {rd }}$ iteration:

PERFORM CORRECT DIAGNOSIS

\begin{tabular}{|c|c|c|c|c|c|c|}
\hline & $\begin{array}{r}0.043 \\
\text { Morale }\end{array}$ & $\begin{array}{c}0.232 \\
\text { Personnel }\end{array}$ & $\begin{array}{c}0.541 \\
\text { Monitoring Sys. }\end{array}$ & $\begin{array}{l}0.092 \\
\text { Lesson Learned }\end{array}$ & $\begin{array}{c}0.092 \\
\text { Troubleshooting }\end{array}$ & $\begin{array}{l}\text { Final } \\
\text { Result }\end{array}$ \\
\hline MTTR & 0.114 & 0.106 & 0.323 & 0.055 & 0.233 & 0.230 \\
\hline OEE & 0.218 & 0.157 & 0.240 & 0.074 & 0.182 & 0.199 \\
\hline MSI & 0.285 & 0.212 & 0.171 & 0.214 & 0.108 & 0.184 \\
\hline Costs & 0.021 & 0.305 & 0.071 & 0.014 & 0.059 & 0.117 \\
\hline Troubleshooting & 0.012 & 0.009 & 0.102 & 0.018 & 0.292 & 0.086 \\
\hline Overtime & 0.039 & 0.074 & 0.019 & 0.291 & 0.012 & 0.057 \\
\hline Applicability & 0.012 & 0.050 & 0.018 & 0.154 & 0.043 & 0.040 \\
\hline Accidents & 0.084 & 0.035 & 0.020 & 0.112 & 0.035 & 0.036 \\
\hline WG & 0.157 & 0.022 & 0.018 & 0.038 & 0.018 & 0.027 \\
\hline CSI & 0.059 & 0.030 & 0.018 & 0.028 & 0.019 & 0.024 \\
\hline
\end{tabular}

IMPROVE IN SITE PERSONNEL COMPETENCE

$1^{\text {st }}, 2^{\text {nd }}$ and $3^{\text {rd }}$ iteration:

\begin{tabular}{|ccc|c|}
\cline { 2 - 4 } \multicolumn{1}{c|}{} & $\begin{array}{c}0.500 \\
\text { Training }\end{array}$ & $\begin{array}{c}0.500 \\
\text { Right position }\end{array}$ & $\begin{array}{c}\text { Final } \\
\text { Result }\end{array}$ \\
\hline MSI & 0.221 & 0.224 & 0.223 \\
OEE & 0.030 & 0.314 & 0.172 \\
Overtime & 0.316 & 0.024 & 0.170 \\
MTTR & 0.076 & 0.160 & 0.118 \\
Applicability & 0.164 & 0.017 & 0.091 \\
Accidents & 0.110 & 0.032 & 0.071 \\
\hline CSI & 0.016 & 0.110 & 0.063 \\
MTBF & 0.028 & 0.077 & 0.052 \\
Costs & 0.039 & 0.043 & 0.041 \\
\hline
\end{tabular}




\section{IMPROVE PERSONNEL COMPETENCE}

$1^{\text {st }}, 2^{\text {nd }}$ and $3^{\text {rd }}$ iteration:

\begin{tabular}{|c|cc|c|}
\cline { 2 - 4 } \multicolumn{1}{c|}{} & $\begin{array}{c}0.500 \\
\text { In site }\end{array}$ & $\begin{array}{c}0.500 \\
\text { Contractor }\end{array}$ & $\begin{array}{c}\text { Final } \\
\text { Result }\end{array}$ \\
\hline Costs & 0.019 & 0.428 & 0.224 \\
OEE & 0.246 & 0.184 & 0.215 \\
MSI & 0.362 & 0.053 & 0.207 \\
MTTR & 0.102 & 0.184 & 0.143 \\
\hline Overtime & 0.161 & 0.115 & 0.138 \\
Applicability & 0.069 & 0.017 & 0.043 \\
Accidents & 0.042 & 0.019 & 0.030 \\
\hline
\end{tabular}

\section{GUARANTEE AN EFFECTIVE ACTION}

$1^{\text {st }}$ iteration:

\begin{tabular}{|c|cccccc|c|}
\cline { 2 - 7 } \multicolumn{1}{c|}{} & $\begin{array}{c}0.494 \\
\text { Tools / spares }\end{array}$ & $\begin{array}{c}0.036 \\
\text { EP / QCO }\end{array}$ & $\begin{array}{c}0.243 \\
\text { Personnel }\end{array}$ & $\begin{array}{c}0.113 \\
\text { Morale }\end{array}$ & $\begin{array}{c}0.113 \\
\text { Maintainability }\end{array}$ & $\begin{array}{c}\text { Final } \\
\text { Result }\end{array}$ \\
\hline MTTR & 0.175 & 0.300 & 0.126 & 0.115 & 0.311 & 0.176 \\
OEE & 0.126 & 0.214 & 0.165 & 0.214 & 0.220 & 0.159 \\
Fill rate & 0.303 & 0.109 & 0.012 & 0.011 & 0.010 & 0.159 \\
MSI & 0.065 & 0.060 & 0.217 & 0.281 & 0.158 & 0.137 \\
Inventory & 0.218 & 0.024 & 0.012 & 0.011 & 0.021 & 0.115 \\
Cost & 0.038 & 0.060 & 0.275 & 0.016 & 0.030 & 0.093 \\
\hline Accidents & 0.030 & 0.103 & 0.051 & 0.087 & 0.069 & 0.049 \\
Overtime & 0.011 & 0.009 & 0.090 & 0.042 & 0.120 & 0.046 \\
CSI & 0.021 & 0.087 & 0.039 & 0.063 & 0.053 & 0.036 \\
WG status & 0.014 & 0.034 & 0.012 & 0.158 & 0.010 & 0.030 \\
\hline
\end{tabular}

$2^{\text {nd }}$ iteration:

\begin{tabular}{|c|c|c|c|c|c|c|}
\hline & $\begin{array}{c}0.344 \\
\text { Tools / spares }\end{array}$ & $\begin{array}{c}0.054 \\
\text { EP / QCO }\end{array}$ & $\begin{array}{c}0.344 \\
\text { Personnel } \\
\end{array}$ & $\begin{array}{c}0.129 \\
\text { Morale } \\
\end{array}$ & $\begin{array}{c}0.129 \\
\text { Maintainability }\end{array}$ & $\begin{array}{l}\text { Final } \\
\text { Result }\end{array}$ \\
\hline Cost & 0.213 & 0.060 & 0.280 & 0.019 & 0.061 & 0.183 \\
\hline MTTR & 0.153 & 0.300 & 0.135 & 0.119 & 0.318 & 0.172 \\
\hline MSI & 0.042 & 0.060 & 0.221 & 0.281 & 0.179 & 0.153 \\
\hline OEE & 0.056 & 0.214 & 0.177 & 0.215 & 0.243 & 0.151 \\
\hline Fill rate & 0.289 & 0.109 & 0.015 & 0.014 & 0.017 & 0.114 \\
\hline Accidents & 0.016 & 0.103 & 0.071 & 0.090 & 0.095 & 0.060 \\
\hline Inventory & 0.111 & 0.024 & 0.015 & 0.014 & 0.017 & 0.049 \\
\hline WG status & 0.031 & 0.034 & 0.015 & 0.164 & 0.017 & 0.041 \\
\hline CSI & 0.009 & 0.087 & 0.055 & 0.069 & 0.034 & 0.040 \\
\hline Items repaired & 0.080 & 0.009 & 0.015 & 0.015 & 0.017 & 0.038 \\
\hline
\end{tabular}


$3^{\text {rd }}$ iteration:

\begin{tabular}{|c|c|c|c|c|c|c|}
\hline & $\begin{array}{c}0.344 \\
\text { Tools / spares }\end{array}$ & $\begin{array}{c}0.054 \\
\text { EP / QCO }\end{array}$ & $\begin{array}{c}0.344 \\
\text { Personnel }\end{array}$ & $\begin{array}{c}0.129 \\
\text { Morale }\end{array}$ & $\begin{array}{c}0.129 \\
\text { Maintainability }\end{array}$ & $\begin{array}{c}\text { Final } \\
\text { Result } \\
\end{array}$ \\
\hline Cost & 0.212 & 0.056 & 0.280 & 0.022 & 0.061 & 0.183 \\
\hline MTTR & 0.111 & 0.305 & 0.135 & 0.119 & 0.318 & 0.158 \\
\hline OEE & 0.064 & 0.217 & 0.177 & 0.214 & 0.243 & 0.154 \\
\hline MSI & 0.041 & 0.061 & 0.221 & 0.281 & 0.179 & 0.153 \\
\hline Fill rate & 0.288 & 0.107 & 0.015 & 0.014 & 0.017 & 0.114 \\
\hline Inventory & 0.149 & 0.020 & 0.015 & 0.014 & 0.017 & 0.061 \\
\hline Accidents & 0.015 & 0.096 & 0.071 & 0.090 & 0.095 & 0.059 \\
\hline WG status & 0.029 & 0.032 & 0.015 & 0.164 & 0.017 & 0.040 \\
\hline CSI & 0.009 & 0.086 & 0.055 & 0.069 & 0.034 & 0.040 \\
\hline Items repaired & 0.080 & 0.020 & 0.015 & 0.014 & 0.017 & 0.038 \\
\hline
\end{tabular}

\section{MANAGE REPAIR ACTIONS WITHOUT ALTERNATIVE PROCESS}

$1^{\text {st }}$ iteration:

\begin{tabular}{|ccc|c|}
\cline { 2 - 4 } \multicolumn{1}{c|}{} & $\begin{array}{c}0.500 \\
\text { Diagnosis }\end{array}$ & $\begin{array}{c}0.500 \\
\text { Action }\end{array}$ & $\begin{array}{c}\text { Final } \\
\text { Result }\end{array}$ \\
\hline MTTR & 0.326 & 0.330 & 0.328 \\
OEE & 0.232 & 0.235 & 0.234 \\
MSI & 0.166 & 0.103 & 0.134 \\
Fill Rate & 0.015 & 0.161 & 0.088 \\
Costs & 0.111 & 0.049 & 0.080 \\
\hline TS & 0.079 & 0.019 & 0.049 \\
Inventory & 0.015 & 0.074 & 0.044 \\
Overtime & 0.056 & 0.028 & 0.042 \\
\hline
\end{tabular}

$2^{\text {nd }}$ iteration:

\begin{tabular}{|ccc|c|}
\cline { 2 - 4 } \multicolumn{1}{c|}{} & $\begin{array}{c}0.500 \\
\text { Diagnosis }\end{array}$ & $\begin{array}{c}0.500 \\
\text { Action }\end{array}$ & $\begin{array}{c}\text { Final } \\
\text { Result }\end{array}$ \\
\hline MTTR & 0.363 & 0.239 & 0.301 \\
Cost & 0.109 & 0.369 & 0.239 \\
OEE & 0.247 & 0.106 & 0.177 \\
MSI & 0.160 & 0.162 & 0.161 \\
\hline Troubleshooting & 0.074 & 0.016 & 0.045 \\
Fill Rate & 0.017 & 0.067 & 0.042 \\
Accidents & 0.031 & 0.040 & 0.036 \\
\hline
\end{tabular}


$3^{\text {rd }}$ iteration:

\begin{tabular}{|ccc|c|}
\cline { 2 - 4 } \multicolumn{1}{c|}{} & $\begin{array}{c}0.500 \\
\text { Diagnosis }\end{array}$ & $\begin{array}{c}0.500 \\
\text { Action }\end{array}$ & $\begin{array}{c}\text { Final } \\
\text { Result }\end{array}$ \\
\hline MTTR & 0.364 & 0.164 & 0.264 \\
OEE & 0.247 & 0.242 & 0.245 \\
Cost & 0.114 & 0.357 & 0.235 \\
MSI & 0.168 & 0.104 & 0.136 \\
\hline Fill Rate & 0.020 & 0.071 & 0.045 \\
Troubleshooting & 0.066 & 0.015 & 0.040 \\
Inventory & 0.020 & 0.048 & 0.034 \\
& & & \\
\end{tabular}

$1^{\text {st }}, 2^{\text {nd }}$ and $3^{\text {rd }}$ iteration:

\section{IMPLEMENT QUICK CHANGE OVER}

\begin{tabular}{|ccc|c|}
\cline { 3 - 4 } \multicolumn{1}{c|}{} & 0.250 & 0.750 & Final \\
\cline { 3 - 4 } \multicolumn{1}{c|}{} & Procedures & Communication & Result \\
\hline WG status & 0.116 & 0.394 & 0.324 \\
CSI & 0.040 & 0.203 & 0.162 \\
MSI & 0.022 & 0.203 & 0.157 \\
BTS & 0.424 & 0.065 & 0.155 \\
\hline OEE & 0.258 & 0.085 & 0.128 \\
Accidents & 0.081 & 0.022 & 0.037 \\
MTTR & 0.059 & 0.029 & 0.036 \\
\hline
\end{tabular}

\section{MANAGE REPAIR ACTIONS THROUGH ALTERNATIVE PROCESS}

$1^{\text {st }}$ iteration:

\begin{tabular}{|ccc|c|}
\cline { 3 - 4 } \multicolumn{1}{c|}{} & 0.250 & 0.750 & Final \\
\cline { 3 - 4 } \multicolumn{1}{c|}{} & QCO & Equipment & Result \\
\hline MTBF & 0.019 & 0.347 & 0.265 \\
PM plan & 0.019 & 0.214 & 0.165 \\
$5 \%$ audits & 0.019 & 0.214 & 0.165 \\
CSI & 0.237 & 0.063 & 0.106 \\
WG & 0.332 & 0.019 & 0.098 \\
\hline OEE & 0.086 & 0.086 & 0.086 \\
MSI & 0.169 & 0.039 & 0.072 \\
BTS & 0.120 & 0.018 & 0.044 \\
\end{tabular}


$2^{\text {nd }}$ and $3^{\text {rd }}$ iteration:

\begin{tabular}{|cc|c|c|}
\cline { 3 - 4 } \multicolumn{1}{c|}{} & 0.250 & 0.750 & Final \\
\cline { 3 - 4 } \multicolumn{1}{c|}{} & QCO & Result \\
\hline OEE & 0.091 & 0.290 & 0.240 \\
PM audits & 0.015 & 0.214 & 0.164 \\
MSI & 0.164 & 0.158 & 0.159 \\
Overtime & 0.015 & 0.108 & 0.085 \\
WG & 0.281 & 0.012 & 0.080 \\
CSI & 0.215 & 0.028 & 0.075 \\
\hline PM plan & 0.015 & 0.078 & 0.062 \\
Costs & 0.069 & 0.055 & 0.058 \\
BTS & 0.119 & 0.020 & 0.045 \\
MTBF & 0.015 & 0.038 & 0.033 \\
\hline
\end{tabular}

$1^{\text {st }}$ iteration:

\section{REACTIVE PILLAR RESULT}

\begin{tabular}{|ccc|c|}
\cline { 2 - 4 } \multicolumn{1}{c|}{} & $\begin{array}{c}0.500 \\
\text { Alt. Proc. }\end{array}$ & $\begin{array}{c}0.500 \\
\text { No Alt. Proc. }\end{array}$ & $\begin{array}{c}\text { Final } \\
\text { Result }\end{array}$ \\
\hline MTTR & 0.025 & 0.291 & 0.158 \\
MTBF & 0.288 & 0.019 & 0.153 \\
OEE & 0.059 & 0.222 & 0.141 \\
PM plan & 0.212 & 0.012 & 0.112 \\
MSI & 0.038 & 0.161 & 0.100 \\
$5 \%$ audits & 0.162 & 0.012 & 0.087 \\
CSI & 0.107 & 0.051 & 0.079 \\
\hline Fill Rate & 0.017 & 0.119 & 0.068 \\
WG status & 0.078 & 0.026 & 0.052 \\
Costs & 0.015 & 0.086 & 0.051 \\
\hline
\end{tabular}

$2^{\text {nd }}$ iteration:

\begin{tabular}{|ccc|c|}
\cline { 2 - 4 } \multicolumn{1}{c|}{} & $\begin{array}{c}0.500 \\
\text { Alt. Proc. }\end{array}$ & $\begin{array}{c}0.500 \\
\text { No Alt. Proc. }\end{array}$ & $\begin{array}{c}\text { Final } \\
\text { Result }\end{array}$ \\
\hline OEE & 0.330 & 0.184 & 0.257 \\
MTTR & 0.027 & 0.332 & 0.179 \\
MSI & 0.161 & 0.123 & 0.142 \\
Costs & 0.019 & 0.237 & 0.128 \\
$5 \%$ audits & 0.235 & 0.014 & 0.125 \\
\hline Overtime & 0.103 & 0.036 & 0.069 \\
CSI & 0.052 & 0.052 & 0.052 \\
WG status & 0.073 & 0.023 & 0.048 \\
\hline
\end{tabular}


$3^{\text {rd }}$ iteration:

\begin{tabular}{|ccc|c|}
\cline { 2 - 4 } \multicolumn{1}{c|}{} & $\begin{array}{c}0.500 \\
\text { Alt. Proc. }\end{array}$ & $\begin{array}{c}0.500 \\
\text { No Alt. Proc. }\end{array}$ & $\begin{array}{c}\text { Final } \\
\text { Result }\end{array}$ \\
\hline OEE & 0.330 & 0.250 & 0.290 \\
MTTR & 0.019 & 0.330 & 0.174 \\
MSI & 0.161 & 0.122 & 0.141 \\
PM audits & 0.235 & 0.013 & 0.124 \\
Costs & 0.028 & 0.171 & 0.100 \\
\hline Overtime & 0.101 & 0.053 & 0.077 \\
WG status & 0.074 & 0.022 & 0.048 \\
CSI & 0.052 & 0.039 & 0.046 \\
\hline
\end{tabular}

PROACTIVE Pillar

ENSURE PROPER DATA COLLECTION AND ANALYSIS

$1^{\text {st }}, 2^{\text {nd }}$ and $3^{\text {rd }}$ iteration:

\begin{tabular}{|c|c|c|c|c|c|}
\hline & $\begin{array}{c}0.067 \\
\text { WG meetings }\end{array}$ & $\begin{array}{c}0.391 \\
\text { In site meetings }\end{array}$ & $\begin{array}{c}0.151 \\
\text { Database }\end{array}$ & $\begin{array}{l}0.391 \\
\text { Cases }\end{array}$ & $\begin{array}{l}\text { Final } \\
\text { Result }\end{array}$ \\
\hline OEE & 0.088 & 0.289 & 0.110 & 0.145 & 0.192 \\
\hline Cases & 0.027 & 0.029 & 0.034 & 0.371 & 0.163 \\
\hline MTTR & 0.088 & 0.160 & 0.110 & 0.145 & 0.142 \\
\hline BTS & 0.034 & 0.210 & 0.015 & 0.081 & 0.118 \\
\hline MTBF & 0.088 & 0.058 & 0.110 & 0.145 & 0.102 \\
\hline MSI & 0.178 & 0.100 & 0.033 & 0.019 & 0.064 \\
\hline $5 \%$ Audits & 0.009 & 0.008 & 0.373 & 0.008 & 0.063 \\
\hline CSI & 0.178 & 0.100 & 0.011 & 0.019 & 0.060 \\
\hline Backload & 0.022 & 0.022 & 0.182 & 0.037 & 0.052 \\
\hline WG & 0.288 & 0.023 & 0.021 & 0.029 & 0.043 \\
\hline
\end{tabular}

CONDUCT THOROUGH RELIABILITY ANALYSIS

$1^{\text {st }}, 2^{\text {nd }}$ and $3^{\text {rd }}$ iteration:

\begin{tabular}{|ccccc|c|}
\cline { 5 - 5 } \multicolumn{1}{c|}{} & 0.258 & 0.637 & 0.105 & Final \\
\cline { 5 - 5 } \multicolumn{1}{c|}{} & Training & Data analysis & Resources & Result \\
\hline OEE & 0.037 & 0.217 & 0.216 & 0.171 \\
MTBF & 0.060 & 0.206 & 0.036 & 0.151 \\
Cases & 0.011 & 0.206 & 0.010 & 0.135 \\
MSI & 0.217 & 0.064 & 0.283 & 0.127 \\
MTTR & 0.081 & 0.133 & 0.121 & 0.118 \\
Overtime & 0.285 & 0.012 & 0.052 & 0.086 \\
BTS & 0.024 & 0.096 & 0.026 & 0.070 \\
Accidents & 0.116 & 0.016 & 0.087 & 0.050 \\
Applicability & 0.152 & 0.012 & 0.010 & 0.048 \\
WG status & 0.015 & 0.036 & 0.159 & 0.044 \\
\hline
\end{tabular}


KEEP A RELIABLE WO AND CMMS SYSTEM

$1^{\text {st }}, 2^{\text {nd }}$ and $3^{\text {rd }}$ iteration:

\begin{tabular}{|c|c|c|c|c|c|}
\hline & $\begin{array}{c}0.150 \\
\text { Personnel }\end{array}$ & $\begin{array}{c}0.513 \\
\text { User friendly }\end{array}$ & $\begin{array}{c}0.076 \\
\text { Integration }\end{array}$ & $\begin{array}{c}0.261 \\
\text { Resource }\end{array}$ & $\begin{array}{l}\text { Final } \\
\text { Result }\end{array}$ \\
\hline MSI & 0.284 & 0.219 & 0.020 & 0.197 & 0.208 \\
\hline WO system Audits & 0.015 & 0.326 & 0.310 & 0.032 & 0.201 \\
\hline Overtime & 0.039 & 0.084 & 0.145 & 0.315 & 0.142 \\
\hline CSI & 0.058 & 0.173 & 0.020 & 0.103 & 0.126 \\
\hline OEE & 0.217 & 0.023 & 0.053 & 0.102 & 0.075 \\
\hline Backload & 0.021 & 0.051 & 0.086 & 0.114 & 0.066 \\
\hline WG status & 0.160 & 0.053 & 0.092 & 0.015 & 0.062 \\
\hline Costs & 0.021 & 0.035 & 0.212 & 0.047 & 0.050 \\
\hline MTTR & 0.105 & 0.023 & 0.050 & 0.059 & 0.047 \\
\hline Accidents & 0.080 & 0.013 & 0.011 & 0.016 & 0.024 \\
\hline
\end{tabular}

CONDUCT APPROPRIATE PLANNING

$1^{\text {st }}, 2^{\text {nd }}$ and $3^{\text {rd }}$ iteration:

\begin{tabular}{|cccccccc|c|}
\cline { 7 - 8 } \multicolumn{1}{c|}{} & 0.066 & 0.257 & 0.042 & 0.104 & 0.404 & 0.127 & Final \\
\cline { 7 - 8 } \multicolumn{1}{c}{} & WO & Reliability & Cases & Bottle neck & Rescheduling & Equipment avail. & Result \\
\hline OEE & 0.088 & 0.287 & 0.204 & 0.194 & 0.166 & 0.185 & 0.199 \\
MBF & 0.027 & 0.219 & 0.204 & 0.119 & 0.206 & 0.114 & 0.177 \\
PM plan & 0.042 & 0.101 & 0.091 & 0.113 & 0.289 & 0.049 & 0.167 \\
Overtime & 0.156 & 0.027 & 0.009 & 0.264 & 0.020 & 0.300 & 0.091 \\
Cases & 0.011 & 0.162 & 0.284 & 0.056 & 0.058 & 0.011 & 0.085 \\
BTS & 0.012 & 0.022 & 0.077 & 0.123 & 0.076 & 0.185 & 0.077 \\
\hline CSI & 0.115 & 0.011 & 0.025 & 0.059 & 0.095 & 0.058 & 0.063 \\
MSI & 0.287 & 0.062 & 0.037 & 0.025 & 0.036 & 0.068 & 0.062 \\
Costs & 0.042 & 0.074 & 0.053 & 0.036 & 0.045 & 0.020 & 0.048 \\
WO sys. Audits & 0.219 & 0.036 & 0.015 & 0.010 & 0.009 & 0.011 & 0.030 \\
\hline
\end{tabular}

IMPROVE IN SITE PERSONNEL COMPETENCE

$1^{\text {st }}, 2^{\text {nd }}$ and $3^{\text {rd }}$ iteration:

\begin{tabular}{|ccc|c|}
\cline { 2 - 4 } \multicolumn{1}{c|}{} & $\begin{array}{c}0.500 \\
\text { Training }\end{array}$ & $\begin{array}{c}0.500 \\
\text { Right position }\end{array}$ & $\begin{array}{c}\text { Final } \\
\text { Result }\end{array}$ \\
\hline MSI & 0.221 & 0.224 & 0.223 \\
OEE & 0.030 & 0.314 & 0.172 \\
Overtime & 0.316 & 0.024 & 0.170 \\
MTTR & 0.076 & 0.160 & 0.118 \\
Applicability & 0.164 & 0.017 & 0.091 \\
Accidents & 0.110 & 0.032 & 0.071 \\
\hline CSI & 0.016 & 0.110 & 0.063 \\
MTBF & 0.028 & 0.077 & 0.052 \\
Costs & 0.039 & 0.043 & 0.041 \\
\hline
\end{tabular}


GUARANTEE IN SITE EFFECTIVE ACTION

$1^{\text {st }}, 2^{\text {nd }}$ and $3^{\text {rd }}$ iteration:

\begin{tabular}{|c|c|c|c|c|c|c|c|}
\hline & $\begin{array}{c}0.133 \\
\text { Tools \& spares }\end{array}$ & $\begin{array}{c}0.362 \\
\text { Personnel }\end{array}$ & $\begin{array}{c}0.133 \\
\text { Morale }\end{array}$ & $\begin{array}{c}0.251 \\
\text { Compliance }\end{array}$ & $\begin{array}{c}0.045 \\
\text { Repairs prog. }\end{array}$ & $\begin{array}{c}0.077 \\
\text { Clear tasks }\end{array}$ & $\begin{array}{l}\text { Final } \\
\text { Result }\end{array}$ \\
\hline $\mathrm{MSI}$ & 0.072 & 0.312 & 0.289 & 0.040 & 0.316 & 0.244 & 0.204 \\
\hline OEE & 0.097 & 0.238 & 0.221 & 0.106 & 0.155 & 0.120 & 0.171 \\
\hline PM audits & 0.010 & 0.053 & 0.029 & 0.262 & 0.017 & 0.297 & 0.114 \\
\hline MTTR & 0.170 & 0.171 & 0.118 & 0.011 & 0.017 & 0.013 & 0.105 \\
\hline MTBF & 0.030 & 0.083 & 0.060 & 0.163 & 0.054 & 0.150 & 0.097 \\
\hline PM plan & 0.040 & 0.028 & 0.012 & 0.262 & 0.017 & 0.025 & 0.086 \\
\hline Costs & 0.226 & 0.015 & 0.053 & 0.056 & 0.053 & 0.052 & 0.063 \\
\hline WG status & 0.053 & 0.038 & 0.177 & 0.018 & 0.111 & 0.072 & 0.059 \\
\hline WO audits & 0.010 & 0.053 & 0.030 & 0.070 & 0.245 & 0.013 & 0.054 \\
\hline Fill rate & 0.292 & 0.009 & 0.011 & 0.011 & 0.015 & 0.013 & 0.048 \\
\hline
\end{tabular}

ENSURE CONTRACTOR EFFECTIVE ACTION

$1^{\text {st }}, 2^{\text {nd }}$ and $3^{\text {rd }}$ iteration:

\begin{tabular}{|ccc|c|}
\cline { 2 - 2 } \multicolumn{1}{c|}{} & $\begin{array}{c}0.750 \\
\text { Compliance }\end{array}$ & $\begin{array}{c}0.250 \\
\text { Repairs prog. }\end{array}$ & $\begin{array}{c}\text { Final } \\
\text { Result }\end{array}$ \\
\hline PM audits & 0.325 & 0.015 & 0.248 \\
PM plan & 0.221 & 0.015 & 0.170 \\
MTBF & 0.144 & 0.029 & 0.115 \\
WO sys audits & 0.073 & 0.224 & 0.111 \\
MSI & 0.038 & 0.303 & 0.104 \\
OEE & 0.110 & 0.083 & 0.103 \\
\hline CSI & 0.058 & 0.116 & 0.073 \\
Overtime & 0.010 & 0.166 & 0.049 \\
Backload & 0.021 & 0.048 & 0.028 \\
\hline
\end{tabular}

\section{GUARANTEE AN EFFECTIVE ACTION}

$1^{\text {st }}, 2^{\text {nd }}$ and $3^{\text {rd }}$ iteration:

\begin{tabular}{|ccc|c|}
\cline { 2 - 4 } \multicolumn{1}{c|}{} & $\begin{array}{c}0.500 \\
\text { In site }\end{array}$ & $\begin{array}{c}0.500 \\
\text { contractor }\end{array}$ & $\begin{array}{c}\text { Final } \\
\text { Result }\end{array}$ \\
\hline PM audits & 0.162 & 0.343 & 0.252 \\
MSI & 0.332 & 0.074 & 0.203 \\
OEE & 0.227 & 0.051 & 0.139 \\
PM plan & 0.049 & 0.227 & 0.138 \\
MTBF & 0.069 & 0.162 & 0.116 \\
\hline WO system audits & 0.018 & 0.108 & 0.063 \\
MTTR & 0.108 & 0.013 & 0.061 \\
Costs & 0.034 & 0.022 & 0.028 \\
\hline
\end{tabular}


MAINTAIN A GOOD PREDICTIVE PROGRAM, MAINTAIN A GOOD PROGRAMMED INSPECTIONS PROGRAM and MAINTAIN A GOOD PROGRAMMED REPLACEMENTS PROGRAM

$1^{\text {st }}, 2^{\text {nd }}$ and $3^{\text {rd }}$ iteration:

\begin{tabular}{|ccc|c|}
\cline { 2 - 4 } \multicolumn{1}{c|}{} & $\begin{array}{c}0.500 \\
\text { Planning }\end{array}$ & $\begin{array}{c}0.500 \\
\text { Execution }\end{array}$ & $\begin{array}{c}\text { Final } \\
\text { Result }\end{array}$ \\
\hline OEE & 0.329 & 0.161 & 0.245 \\
PM audits & 0.012 & 0.331 & 0.172 \\
MTBF & 0.235 & 0.082 & 0.158 \\
MSI & 0.041 & 0.236 & 0.139 \\
PM plan & 0.160 & 0.115 & 0.138 \\
\hline Overtime & 0.107 & 0.044 & 0.076 \\
Cases & 0.076 & 0.015 & 0.046 \\
BTS & 0.039 & 0.015 & 0.027 \\
& & &
\end{tabular}

\section{IMPROVE IN SITE PERSONNEL COMPETENCE}

$1^{\text {st }}, 2^{\text {nd }}$ and $3^{\text {rd }}$ iteration:

\begin{tabular}{|ccc|c|}
\cline { 2 - 4 } \multicolumn{1}{c|}{} & $\begin{array}{c}0.500 \\
\text { Training }\end{array}$ & $\begin{array}{c}0.500 \\
\text { Right position }\end{array}$ & $\begin{array}{c}\text { Final } \\
\text { Result }\end{array}$ \\
\hline MSI & 0.221 & 0.224 & 0.223 \\
OEE & 0.030 & 0.314 & 0.172 \\
Overtime & 0.316 & 0.024 & 0.170 \\
MTTR & 0.076 & 0.160 & 0.118 \\
Applicability & 0.164 & 0.017 & 0.091 \\
Accidents & 0.110 & 0.032 & 0.071 \\
\hline CSI & 0.016 & 0.110 & 0.063 \\
MTBF & 0.028 & 0.077 & 0.052 \\
Costs & 0.039 & 0.043 & 0.041 \\
\hline
\end{tabular}

GUARANTEE AN EFFECTIVE IN SITE PROYECT EXECUTION $1^{\text {st }}, 2^{\text {nd }}$ and $3^{\text {rd }}$ iteration:

\begin{tabular}{|ccccc|c|}
\cline { 5 - 5 } \multicolumn{1}{c|}{} & $\begin{array}{c}0.281 \\
\text { Equipment }\end{array}$ & $\begin{array}{c}0.584 \\
\text { Personnel }\end{array}$ & $\begin{array}{c}0.135 \\
\text { Morale }\end{array}$ & $\begin{array}{c}\text { Final } \\
\text { Result }\end{array}$ \\
\hline MSI & 0.044 & 0.289 & 0.295 & 0.221 \\
OEE & 0.059 & 0.221 & 0.225 & 0.176 \\
MTTR & 0.155 & 0.121 & 0.129 & 0.132 \\
Overtime & 0.011 & 0.159 & 0.069 & 0.105 \\
Fill rate & 0.286 & 0.013 & 0.017 & 0.090 \\
Cost & 0.211 & 0.030 & 0.045 & 0.083 \\
\hline Applicability & 0.011 & 0.092 & 0.017 & 0.059 \\
WG status & 0.029 & 0.048 & 0.169 & 0.059 \\
Inventory & 0.113 & 0.013 & 0.017 & 0.042 \\
Items repaired & 0.082 & 0.013 & 0.017 & 0.033 \\
\hline
\end{tabular}




\section{GUARANTEE AN EFFECTIVE PROYECT EXECUTION}

$1^{\text {st }}, 2^{\text {nd }}$ and $3^{\text {rd }}$ iteration:

\begin{tabular}{|c|cc|c|}
\cline { 2 - 3 } \multicolumn{1}{c|}{} & $\begin{array}{c}0.500 \\
\text { In site }\end{array}$ & $\begin{array}{c}0.500 \\
\text { Contractor }\end{array}$ & $\begin{array}{c}\text { Final } \\
\text { Result }\end{array}$ \\
\hline MSI & 0.336 & 0.143 & 0.240 \\
Costs & 0.051 & 0.291 & 0.171 \\
Audits & 0.012 & 0.291 & 0.151 \\
OEE & 0.230 & 0.051 & 0.140 \\
Overtime & 0.105 & 0.078 & 0.091 \\
\hline MTTR & 0.164 & 0.015 & 0.089 \\
CSI & 0.028 & 0.116 & 0.072 \\
Fill Rate & 0.075 & 0.015 & 0.045 \\
\cline { 3 - 4 }
\end{tabular}

DEVELOP COMPLETE ENGINEERING SPECIFICATIONS

$1^{\text {st }}, 2^{\text {nd }}$ and $3^{\text {rd }}$ iteration:

\begin{tabular}{|cccccc|c|}
\cline { 5 - 6 } \multicolumn{1}{c}{} & 0.277 & 0.122 & 0.122 & 0.480 & Final \\
\cline { 5 - 6 } \multicolumn{1}{c|}{} & $\begin{array}{c}0.27 \\
\text { Manpower }\end{array}$ & task description & Sketches & Time mgnt & Result \\
\hline Overtime & 0.438 & 0.129 & 0.146 & 0.453 & 0.372 \\
Costs & 0.287 & 0.085 & 0.230 & 0.261 & 0.243 \\
MSI & 0.127 & 0.440 & 0.478 & 0.042 & 0.167 \\
Accidents & 0.085 & 0.288 & 0.081 & 0.024 & 0.080 \\
\hline BTS & 0.018 & 0.021 & 0.018 & 0.145 & 0.079 \\
Backload & 0.044 & 0.037 & 0.047 & 0.076 & 0.059 \\
\hline
\end{tabular}

\section{CONDUCT APPROPRIATE PRYECT PLANNING}

$1^{\text {st }}, 2^{\text {nd }}$ and $3^{\text {rd }}$ iteration:

\begin{tabular}{|cccc|c|}
\multicolumn{1}{c}{} & 0.200 & 0.200 & 0.600 & Final \\
\cline { 5 - 5 } \multicolumn{1}{c|}{} & Tools and spares & $\begin{array}{c}0.200 \\
\text { Equip. avail. }\end{array}$ & $\begin{array}{c}\text { Result } \\
\text { Engineering }\end{array}$ \\
\hline Overtime & 0.011 & 0.317 & 0.287 & 0.238 \\
costs & 0.210 & 0.121 & 0.219 & 0.197 \\
MSI & 0.045 & 0.071 & 0.161 & 0.120 \\
BTS & 0.011 & 0.234 & 0.089 & 0.102 \\
Accidents & 0.022 & 0.019 & 0.123 & 0.082 \\
OEE & 0.058 & 0.164 & 0.060 & 0.081 \\
Fill rate & 0.294 & 0.019 & 0.015 & 0.072 \\
\hline MTTR & 0.156 & 0.019 & 0.015 & 0.044 \\
Inventory & 0.113 & 0.019 & 0.015 & 0.036 \\
Items repaired & 0.079 & 0.019 & 0.015 & 0.029 \\
\hline
\end{tabular}




\section{IMPLEMENT IMPROVEMENT PROJECTS}

$1^{\text {st }}, 2^{\text {nd }}$ and $3^{\text {rd }}$ iteration:

\begin{tabular}{|ccc|c|}
\cline { 2 - 4 } \multicolumn{1}{c|}{} & $\begin{array}{c}0.500 \\
\text { planning }\end{array}$ & $\begin{array}{c}0.500 \\
\text { Execution }\end{array}$ & $\begin{array}{c}\text { Final } \\
\text { Result }\end{array}$ \\
\hline MSI & 0.162 & 0.320 & 0.241 \\
costs & 0.227 & 0.243 & 0.235 \\
Overtime & 0.332 & 0.079 & 0.206 \\
Contractor audits & 0.012 & 0.166 & 0.089 \\
OEE & 0.052 & 0.118 & 0.085 \\
\hline BTS & 0.108 & 0.017 & 0.063 \\
Accidents & 0.072 & 0.017 & 0.045 \\
Fill rate & 0.034 & 0.039 & 0.037 \\
\end{tabular}

$1^{\text {st }}, 2^{\text {nd }}$ and $3^{\text {rd }}$ iteration:

\section{CARRY OUT SELF-DIRECTED INSPECTIONS}

\begin{tabular}{|cccccc|c|}
\cline { 6 - 8 } \multicolumn{1}{c}{} & 0.172 & 0.100 & 0.047 & 0.267 & 0.414 & Final \\
\cline { 6 - 8 } & Union & Training & Tools \& spares & Morale & Time available & Result \\
\hline Overtime & 0.300 & 0.265 & 0.014 & 0.054 & 0.302 & 0.218 \\
CSI & 0.217 & 0.218 & 0.069 & 0.261 & 0.201 & 0.215 \\
BTS & 0.118 & 0.068 & 0.025 & 0.131 & 0.179 & 0.137 \\
WG status & 0.147 & 0.032 & 0.043 & 0.105 & 0.102 & 0.101 \\
MSI & 0.044 & 0.171 & 0.055 & 0.210 & 0.035 & 0.098 \\
OEE & 0.081 & 0.026 & 0.093 & 0.168 & 0.055 & 0.089 \\
Costs & 0.055 & 0.061 & 0.223 & 0.031 & 0.086 & 0.070 \\
Fill Rate & 0.012 & 0.012 & 0.312 & 0.013 & 0.014 & 0.027 \\
Applicability & 0.012 & 0.137 & 0.011 & 0.013 & 0.014 & 0.026 \\
Inventory & 0.012 & 0.012 & 0.156 & 0.013 & 0.014 & 0.020 \\
\hline
\end{tabular}

PROACTIVE PILLAR RESULT

$1^{\text {st }}, 2^{\text {nd }}$ and $3^{\text {rd }}$ iteration:

\begin{tabular}{|ccccc|c|}
\cline { 5 - 6 } \multicolumn{1}{c|}{} & 0.600 & 0.200 & 0.200 & Final \\
\cline { 5 - 6 } \multicolumn{1}{c|}{} & PM & Projects & Self-directed & Result \\
\hline OEE & 0.288 & 0.084 & 0.081 & 0.206 \\
MSI & 0.110 & 0.289 & 0.106 & 0.145 \\
PM audits & 0.212 & 0.010 & 0.012 & 0.132 \\
Overtime & 0.055 & 0.152 & 0.284 & 0.120 \\
MTBF & 0.149 & 0.039 & 0.039 & 0.105 \\
Costs & 0.021 & 0.213 & 0.063 & 0.068 \\
CSI & 0.028 & 0.032 & 0.221 & 0.067 \\
BTS & 0.038 & 0.053 & 0.168 & 0.067 \\
PM plan & 0.079 & 0.010 & 0.012 & 0.052 \\
Contractor audits & 0.021 & 0.116 & 0.012 & 0.038 \\
\hline
\end{tabular}




\section{LOGISTICS Pillar}

CONTROL STORES INTEGRITY

$1^{\text {st }}, 2^{\text {nd }}$ and $3^{\text {rd }}$ iteration:

\begin{tabular}{|ccc|c|}
\cline { 2 - 4 } \multicolumn{1}{c|}{} & $\begin{array}{c}0.500 \\
\text { Security }\end{array}$ & $\begin{array}{c}0.500 \\
\text { Auditing }\end{array}$ & $\begin{array}{c}\text { Final } \\
\text { Result }\end{array}$ \\
\hline Inventory & 0.471 & 0.270 & 0.371 \\
Audits & 0.049 & 0.497 & 0.273 \\
Costs & 0.274 & 0.133 & 0.203 \\
\hline Fill Rate & 0.130 & 0.065 & 0.098 \\
MSI & 0.076 & 0.035 & 0.056 \\
\hline
\end{tabular}

IMPROVE PERSONNEL COMPETENCE

$1^{\text {st }}, 2^{\text {nd }}$ and $3^{\text {rd }}$ iteration:

\begin{tabular}{|ccc|c|}
\cline { 2 - 4 } \multicolumn{1}{c|}{} & $\begin{array}{c}0.500 \\
\text { Training }\end{array}$ & $\begin{array}{c}0.500 \\
\text { Right position }\end{array}$ & $\begin{array}{c}\text { Final } \\
\text { Result }\end{array}$ \\
\hline MSI & 0.221 & 0.224 & 0.223 \\
OEE & 0.030 & 0.314 & 0.172 \\
Overtime & 0.316 & 0.024 & 0.170 \\
MTTR & 0.076 & 0.160 & 0.118 \\
Applicability & 0.164 & 0.017 & 0.091 \\
Accidents & 0.110 & 0.032 & 0.071 \\
\hline CSI & 0.016 & 0.110 & 0.063 \\
MTBF & 0.028 & 0.077 & 0.052 \\
Costs & 0.039 & 0.043 & 0.041 \\
\hline
\end{tabular}

\section{ADMINISTRATE REPAIRS EFFICIENTLY}

$1^{\text {st }}, 2^{\text {nd }}$ and $3^{\text {rd }}$ iteration:

\begin{tabular}{|ccc|c|}
\cline { 3 - 4 } \multicolumn{1}{c|}{} & 0.250 & 0.750 & Final \\
\cline { 3 - 4 } \multicolumn{1}{c|}{ Emergency } & Planned & Result \\
\hline Items repaired & 0.010 & 0.316 & 0.240 \\
Fill rate & 0.061 & 0.217 & 0.178 \\
Costs & 0.041 & 0.170 & 0.138 \\
Backload & 0.084 & 0.119 & 0.110 \\
MTTR & 0.339 & 0.015 & 0.096 \\
OEE & 0.247 & 0.015 & 0.073 \\
\hline Inventory & 0.029 & 0.076 & 0.064 \\
FTT repair & 0.053 & 0.056 & 0.055 \\
CSI & 0.135 & 0.015 & 0.045 \\
\hline
\end{tabular}




\section{ENSURE QUALITY OF REPAIR}

$1^{\text {st }}, 2^{\text {nd }}$ and $3^{\text {rd }}$ iteration:

\begin{tabular}{|c|cc|c|c|}
\cline { 2 - 3 } \multicolumn{1}{c|}{} & $\begin{array}{c}0.429 \\
\text { Test Equipment }\end{array}$ & $\begin{array}{c}0.143 \\
\text { Procedures }\end{array}$ & $\begin{array}{c}0.429 \\
\text { Labs }\end{array}$ & $\begin{array}{c}\text { Final } \\
\text { Result }\end{array}$ \\
\hline FTT repair & 0.467 & 0.186 & 0.301 & 0.356 \\
Backload & 0.147 & 0.269 & 0.422 & 0.282 \\
PM plan & 0.258 & 0.041 & 0.080 & 0.151 \\
\hline Fill Rate & 0.044 & 0.404 & 0.141 & 0.137 \\
Costs & 0.057 & 0.075 & 0.034 & 0.050 \\
OEE & 0.027 & 0.025 & 0.022 & 0.025 \\
\hline
\end{tabular}

$1^{\text {st }}$ iteration:

\section{ADMINISTRATE PART REPAIRS}

\begin{tabular}{|c|c|c|c|c|c|c|}
\hline & $\begin{array}{c}0.195 \\
\text { Personnel }\end{array}$ & $\begin{array}{c}0.073 \\
\text { Equipment }\end{array}$ & $\begin{array}{c}0.463 \\
\text { Repair admin. }\end{array}$ & $\begin{array}{c}0.073 \\
\text { Workshops }\end{array}$ & $\begin{array}{c}0.195 \\
\text { Quality assurance }\end{array}$ & $\begin{array}{l}\text { Final } \\
\text { Result }\end{array}$ \\
\hline Items repaired & 0.061 & 0.036 & 0.287 & 0.329 & 0.017 & 0.175 \\
\hline Fill rate & 0.028 & 0.009 & 0.219 & 0.101 & 0.109 & 0.136 \\
\hline Backload & 0.037 & 0.029 & 0.116 & 0.180 & 0.216 & 0.119 \\
\hline OEE & 0.244 & 0.182 & 0.076 & 0.060 & 0.065 & 0.113 \\
\hline Costs & 0.010 & 0.034 & 0.170 & 0.036 & 0.080 & 0.101 \\
\hline MSI & 0.304 & 0.099 & 0.032 & 0.152 & 0.034 & 0.099 \\
\hline FTT repair & 0.053 & 0.053 & 0.048 & 0.092 & 0.283 & 0.098 \\
\hline PM plan & 0.010 & 0.275 & 0.026 & 0.008 & 0.160 & 0.066 \\
\hline MTBF & 0.079 & 0.275 & 0.011 & 0.017 & 0.027 & 0.047 \\
\hline Overtime & 0.174 & 0.009 & 0.015 & 0.024 & 0.008 & 0.045 \\
\hline
\end{tabular}

$2^{\text {nd }}$ and $3^{\text {rd }}$ iteration:

\begin{tabular}{|c|c|c|c|c|c|c|}
\hline & $\begin{array}{c}0.195 \\
\text { Personnel }\end{array}$ & $\begin{array}{c}\quad 0.073 \\
\text { Equipment }\end{array}$ & $\begin{array}{c}\quad 0.463 \\
\text { Repair admin. }\end{array}$ & $\begin{array}{c}0.073 \\
\text { Workshops }\end{array}$ & $\begin{array}{c}0.195 \\
\text { Quality assurance }\end{array}$ & $\begin{array}{l}\text { Final } \\
\text { Result }\end{array}$ \\
\hline Items repaired & 0.061 & 0.014 & 0.287 & 0.325 & 0.018 & 0.173 \\
\hline Fill rate & 0.011 & 0.013 & 0.219 & 0.103 & 0.110 & 0.133 \\
\hline Backload & 0.037 & 0.027 & 0.116 & 0.183 & 0.218 & 0.119 \\
\hline OEE & 0.243 & 0.283 & 0.075 & 0.063 & 0.049 & 0.117 \\
\hline Costs & 0.016 & 0.068 & 0.170 & 0.038 & 0.081 & 0.105 \\
\hline MSI & 0.303 & 0.161 & 0.032 & 0.154 & 0.028 & 0.102 \\
\hline FTT repair & 0.056 & 0.013 & 0.049 & 0.087 & 0.286 & 0.097 \\
\hline Overtime & 0.178 & 0.116 & 0.016 & 0.027 & 0.009 & 0.054 \\
\hline PM plan & 0.014 & 0.089 & 0.026 & 0.010 & 0.157 & 0.052 \\
\hline PM audits & 0.080 & 0.216 & 0.010 & 0.010 & 0.045 & 0.046 \\
\hline
\end{tabular}




\section{CONDUCT ADEQUATE PARTS PLANNING}

$1^{\text {st }}, 2^{\text {nd }}$ and $3^{\text {rd }}$ iteration:

\begin{tabular}{|c|cc|c|}
\cline { 2 - 4 } \multicolumn{1}{c|}{} & $\begin{array}{c}0.500 \\
\text { New }\end{array}$ & $\begin{array}{c}0.500 \\
\text { Repaired }\end{array}$ & $\begin{array}{c}\text { Final } \\
\text { Result }\end{array}$ \\
\hline Fill rate & 0.310 & 0.237 & 0.273 \\
Items Repaired & 0.018 & 0.366 & 0.192 \\
Costs & 0.310 & 0.064 & 0.187 \\
OEE & 0.180 & 0.101 & 0.141 \\
\hline Backload & 0.113 & 0.161 & 0.137 \\
MSI & 0.052 & 0.044 & 0.048 \\
FTT repair & 0.018 & 0.028 & 0.023 \\
\hline
\end{tabular}

$1^{\text {st }}$ iteration:

\section{CONDUCT ADEQUATE PLANNING}

\begin{tabular}{|ccccc|c|}
\cline { 5 - 5 } \multicolumn{1}{c}{} & 0.200 & 0.200 & 0.600 & Final \\
\cline { 5 - 5 } \multicolumn{1}{c}{} & Tools & Machinery & Parts & Result \\
\hline Fill rate & 0.272 & 0.029 & 0.291 & 0.235 \\
Items repaired & 0.040 & 0.059 & 0.222 & 0.153 \\
Costs & 0.075 & 0.173 & 0.170 & 0.151 \\
MSI & 0.123 & 0.121 & 0.075 & 0.094 \\
OEE & 0.092 & 0.027 & 0.110 & 0.090 \\
MTTR & 0.207 & 0.018 & 0.058 & 0.080 \\
\hline MTBF & 0.013 & 0.229 & 0.025 & 0.063 \\
PM & 0.013 & 0.229 & 0.025 & 0.063 \\
Accidents & 0.153 & 0.084 & 0.008 & 0.052 \\
CSI & 0.013 & 0.032 & 0.017 & 0.019 \\
\hline
\end{tabular}

$2^{\text {nd }}$ and $3^{\text {rd }}$ iteration:

\begin{tabular}{|ccccc|c|}
\cline { 5 - 5 } \multicolumn{1}{c}{} & 0.200 & 0.200 & 0.600 & Final \\
& Tools & Machinery & Parts & Result \\
\hline Fill rate & 0.306 & 0.040 & 0.305 & 0.252 \\
OEE & 0.117 & 0.308 & 0.113 & 0.153 \\
Items repaired & 0.049 & 0.031 & 0.226 & 0.152 \\
Costs & 0.094 & 0.067 & 0.177 & 0.138 \\
MSI & 0.162 & 0.198 & 0.079 & 0.119 \\
\hline MTTR & 0.227 & 0.013 & 0.055 & 0.081 \\
PM audits & 0.015 & 0.172 & 0.015 & 0.046 \\
Overtime & 0.015 & 0.117 & 0.015 & 0.035 \\
PM plan & 0.015 & 0.053 & 0.015 & 0.023 \\
\hline
\end{tabular}




\section{ENSURE ASSETS IN STOCK}

$1^{\text {st }}$ iteration:

\begin{tabular}{|ccccc|c|}
\cline { 3 - 3 } \multicolumn{1}{c|}{} & 0.135 & 0.584 & 0.281 & Final \\
\cline { 5 - 5 } \multicolumn{1}{c|}{} & Stores & Planning & Emergency req. & Result \\
\hline Fill Rate & 0.120 & 0.306 & 0.228 & 0.259 \\
Costs & 0.166 & 0.163 & 0.303 & 0.203 \\
Items Repaired & 0.019 & 0.227 & 0.034 & 0.145 \\
MSI & 0.089 & 0.110 & 0.056 & 0.092 \\
MTTR & 0.034 & 0.055 & 0.166 & 0.083 \\
OEE & 0.015 & 0.074 & 0.090 & 0.071 \\
\hline Inventory & 0.312 & 0.023 & 0.023 & 0.062 \\
CSI & 0.016 & 0.032 & 0.090 & 0.046 \\
Audits & 0.231 & 0.010 & 0.011 & 0.040 \\
\hline
\end{tabular}

$2^{\text {nd }}$ and $3^{\text {rd }}$ iteration:

\begin{tabular}{|ccccc|c|}
\cline { 3 - 3 } \multicolumn{1}{c|}{} & 0.135 & 0.584 & 0.281 & Final \\
\cline { 5 - 5 } \multicolumn{1}{c|}{} & Stores & Planning & Emergency req. & Result \\
\hline Fill Rate & 0.120 & 0.288 & 0.228 & 0.249 \\
Costs & 0.166 & 0.120 & 0.303 & 0.178 \\
OEE & 0.015 & 0.226 & 0.090 & 0.159 \\
Items Repaired & 0.019 & 0.167 & 0.034 & 0.110 \\
MTTR & 0.034 & 0.058 & 0.166 & 0.085 \\
MSI & 0.089 & 0.081 & 0.056 & 0.075 \\
\hline Inventory & 0.312 & 0.019 & 0.023 & 0.060 \\
CSI & 0.016 & 0.031 & 0.090 & 0.046 \\
Audits & 0.231 & 0.010 & 0.011 & 0.040 \\
\hline
\end{tabular}

$1^{\text {st }}, 2^{\text {nd }}$ and $3^{\text {rd }}$ iteration:

\section{MINIMIZE HANDLING TIME}

\begin{tabular}{|ccc|c|}
\cline { 2 - 4 } \multicolumn{1}{c|}{} & $\begin{array}{c}0.500 \\
\text { Identification }\end{array}$ & $\begin{array}{c}0.500 \\
\text { Procedures }\end{array}$ & $\begin{array}{c}\text { Final } \\
\text { Result }\end{array}$ \\
\hline WG status & 0.532 & 0.478 & 0.505 \\
MTTR & 0.236 & 0.278 & 0.257 \\
OEE & 0.137 & 0.139 & 0.138 \\
\hline MSI & 0.075 & 0.081 & 0.078 \\
CSI & 0.021 & 0.025 & 0.023 \\
\hline
\end{tabular}


MINIMIZE TIME TO OBTAIN THE SPARE

$1^{\text {st }}, 2^{\text {nd }}$ and $3^{\text {rd }}$ iteration:

\begin{tabular}{|c|cc|c|}
\cline { 2 - 3 } \multicolumn{1}{c|}{} & $\begin{array}{c}0.750 \\
\text { Near to site }\end{array}$ & $\begin{array}{c}0.250 \\
\text { Quick handling }\end{array}$ & $\begin{array}{c}\text { Final } \\
\text { Result }\end{array}$ \\
\hline MTTR & 0.384 & 0.257 & 0.352 \\
Costs & 0.252 & 0.036 & 0.198 \\
OEE & 0.160 & 0.178 & 0.165 \\
WG status & 0.033 & 0.404 & 0.126 \\
\hline Inventory & 0.111 & 0.016 & 0.087 \\
MSI & 0.060 & 0.109 & 0.072 \\
\hline
\end{tabular}

\section{ENSURE PARTS EQUIPMENT AND TOOLS AVAILABILITY}

$1^{\text {st }}$ iteration:

\begin{tabular}{|c|cc|c|}
\cline { 2 - 2 } \multicolumn{1}{c|}{} & $\begin{array}{c}0.750 \\
\text { In stock }\end{array}$ & $\begin{array}{c}0.250 \\
\text { Prompt Avail. }\end{array}$ & $\begin{array}{c}\text { Final } \\
\text { Result }\end{array}$ \\
\hline Fill rate & 0.358 & 0.027 & 0.275 \\
Costs & 0.243 & 0.246 & 0.244 \\
MTTR & 0.067 & 0.363 & 0.141 \\
Items repaired & 0.165 & 0.015 & 0.127 \\
\hline MSI & 0.099 & 0.066 & 0.091 \\
OEE & 0.046 & 0.174 & 0.078 \\
WG status & 0.022 & 0.110 & 0.044 \\
\hline
\end{tabular}

$2^{\text {nd }}$ and $3^{\text {rd }}$ iteration:

\begin{tabular}{|c|cc|c|}
\cline { 2 - 2 } \multicolumn{1}{c|}{} & $\begin{array}{c}0.750 \\
\text { In stock }\end{array}$ & $\begin{array}{c}0.250 \\
\text { Prompt Avail. }\end{array}$ & $\begin{array}{c}\text { Final } \\
\text { Result }\end{array}$ \\
\hline Fill rate & 0.358 & 0.027 & 0.275 \\
Costs & 0.243 & 0.246 & 0.244 \\
OEE & 0.157 & 0.174 & 0.161 \\
MTTR & 0.071 & 0.363 & 0.144 \\
\hline Items repaired & 0.104 & 0.015 & 0.082 \\
MSI & 0.046 & 0.066 & 0.051 \\
WG status & 0.021 & 0.110 & 0.043 \\
\hline
\end{tabular}


MINIMIZE NEW MATERIAL IN STOCK

$1^{\text {st }}, 2^{\text {nd }}$ and $3^{\text {rd }}$ iteration:

\begin{tabular}{|ccc|c|}
\cline { 2 - 4 } \multicolumn{1}{c|}{} & $\begin{array}{c}0.500 \\
\text { Repairs }\end{array}$ & $\begin{array}{c}0.500 \\
\text { Reduce quantity }\end{array}$ & $\begin{array}{c}\text { Final } \\
\text { Result }\end{array}$ \\
\hline Fill rate & 0.222 & 0.162 & 0.192 \\
Inventory & 0.023 & 0.346 & 0.185 \\
Items repaired & 0.311 & 0.029 & 0.170 \\
Costs & 0.075 & 0.256 & 0.166 \\
Backload & 0.164 & 0.066 & 0.115 \\
\hline OEE & 0.107 & 0.018 & 0.063 \\
MSI & 0.048 & 0.042 & 0.045 \\
WG status & 0.016 & 0.052 & 0.034 \\
FTT & 0.034 & 0.029 & 0.032 \\
\hline
\end{tabular}

$1^{\text {st }}$ iteration:

\section{MINIMIZE INVENTORY}

\begin{tabular}{|c|c|c|c|c|c|}
\hline & $\begin{array}{c}0.261 \\
\text { Unification }\end{array}$ & $\begin{array}{c}0.513 \\
\text { Minimum new material }\end{array}$ & $\begin{array}{c}0.076 \\
\text { Reliable record } \\
\end{array}$ & $\begin{array}{c}0.150 \\
\text { Minimum use }\end{array}$ & $\begin{array}{l}\text { Final } \\
\text { Result }\end{array}$ \\
\hline Fill rate & 0.143 & 0.290 & 0.068 & 0.017 & 0.194 \\
\hline Inventory & 0.242 & 0.214 & 0.227 & 0.017 & 0.193 \\
\hline Costs & 0.331 & 0.127 & 0.162 & 0.047 & 0.171 \\
\hline Items repaired & 0.050 & 0.166 & 0.040 & 0.017 & 0.104 \\
\hline WG status & 0.106 & 0.074 & 0.099 & 0.061 & 0.082 \\
\hline Stock audits & 0.053 & 0.048 & 0.323 & 0.015 & 0.066 \\
\hline PM plan & 0.015 & 0.012 & 0.013 & 0.314 & 0.058 \\
\hline OEE & 0.030 & 0.044 & 0.044 & 0.097 & 0.048 \\
\hline MTBF & 0.015 & 0.012 & 0.013 & 0.208 & 0.042 \\
\hline PM audits & 0.015 & 0.012 & 0.013 & 0.208 & 0.042 \\
\hline
\end{tabular}

$2^{\text {nd }}$ and $3^{\text {rd }}$ iteration:

\begin{tabular}{|c|c|c|c|c|c|}
\hline & $\begin{array}{c}0.261 \\
\text { Unification }\end{array}$ & $\begin{array}{c}0.513 \\
\text { Minimum new material }\end{array}$ & $\begin{array}{c}0.076 \\
\text { Reliable record }\end{array}$ & $\begin{array}{c}0.150 \\
\text { Minimum use }\end{array}$ & $\begin{array}{l}\text { Final } \\
\text { Result }\end{array}$ \\
\hline Inventory & 0.245 & 0.211 & 0.230 & 0.018 & 0.192 \\
\hline Fill rate & 0.142 & 0.285 & 0.061 & 0.018 & 0.191 \\
\hline Items repaired & 0.046 & 0.161 & 0.034 & 0.018 & 0.100 \\
\hline Costs & 0.335 & 0.122 & 0.164 & 0.087 & 0.176 \\
\hline WG status & 0.104 & 0.056 & 0.100 & 0.036 & 0.069 \\
\hline MSI & 0.038 & 0.020 & 0.026 & 0.190 & 0.051 \\
\hline Backload & 0.021 & 0.078 & 0.015 & 0.069 & 0.057 \\
\hline PM audits & 0.011 & 0.010 & 0.010 & 0.243 & 0.045 \\
\hline Stock audits & 0.033 & 0.024 & 0.327 & 0.018 & 0.048 \\
\hline OEE & 0.024 & 0.034 & 0.033 & 0.302 & 0.072 \\
\hline
\end{tabular}


PROMOTE PERSONNEL INVOLVEMENT

$1^{\text {st, }} 2^{\text {nd }}$ and $3^{\text {rd }}$ iteration:

\begin{tabular}{|c|ccc|c|}
\cline { 2 - 2 } \multicolumn{1}{c|}{} & 0.750 & 0.250 & Final \\
\multicolumn{1}{c|}{} & Morale & Awareness & Result \\
\hline MSI & 0.309 & 0.224 & 0.288 \\
OEE & 0.222 & 0.033 & 0.175 \\
WG status & 0.159 & 0.023 & 0.125 \\
Over time & 0.036 & 0.312 & 0.105 \\
MTTR & 0.111 & 0.073 & 0.101 \\
\hline Accidents & 0.079 & 0.108 & 0.086 \\
Applicability & 0.012 & 0.160 & 0.049 \\
CSI & 0.054 & 0.016 & 0.044 \\
Costs & 0.019 & 0.051 & 0.027 \\
\end{tabular}

MINIMIZE CONSUMPTION IN NON OPERATING HOURS

$1^{\text {st, }} 2^{\text {nd }}$ and $3^{\text {rd }}$ iteration:

\begin{tabular}{|c|cc|c|}
\cline { 2 - 4 } \multicolumn{1}{c|}{} & $\begin{array}{c}0.500 \\
\text { Shut } \\
\text { down }\end{array}$ & Personnel involvement & Final \\
\hline Costs & 0.471 & 0.023 & 0.247 \\
MSI & 0.102 & 0.360 & 0.231 \\
WG status & 0.264 & 0.158 & 0.211 \\
OEE & 0.033 & 0.245 & 0.139 \\
\hline Overtime & 0.033 & 0.100 & 0.066 \\
Accidents & 0.066 & 0.046 & 0.056 \\
MTTR & 0.033 & 0.068 & 0.050 \\
\hline
\end{tabular}

$1^{\text {st }}$ iteration:

\section{MINIMIZE LOSSES}

\begin{tabular}{|ccc|c|}
\cline { 2 - 4 } \multicolumn{1}{c|}{} & 0.250 & 0.750 & Final \\
\cline { 3 - 4 } \multicolumn{1}{c|}{} & Personnel detection & PM program & Result \\
\hline PM plan & 0.014 & 0.307 & 0.233 \\
OEE & 0.215 & 0.125 & 0.148 \\
MTBF & 0.028 & 0.177 & 0.140 \\
$5 \%$ Audits & 0.009 & 0.171 & 0.131 \\
MSI & 0.282 & 0.037 & 0.098 \\
CSI & 0.044 & 0.079 & 0.070 \\
\hline WG status & 0.159 & 0.033 & 0.065 \\
Overtime & 0.111 & 0.037 & 0.056 \\
MTTR & 0.085 & 0.014 & 0.032 \\
Accidents & 0.052 & 0.020 & 0.028 \\
\hline
\end{tabular}


$2^{\text {nd }}$ and $3^{\text {rd }}$ iteration:

\begin{tabular}{|ccc|c|}
\cline { 2 - 3 } \multicolumn{1}{c|}{} & 0.250 & 0.750 & Final \\
\multicolumn{1}{c|}{ Detection } & Control program & Result \\
\hline OEE & 0.217 & 0.291 & 0.273 \\
MSI & 0.284 & 0.160 & 0.191 \\
PM audits & 0.013 & 0.209 & 0.160 \\
Overtime & 0.113 & 0.108 & 0.109 \\
PM plan & 0.013 & 0.076 & 0.061 \\
\hline WG status & 0.165 & 0.019 & 0.056 \\
Cost & 0.029 & 0.058 & 0.051 \\
MTBF & 0.020 & 0.043 & 0.037 \\
Accidents & 0.060 & 0.024 & 0.033 \\
MTTR & 0.086 & 0.011 & 0.029 \\
\hline
\end{tabular}

$1^{\text {st }}$ iteration:

\section{OPTIMIZE ENERGY CONSUMPTION}

\begin{tabular}{|ccccc|c|}
\cline { 2 - 3 } \multicolumn{1}{c|}{} & \begin{tabular}{c}
0.429 \\
\cline { 4 - 5 } \multicolumn{1}{c|}{}
\end{tabular} & $\begin{array}{c}0.143 \\
\text { Losses }\end{array}$ & $\begin{array}{c}0.429 \\
\text { Equipment performance }\end{array}$ & $\begin{array}{c}\text { Final } \\
\text { Shut Down }\end{array}$ \\
\hline PM plan & 0.332 & 0.337 & 0.024 & 0.201 \\
Costs & 0.048 & 0.041 & 0.343 & 0.173 \\
OEE & 0.227 & 0.112 & 0.132 & 0.170 \\
MSI & 0.068 & 0.031 & 0.244 & 0.138 \\
MTBF & 0.162 & 0.225 & 0.024 & 0.112 \\
\hline WG status & 0.025 & 0.012 & 0.186 & 0.092 \\
5\% Audits & 0.101 & 0.157 & 0.024 & 0.076 \\
CSI & 0.037 & 0.085 & 0.024 & 0.038 \\
\hline
\end{tabular}

$2^{\text {nd }}$ and $3^{\text {rd }}$ iteration:

\begin{tabular}{|c|ccc|c|}
\cline { 2 - 3 } \multicolumn{1}{c|}{} & \begin{tabular}{c}
0.429 \\
\cline { 4 - 5 } \multicolumn{1}{c|}{}
\end{tabular} & $\begin{array}{c}0.143 \\
\text { Losses }\end{array}$ & $\begin{array}{c}0.429 \\
\text { Equipment performance }\end{array}$ & $\begin{array}{c}\text { Final } \\
\text { Shut Down }\end{array}$ \\
\hline OEE & 0.361 & 0.359 & 0.113 & 0.254 \\
MSI & 0.245 & 0.165 & 0.245 & 0.234 \\
Costs & 0.025 & 0.047 & 0.361 & 0.172 \\
PM audits & 0.159 & 0.244 & 0.019 & 0.111 \\
WG status & 0.068 & 0.016 & 0.167 & 0.103 \\
\hline Overtime & 0.100 & 0.101 & 0.077 & 0.090 \\
PM plan & 0.043 & 0.068 & 0.019 & 0.036 \\
\hline
\end{tabular}




\section{LOGISTICS PILLAR RESULT}

$1^{\text {st }}$ iteration:

\begin{tabular}{|c|cccc|c|}
\cline { 2 - 3 } \multicolumn{1}{c|}{} & \begin{tabular}{c}
0.637 \\
\multicolumn{1}{c}{ Available parts }
\end{tabular} & $\begin{array}{c}0.258 \\
\text { Inventory }\end{array}$ & $\begin{array}{c}0.105 \\
\text { Energy consumption }\end{array}$ & $\begin{array}{c}\text { Final } \\
\text { Result }\end{array}$ \\
\hline Fill rate & 0.287 & 0.156 & 0.019 & 0.225 \\
Costs & 0.212 & 0.211 & 0.228 & 0.213 \\
MTTR & 0.156 & 0.011 & 0.019 & 0.104 \\
Inventory & 0.040 & 0.287 & 0.019 & 0.102 \\
Items repaired & 0.109 & 0.113 & 0.019 & 0.101 \\
OEE & 0.057 & 0.032 & 0.183 & 0.064 \\
MSI & 0.079 & 0.011 & 0.086 & 0.062 \\
WG status & 0.030 & 0.082 & 0.096 & 0.050 \\
PM plan & 0.010 & 0.044 & 0.299 & 0.049 \\
Stock audit & 0.020 & 0.053 & 0.030 & 0.029 \\
\hline
\end{tabular}

$2^{\text {nd }}$ and $3^{\text {rd }}$ iteration:

\begin{tabular}{|ccccc|c|}
\cline { 2 - 3 } \multicolumn{1}{c|}{} & $\begin{array}{c}0.637 \\
\text { Available parts }\end{array}$ & $\begin{array}{c}0.258 \\
\text { Inventory }\end{array}$ & $\begin{array}{c}0.105 \\
\text { Energy consumption }\end{array}$ & $\begin{array}{c}\text { Final } \\
\text { Result }\end{array}$ \\
\hline Fill rate & 0.311 & 0.164 & 0.019 & 0.243 \\
Costs & 0.214 & 0.222 & 0.168 & 0.211 \\
OEE & 0.158 & 0.061 & 0.318 & 0.150 \\
Inventory & 0.030 & 0.311 & 0.019 & 0.102 \\
Items repaired & 0.073 & 0.111 & 0.019 & 0.077 \\
MTTR & 0.111 & 0.013 & 0.019 & 0.076 \\
MSI & 0.054 & 0.033 & 0.227 & 0.067 \\
WG status & 0.039 & 0.056 & 0.092 & 0.049 \\
PM audit & 0.010 & 0.031 & 0.120 & 0.027 \\
\hline
\end{tabular}

\section{TRAINING Pillar}

$1^{\text {st, }} 2^{\text {nd }}$ and $3^{\text {rd }}$ iteration:

\section{DEFINE ON THE JOB TRAINING COURSES}

\begin{tabular}{|c|cccc|c|}
\cline { 2 - 2 } \multicolumn{1}{c|}{} & 0.600 & 0.200 & 0.200 & Final \\
\cline { 5 - 6 } & SKILLS & PROACTIVE & REACTIVE & Result \\
\hline FTT & 0.419 & 0.056 & 0.096 & 0.282 \\
Accidents & 0.290 & 0.110 & 0.080 & 0.212 \\
MTBF & 0.104 & 0.503 & 0.025 & 0.168 \\
MTTR & 0.104 & 0.027 & 0.453 & 0.158 \\
\hline CSI & 0.029 & 0.235 & 0.230 & 0.110 \\
MSI & 0.055 & 0.070 & 0.115 & 0.070 \\
\hline
\end{tabular}




\section{DEFINE COURSES APPLICABLE TO THE POSITION}

$1^{\text {st, }} 2^{\text {nd }}$ and $3^{\text {rd }}$ iteration:

\begin{tabular}{|c|ccccc|c|}
\cline { 2 - 3 } \multicolumn{1}{c|}{} & $\begin{array}{c}0.391 \\
\text { Attitudinal }\end{array}$ & $\begin{array}{c}0.391 \\
\text { Lesson Learned }\end{array}$ & $\begin{array}{c}0.151 \\
\text { On the job }\end{array}$ & $\begin{array}{c}0.067 \\
\text { General }\end{array}$ & $\begin{array}{c}\text { Final } \\
\text { Result }\end{array}$ \\
\hline Accidents & 0.207 & 0.194 & 0.301 & 0.029 & 0.204 \\
MTTR & 0.099 & 0.204 & 0.162 & 0.089 & 0.149 \\
MSI & 0.252 & 0.019 & 0.097 & 0.213 & 0.135 \\
TS & 0.024 & 0.278 & 0.023 & 0.028 & 0.123 \\
5\%Audits & 0.159 & 0.024 & 0.043 & 0.016 & 0.079 \\
CASES & 0.018 & 0.131 & 0.024 & 0.244 & 0.078 \\
\hline MTBF & 0.037 & 0.052 & 0.202 & 0.157 & 0.076 \\
WG & 0.114 & 0.050 & 0.015 & 0.090 & 0.072 \\
CSI & 0.077 & 0.028 & 0.121 & 0.028 & 0.061 \\
COSTS & 0.013 & 0.020 & 0.011 & 0.105 & 0.022 \\
\hline
\end{tabular}

$1^{\text {st, }} 2^{\text {nd }}$ and $3^{\text {rd }}$ iteration:

\section{DETERMINE RIGHT COURSE FOR THE PERSON}

\begin{tabular}{|cccc|c|}
\multicolumn{1}{c|}{} & $\begin{array}{c}0.750 \\
\text { Applicable }\end{array}$ & $\begin{array}{c}0.250 \\
\text { Adequate level }\end{array}$ & Final \\
\multicolumn{1}{c|}{} & 0.298 & 0.019 & 0.228 \\
\hline Accidents & 0.243 & 0.130 & 0.215 \\
MTTR & 0.168 & 0.183 & 0.172 \\
MSI & 0.025 & 0.458 & 0.134 \\
Understanding & 0.112 & 0.031 & 0.092 \\
TS & 0.075 & 0.039 & 0.066 \\
\hline 5\% Audits & 0.050 & 0.089 & 0.060 \\
MTBF & 0.028 & 0.051 & 0.034 \\
CASES & & &
\end{tabular}

ENSURE MATERIALS AND INSTALLATIONS APPLICABILITY $1^{\text {st, }} 2^{\text {nd }}$ and $3^{\text {rd }}$ iteration:

\begin{tabular}{|c|cc|c|}
\cline { 2 - 2 } \multicolumn{1}{c|}{} & $\begin{array}{c}0.750 \\
\text { Similar Inst. }\end{array}$ & $\begin{array}{c}0.250 \\
\text { Course adapt. }\end{array}$ & $\begin{array}{c}\text { Final } \\
\text { Result }\end{array}$ \\
\hline Applicability & 0.594 & 0.501 & 0.571 \\
Understanding & 0.121 & 0.246 & 0.152 \\
MTTR & 0.104 & 0.104 & 0.104 \\
MTBF & 0.104 & 0.104 & 0.104 \\
\hline MSI & 0.078 & 0.045 & 0.070 \\
\hline
\end{tabular}


USE EXTERNAL MATERIAL AND INSTALLATIONS

$1^{\text {st, }} 2^{\text {nd }}$ and $3^{\text {rd }}$ iteration:

\begin{tabular}{|c|cc|c|}
\cline { 2 - 2 } \multicolumn{1}{c|}{} & $\begin{array}{c}0.750 \\
\text { Participation }\end{array}$ & $\begin{array}{c}0.250 \\
\text { Applicable }\end{array}$ & $\begin{array}{c}\text { Final } \\
\text { Result }\end{array}$ \\
\hline Overtime & 0.290 & 0.014 & 0.221 \\
MTTR & 0.165 & 0.167 & 0.166 \\
Backload & 0.178 & 0.014 & 0.137 \\
PM plan & 0.152 & 0.020 & 0.119 \\
Applicability & 0.030 & 0.305 & 0.099 \\
Costs & 0.101 & 0.038 & 0.085 \\
\hline Understanding & 0.013 & 0.226 & 0.066 \\
MSI & 0.045 & 0.092 & 0.056 \\
MTBF & 0.025 & 0.124 & 0.050 \\
\hline
\end{tabular}

$1^{\text {st, }} 2^{\text {nd }}$ and $3^{\text {rd }}$ iteration:

DEVELOP MATERIAL AND INSTALLATIONS INTERNALLY

\begin{tabular}{|c|cccc|c|}
\multicolumn{1}{c|}{} & $\begin{array}{c}0.637 \\
\text { Equipment }\end{array}$ & $\begin{array}{c}0.258 \\
\text { Material }\end{array}$ & $\begin{array}{c}0.105 \\
\text { Logistics }\end{array}$ & $\begin{array}{c}\text { Final } \\
\text { Result }\end{array}$ \\
\hline Costs & 0.481 & 0.076 & 0.554 & 0.384 \\
Applicability & 0.310 & 0.440 & 0.038 & 0.315 \\
Understanding & 0.116 & 0.265 & 0.038 & 0.146 \\
\hline Overtime & 0.034 & 0.154 & 0.291 & 0.092 \\
MSI & 0.059 & 0.064 & 0.080 & 0.063 \\
\hline
\end{tabular}

HAVE APPROPRIATE TRAINING MATERIAL AND INSTALLATIONS $1^{\text {st, }} 2^{\text {nd }}$ and $3^{\text {rd }}$ iteration:

\begin{tabular}{|c|cc|c|}
\cline { 2 - 3 } \multicolumn{1}{c|}{} & $\begin{array}{c}0.500 \\
\text { In site }\end{array}$ & $\begin{array}{c}0.500 \\
\text { Off site }\end{array}$ & $\begin{array}{c}\text { Final } \\
\text { Result }\end{array}$ \\
\hline Overtime & 0.118 & 0.335 & 0.226 \\
Costs & 0.350 & 0.045 & 0.197 \\
Applicability & 0.255 & 0.066 & 0.161 \\
MTTR & 0.048 & 0.245 & 0.146 \\
Understanding & 0.186 & 0.031 & 0.108 \\
\hline Backload & 0.025 & 0.166 & 0.096 \\
PM Plan & 0.017 & 0.113 & 0.065 \\
\cline { 4 - 4 } & & &
\end{tabular}




\section{DEVELOP INTERNAL TRAINER WITHOUT OVERTIME}

$1^{\text {st, }} 2^{\text {nd }}$ and $3^{\text {rd }}$ iteration:

\begin{tabular}{|ccc|c|}
\cline { 2 - 4 } \multicolumn{1}{c|}{} & $\begin{array}{c}0.500 \\
\text { Replacement }\end{array}$ & $\begin{array}{c}0.500 \\
\text { No replacement }\end{array}$ & $\begin{array}{c}\text { Final } \\
\text { Result }\end{array}$ \\
\hline MSI & 0.266 & 0.165 & 0.216 \\
Backload & 0.339 & 0.022 & 0.180 \\
MTTR & 0.028 & 0.298 & 0.163 \\
OEE & 0.028 & 0.298 & 0.163 \\
PM plan & 0.181 & 0.022 & 0.101 \\
\hline CSI & 0.061 & 0.136 & 0.098 \\
Understanding & 0.096 & 0.061 & 0.079 \\
\hline
\end{tabular}

$1^{\text {st, }} 2^{\text {nd }}$ and $3^{\text {rd }}$ iteration:

\section{HAVE PREPARED TRAINERS}

\begin{tabular}{|ccc|c|}
\cline { 2 - 4 } \multicolumn{1}{c|}{} & $\begin{array}{c}0.500 \\
\text { External }\end{array}$ & $\begin{array}{c}0.500 \\
\text { Internal }\end{array}$ & $\begin{array}{c}\text { Final } \\
\text { Result }\end{array}$ \\
\hline Costs & 0.362 & 0.130 & 0.246 \\
Overtime & 0.032 & 0.376 & 0.204 \\
Applicability & 0.226 & 0.090 & 0.158 \\
MSI & 0.091 & 0.221 & 0.156 \\
Understanding & 0.226 & 0.066 & 0.146 \\
\hline Backload & 0.032 & 0.080 & 0.056 \\
MTTR & 0.032 & 0.037 & 0.034 \\
\hline
\end{tabular}

HAVE PEOPLE AVAILABLE FOR TRAINING

$1^{\text {st, }} 2^{\text {nd }}$ and $3^{\text {rd }}$ iteration:

\begin{tabular}{|ccc|c|}
\cline { 2 - 4 } \multicolumn{1}{c|}{} & $\begin{array}{c}0.500 \\
\text { overtime }\end{array}$ & $\begin{array}{c}0.500 \\
\text { No overtime }\end{array}$ & $\begin{array}{c}\text { Final } \\
\text { Result }\end{array}$ \\
\hline Over time & 0.445 & 0.022 & 0.233 \\
MSI & 0.131 & 0.323 & 0.227 \\
Backload & 0.032 & 0.230 & 0.131 \\
Costs & 0.226 & 0.017 & 0.121 \\
MTTR & 0.032 & 0.164 & 0.098 \\
\hline OEE & 0.032 & 0.110 & 0.071 \\
CSI & 0.072 & 0.056 & 0.064 \\
PM plan & 0.032 & 0.078 & 0.055 \\
\cline { 3 - 4 }
\end{tabular}


TRAINING PILLAR RESULT

$1^{\text {st, }} 2^{\text {nd }}$ and $3^{\text {rd }}$ iteration:

\begin{tabular}{|c|ccccc|c|}
\cline { 2 - 5 } \multicolumn{1}{c|}{} & $\begin{array}{c}0.500 \\
\text { Right course }\end{array}$ & $\begin{array}{c}0.147 \\
\text { Installations }\end{array}$ & $\begin{array}{c}0.288 \\
\text { People availability }\end{array}$ & $\begin{array}{c}0.066 \\
\text { Trainer }\end{array}$ & $\begin{array}{c}\text { Final } \\
\text { Result }\end{array}$ \\
\hline Overtime & 0.014 & 0.306 & 0.313 & 0.220 & 0.157 \\
MSI & 0.126 & 0.037 & 0.225 & 0.114 & 0.141 \\
Applicability & 0.194 & 0.159 & 0.028 & 0.163 & 0.139 \\
Accidents & 0.246 & 0.014 & 0.032 & 0.010 & 0.135 \\
MTTR & 0.170 & 0.107 & 0.089 & 0.042 & 0.129 \\
Cost & 0.037 & 0.220 & 0.120 & 0.297 & 0.105 \\
\hline Understanding & 0.127 & 0.082 & 0.014 & 0.080 & 0.085 \\
Backload & 0.016 & 0.055 & 0.167 & 0.057 & 0.068 \\
Troubleshooting & 0.069 & 0.019 & 0.013 & 0.017 & 0.042 \\
\hline
\end{tabular}

\section{PEOPLE Pillar}

$1^{\text {st, }} 2^{\text {nd }}$ and $3^{\text {rd }}$ iteration:

INDUCE EFFECTIVE BOTTOM UP COMMUNICATION

\begin{tabular}{|cccc|c|}
\cline { 2 - 5 } \multicolumn{1}{c|}{} & $\begin{array}{c}0.333 \\
\text { Survey }\end{array}$ & $\begin{array}{c}0.333 \\
\text { Meetings }\end{array}$ & $\begin{array}{c}0.333 \\
\text { Personnel suggestions }\end{array}$ & $\begin{array}{c}\text { Final } \\
\text { Result }\end{array}$ \\
\hline Ideas Implementation & 0.274 & 0.266 & 0.448 & 0.329 \\
WG status & 0.160 & 0.381 & 0.149 & 0.230 \\
MSI & 0.376 & 0.104 & 0.193 & 0.224 \\
CSI & 0.034 & 0.104 & 0.020 & 0.053 \\
\hline Cost & 0.016 & 0.066 & 0.073 & 0.052 \\
MTTR & 0.059 & 0.034 & 0.050 & 0.048 \\
MTBF & 0.059 & 0.020 & 0.027 & 0.035 \\
Accidents & 0.022 & 0.026 & 0.041 & 0.029 \\
\hline
\end{tabular}

INDUCE EFFECTIVE TOP DOWN COMMUNICATION

$1^{\text {st, }} 2^{\text {nd }}$ and $3^{\text {rd }}$ iteration:

\begin{tabular}{|ccccc|c|}
\cline { 2 - 4 } \multicolumn{1}{c|}{} & $\begin{array}{c}0.637 \\
\text { Leadership }\end{array}$ & WG participation & $\begin{array}{c}0.258 \\
\text { Cascades }\end{array}$ & $\begin{array}{c}\text { Final } \\
\text { Result }\end{array}$ \\
\hline MSI & 0.334 & 0.206 & 0.325 & 0.300 \\
OEE & 0.156 & 0.064 & 0.146 & 0.131 \\
MTTR & 0.156 & 0.064 & 0.146 & 0.131 \\
MTBF & 0.156 & 0.064 & 0.146 & 0.131 \\
CSI & 0.084 & 0.206 & 0.043 & 0.112 \\
\hline WG status & 0.023 & 0.332 & 0.031 & 0.103 \\
Cost & 0.060 & 0.032 & 0.146 & 0.062 \\
Ideas Impl. & 0.032 & 0.032 & 0.018 & 0.030 \\
\hline
\end{tabular}


INDUCE EFFECTIVE COMMUNICATION AMONG MAINTENANCE $1^{\text {st, }} 2^{\text {nd }}$ and $3^{\text {rd }}$ iteration:

\begin{tabular}{|c|c|c|c|c|}
\hline & $\begin{array}{c}0.258 \\
\text { Between shifts }\end{array}$ & $\begin{array}{c}0.637 \\
\text { WG meetings }\end{array}$ & $\begin{array}{l}0.105 \\
\text { Union }\end{array}$ & $\begin{array}{l}\text { Final } \\
\text { Result }\end{array}$ \\
\hline WG status & 0.044 & 0.328 & 0.073 & 0.228 \\
\hline $\mathrm{MSI}$ & 0.292 & 0.170 & 0.289 & 0.214 \\
\hline Ideas & 0.014 & 0.201 & 0.073 & 0.139 \\
\hline Accidents & 0.049 & 0.088 & 0.222 & 0.092 \\
\hline Backload & 0.188 & 0.033 & 0.039 & 0.074 \\
\hline MTTR & 0.104 & 0.056 & 0.043 & 0.067 \\
\hline CSI & 0.156 & 0.023 & 0.039 & 0.059 \\
\hline PM plan & 0.110 & 0.033 & 0.016 & 0.051 \\
\hline MTBF & 0.031 & 0.056 & 0.016 & 0.046 \\
\hline Overtime & 0.011 & 0.011 & 0.191 & 0.030 \\
\hline
\end{tabular}

INDUCE EFFECTIVE COMMUNICATION WITH OTHERS $1^{\text {st, }} 2^{\text {nd }}$ and $3^{\text {rd }}$ iteration:

\begin{tabular}{|ccc|c|}
\cline { 3 - 4 } \multicolumn{1}{c|}{} & 0.250 & 0.750 & Final \\
\cline { 3 - 4 } \multicolumn{1}{c|}{ WG meetings } & In site meetings & Result \\
\hline OEE & 0.076 & 0.252 & 0.208 \\
BTS & 0.018 & 0.252 & 0.194 \\
WG status & 0.392 & 0.019 & 0.112 \\
CSI & 0.146 & 0.082 & 0.098 \\
MSI & 0.146 & 0.082 & 0.098 \\
MTTR & 0.076 & 0.098 & 0.092 \\
\hline MTBF & 0.076 & 0.072 & 0.073 \\
Ideas implementation & 0.025 & 0.082 & 0.068 \\
Accidents & 0.044 & 0.061 & 0.057 \\
\hline
\end{tabular}

INDUCE EFFECTIVE LATERAL COMMUNICATION $1^{\text {st, }} 2^{\text {nd }}$ and $3^{\text {rd }}$ iteration:

\begin{tabular}{|ccc|c|}
\cline { 2 - 4 } \multicolumn{1}{c|}{} & $\begin{array}{c}0.500 \\
\text { Maintenance }\end{array}$ & $\begin{array}{c}0.500 \\
\text { Others }\end{array}$ & $\begin{array}{c}\text { Final } \\
\text { Result }\end{array}$ \\
\hline WG status & 0.307 & 0.154 & 0.230 \\
OEE & 0.026 & 0.315 & 0.171 \\
MSI & 0.219 & 0.088 & 0.153 \\
BTS & 0.010 & 0.238 & 0.124 \\
Ideas implementation & 0.162 & 0.030 & 0.096 \\
Accidents & 0.109 & 0.022 & 0.066 \\
\hline CSI & 0.038 & 0.088 & 0.063 \\
MTTR & 0.053 & 0.050 & 0.052 \\
Backload & 0.076 & 0.014 & 0.045 \\
\hline
\end{tabular}


INDUCE EFFECTIVE COMMUNICATION

$1^{\text {st, }} 2^{\text {nd }}$ and $3^{\text {rd }}$ iteration:

\begin{tabular}{|c|ccc|c|}
\cline { 2 - 5 } \multicolumn{1}{c|}{} & $\begin{array}{c}0.333 \\
\text { Bottom up }\end{array}$ & $\begin{array}{c}0.333 \\
\text { Top Down }\end{array}$ & $\begin{array}{c}0.333 \\
\text { Lateral }\end{array}$ & $\begin{array}{c}\text { Final } \\
\text { Result }\end{array}$ \\
\hline MSI & 0.171 & 0.293 & 0.152 & 0.205 \\
WG & 0.213 & 0.056 & 0.284 & 0.184 \\
OEE & 0.027 & 0.205 & 0.217 & 0.150 \\
Ideas & 0.288 & 0.039 & 0.079 & 0.135 \\
MTTR & 0.070 & 0.155 & 0.019 & 0.082 \\
CSI & 0.117 & 0.083 & 0.039 & 0.080 \\
MTBF & 0.052 & 0.112 & 0.019 & 0.061 \\
BTS & 0.009 & 0.011 & 0.108 & 0.043 \\
Accidents & 0.039 & 0.029 & 0.054 & 0.041 \\
Backload & 0.015 & 0.016 & 0.028 & 0.020 \\
\hline
\end{tabular}

$1^{\text {st, }} 2^{\text {nd }}$ and $3^{\text {rd }}$ iteration:

\section{COMMUNICATE CLEAR OBJECTIVES}

\begin{tabular}{|ccc|c|}
\cline { 2 - 4 } \multicolumn{1}{c|}{} & $\begin{array}{c}0.500 \\
\text { Defined objectives }\end{array}$ & $\begin{array}{c}0.500 \\
\text { Communication }\end{array}$ & $\begin{array}{c}\text { Final } \\
\text { Result }\end{array}$ \\
\hline MSI & 0.447 & 0.371 & 0.409 \\
WG status & 0.026 & 0.240 & 0.133 \\
OEE & 0.170 & 0.067 & 0.118 \\
Cost & 0.170 & 0.024 & 0.097 \\
MTTR & 0.086 & 0.106 & 0.096 \\
\hline Ideas Implementation & 0.014 & 0.155 & 0.085 \\
MTBF & 0.086 & 0.037 & 0.062 \\
\hline
\end{tabular}

MAKE PERSONNEL BE COMFORTABLE IN THEIR POSITION $1^{\text {st, }} 2^{\text {nd }}$ and $3^{\text {rd }}$ iteration:

\begin{tabular}{|ccc|c|}
\cline { 3 - 4 } \multicolumn{1}{c|}{} & 0.250 & $\begin{array}{c}0.750 \\
\text { training }\end{array}$ & $\begin{array}{c}\text { Final } \\
\text { Result }\end{array}$ \\
\hline OEE & 0.044 & 0.282 & 0.223 \\
MSI & 0.211 & 0.217 & 0.216 \\
MTTR & 0.080 & 0.166 & 0.144 \\
CSI & 0.026 & 0.118 & 0.095 \\
Overtime & 0.293 & 0.026 & 0.093 \\
MTBF & 0.026 & 0.087 & 0.072 \\
\hline Accidents & 0.109 & 0.031 & 0.051 \\
Applicability & 0.161 & 0.010 & 0.048 \\
PM plan & 0.016 & 0.042 & 0.035 \\
Cost & 0.034 & 0.021 & 0.024 \\
\hline
\end{tabular}


INCREASE EMPLOYEES MOTIVATION

$1^{\text {st, }} 2^{\text {nd }}$ and $3^{\text {rd }}$ iteration:

\begin{tabular}{|c|c|c|c|c|c|c|}
\hline & $\begin{array}{c}0.166 \\
\text { Clear objectives }\end{array}$ & $\begin{array}{c}0.046 \\
\text { Challenging } \\
\text { objectives }\end{array}$ & $\begin{array}{c}0.443 \\
\text { Recognition plan }\end{array}$ & $\begin{array}{l}0.258 \\
\text { Right position }\end{array}$ & $\begin{array}{l}\quad 0.087 \\
\text { Compensation }\end{array}$ & $\begin{array}{l}\text { Final } \\
\text { Result }\end{array}$ \\
\hline MSI & 0.282 & 0.288 & 0.285 & 0.225 & 0.315 & 0.272 \\
\hline OEE & 0.164 & 0.071 & 0.093 & 0.288 & 0.052 & 0.151 \\
\hline WG status & 0.215 & 0.137 & 0.158 & 0.015 & 0.028 & 0.118 \\
\hline Ideas implementation & 0.063 & 0.213 & 0.197 & 0.025 & 0.027 & 0.116 \\
\hline MTTR & 0.086 & 0.071 & 0.093 & 0.163 & 0.056 & 0.106 \\
\hline Costs & 0.112 & 0.033 & 0.093 & 0.031 & 0.221 & 0.089 \\
\hline Overtime & 0.017 & 0.020 & 0.014 & 0.109 & 0.108 & 0.048 \\
\hline $5 \%$ audits & 0.033 & 0.038 & 0.040 & 0.046 & 0.018 & 0.038 \\
\hline Absenteeism & 0.010 & 0.120 & 0.017 & 0.012 & 0.166 & 0.032 \\
\hline CSI & 0.018 & 0.009 & 0.009 & 0.086 & 0.008 & 0.030 \\
\hline
\end{tabular}

CONDUCT APPROPRIATE MANAGER SELECTION

$1^{\text {st, }} 2^{\text {nd }}$ and $3^{\text {rd }}$ iteration:

\begin{tabular}{|ccc|c|}
\cline { 2 - 4 } \multicolumn{1}{c|}{} & $\begin{array}{c}0.500 \\
\text { Internal }\end{array}$ & $\begin{array}{c}0.500 \\
\text { External }\end{array}$ & $\begin{array}{c}\text { Final } \\
\text { Result }\end{array}$ \\
\hline OEE & 0.250 & 0.165 & 0.208 \\
MTTR & 0.250 & 0.165 & 0.208 \\
MTBF & 0.250 & 0.165 & 0.208 \\
cost & 0.030 & 0.374 & 0.202 \\
MSI & 0.133 & 0.079 & 0.106 \\
CSI & 0.088 & 0.051 & 0.069 \\
\cline { 3 - 4 } & & &
\end{tabular}

$1^{\text {st, }} 2^{\text {nd }}$ and $3^{\text {rd }}$ iteration:

DEVELOP HIGHLY QUALIFIED MANAGERS

\begin{tabular}{|ccc|c|}
\multicolumn{1}{c|}{} & 0.750 & 0.250 & Final \\
\multicolumn{1}{c|}{} & Good selection & Training & Result \\
\hline MTTR & 0.240 & 0.067 & 0.197 \\
OEE & 0.240 & 0.028 & 0.187 \\
MTBF & 0.240 & 0.028 & 0.187 \\
MSI & 0.078 & 0.240 & 0.119 \\
Cost & 0.130 & 0.028 & 0.105 \\
\hline Overtime & 0.018 & 0.337 & 0.098 \\
Accidents & 0.039 & 0.107 & 0.056 \\
Applicability & 0.013 & 0.164 & 0.051 \\
\hline
\end{tabular}




\section{SHOW INVOLVEMENT BY GIVING THE EXAMPLE (FOLLOWING STANDARDS)}

$1^{\text {st, }} 2^{\text {nd }}$ and $3^{\text {rd }}$ iteration:

\begin{tabular}{|ccc|c|}
\multicolumn{1}{c|}{} & $\begin{array}{c}0.750 \\
\text { High morale }\end{array}$ & 0.250 & Final \\
Awareness & Result \\
\hline MSI & 0.381 & 0.229 & 0.343 \\
Absenteeism & 0.225 & 0.014 & 0.172 \\
Overtime & 0.071 & 0.331 & 0.136 \\
Accidents & 0.100 & 0.113 & 0.104 \\
CSI & 0.107 & 0.023 & 0.086 \\
\hline MTTR & 0.071 & 0.078 & 0.073 \\
Applicability & 0.013 & 0.168 & 0.052 \\
Cost & 0.032 & 0.043 & 0.035 \\
\hline
\end{tabular}

$1^{\text {st, }} 2^{\text {nd }}$ and $3^{\text {rd }}$ iteration:

\section{INCREASE MANAGEMENT INVOLVEMENT}

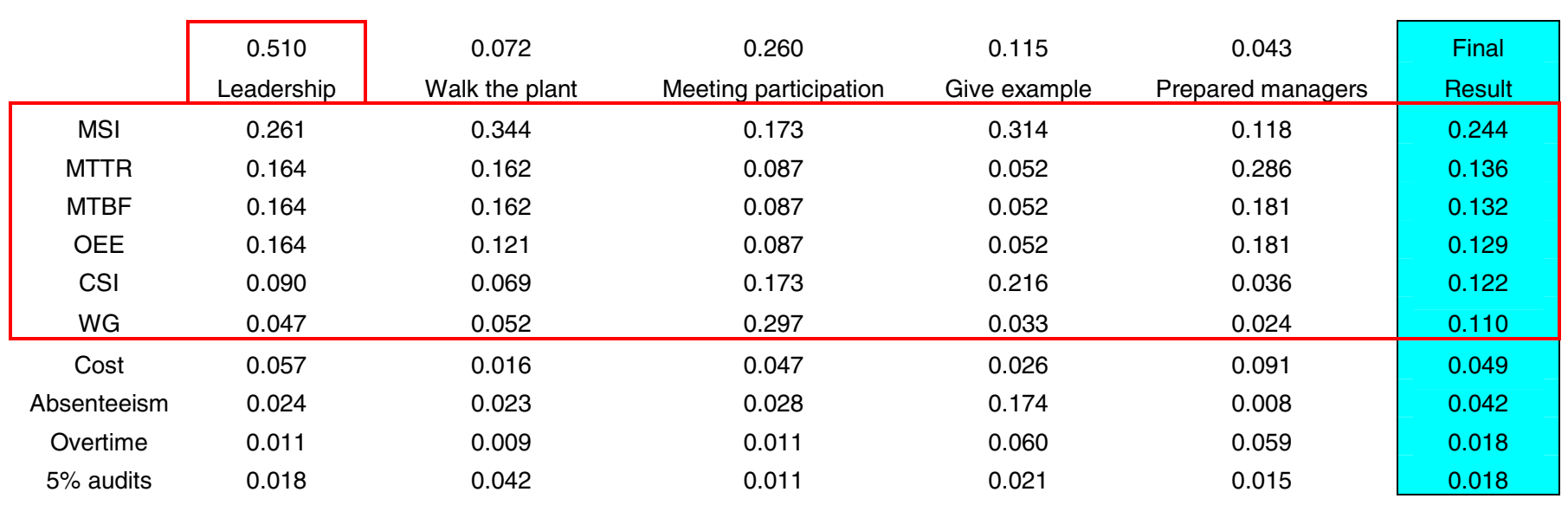

$1^{\text {st, }} 2^{\text {nd }}$ and $3^{\text {rd }}$ iteration:

\section{PROVIDE EMPLOYMENT PLANNING}

\begin{tabular}{|c|c|c|c|c|c|}
\hline & $\begin{array}{c}0.076 \\
\text { Retired employees }\end{array}$ & $\begin{array}{l}0.513 \\
\text { Right position }\end{array}$ & $\begin{array}{c}0.150 \\
\text { Budget }\end{array}$ & $\begin{array}{c}0.261 \\
\text { Shift coverage }\end{array}$ & $\begin{array}{l}\text { Final } \\
\text { Result }\end{array}$ \\
\hline OEE & 0.357 & 0.305 & 0.182 & 0.244 & 0.275 \\
\hline MTTR & 0.174 & 0.155 & 0.059 & 0.122 & 0.133 \\
\hline MSI & 0.041 & 0.200 & 0.018 & 0.036 & 0.118 \\
\hline CSI & 0.078 & 0.095 & 0.028 & 0.147 & 0.097 \\
\hline Cost & 0.126 & 0.033 & 0.300 & 0.015 & 0.076 \\
\hline PM plan & 0.032 & 0.027 & 0.071 & 0.157 & 0.068 \\
\hline Backload & 0.063 & 0.053 & 0.027 & 0.120 & 0.067 \\
\hline MTBF & 0.017 & 0.077 & 0.059 & 0.065 & 0.067 \\
\hline Overtime & 0.011 & 0.013 & 0.241 & 0.075 & 0.063 \\
\hline FTT repair & 0.100 & 0.042 & 0.014 & 0.019 & 0.036 \\
\hline
\end{tabular}




\section{PROVIDE WITH A GOOD WORK ENVIRONMENT}

$1^{\text {st }}$ iteration:

\begin{tabular}{|ccc|ccc|c|}
\multicolumn{1}{c}{} & 0.288 & 0.147 & 0.500 & 0.066 & Final \\
\multicolumn{1}{c}{} & O / M ratio & Healthy & Safe & Tools \& equip. & Result \\
\hline Accidents & 0.045 & 0.119 & 0.310 & 0.069 & 0.190 \\
MSI & 0.201 & 0.271 & 0.140 & 0.095 & 0.174 \\
CSI & 0.066 & 0.271 & 0.140 & 0.024 & 0.130 \\
Absenteeism & 0.021 & 0.119 & 0.205 & 0.013 & 0.127 \\
Overtime & 0.287 & 0.036 & 0.035 & 0.009 & 0.106 \\
MTTR & 0.153 & 0.089 & 0.059 & 0.138 & 0.096 \\
\hline OEE & 0.080 & 0.050 & 0.073 & 0.057 & 0.070 \\
Backload & 0.124 & 0.025 & 0.019 & 0.032 & 0.051 \\
Fill rate & 0.011 & 0.011 & 0.010 & 0.282 & 0.028 \\
Inventory & 0.011 & 0.011 & 0.010 & 0.282 & 0.028 \\
\hline
\end{tabular}

$2^{\text {nd }}$ and $3^{\text {rd }}$ iteration:

\begin{tabular}{|c|c|c|c|c|c|}
\hline & $\begin{array}{c}0.288 \\
\mathrm{O} / \mathrm{M} \text { ratio }\end{array}$ & $\begin{array}{c}0.147 \\
\text { Healthy }\end{array}$ & $\begin{array}{l}0.500 \\
\text { Safe }\end{array}$ & $\begin{array}{c}0.066 \\
\text { Tools \& equip. }\end{array}$ & $\begin{array}{c}\text { Final } \\
\text { Result }\end{array}$ \\
\hline Accidents & 0.045 & 0.119 & 0.310 & 0.032 & 0.187 \\
\hline MSI & 0.201 & 0.271 & 0.140 & 0.083 & 0.173 \\
\hline CSI & 0.066 & 0.271 & 0.140 & 0.018 & 0.130 \\
\hline Absenteeism & 0.021 & 0.119 & 0.205 & 0.012 & 0.126 \\
\hline Overtime & 0.287 & 0.036 & 0.035 & 0.012 & 0.106 \\
\hline MTTR & 0.153 & 0.089 & 0.059 & 0.158 & 0.097 \\
\hline OEE & 0.080 & 0.050 & 0.073 & 0.112 & 0.074 \\
\hline Backload & 0.124 & 0.025 & 0.019 & 0.032 & 0.051 \\
\hline Fill rate & 0.011 & 0.011 & 0.010 & 0.311 & 0.030 \\
\hline Costs & 0.011 & 0.011 & 0.010 & 0.230 & 0.025 \\
\hline
\end{tabular}

\section{PEOPLE PILLAR RESULT}

$1^{\text {st, }} 2^{\text {nd }}$ and $3^{\text {rd }}$ iteration:

\begin{tabular}{|c|cccccc|c|}
\cline { 2 - 4 } \multicolumn{1}{c|}{} & $\begin{array}{c}0.452 \\
\text { Motivation }\end{array}$ & $\begin{array}{c}0.158 \\
\text { Management }\end{array}$ & $\begin{array}{c}0.034 \\
\text { Employment planning }\end{array}$ & $\begin{array}{c}0.092 \\
\text { Communication }\end{array}$ & $\begin{array}{c}0.263 \\
\text { Work environment }\end{array}$ & $\begin{array}{c}\text { Final } \\
\text { Result }\end{array}$ \\
\hline MSI & 0.282 & 0.284 & 0.170 & 0.281 & 0.205 & 0.258 \\
OEE & 0.215 & 0.112 & 0.297 & 0.154 & 0.042 & 0.150 \\
WG status & 0.159 & 0.058 & 0.017 & 0.207 & 0.021 & 0.106 \\
MTTR & 0.082 & 0.217 & 0.219 & 0.083 & 0.059 & 0.102 \\
Accidents & 0.010 & 0.012 & 0.015 & 0.030 & 0.293 & 0.086 \\
CSI & 0.024 & 0.080 & 0.119 & 0.062 & 0.157 & 0.075 \\
Ideas implementation & 0.113 & 0.020 & 0.010 & 0.114 & 0.012 & 0.068 \\
Overtime & 0.056 & 0.030 & 0.056 & 0.015 & 0.080 & 0.055 \\
Absenteeism & 0.038 & 0.028 & 0.027 & 0.009 & 0.116 & 0.054 \\
MTBF & 0.020 & 0.160 & 0.072 & 0.045 & 0.014 & 0.045 \\
\hline
\end{tabular}




\section{References}

1. P. Willmott, "Total productive maintenance. The Western way", Boston MA, Butterworth-Heinemann, 1994.

2. S. O. Duffuaa, A Raouf, J.D. Campbell, "Planning and Control of Maintenance Systems. Modeling and Analysis”, NY, John Wiley \& Sons, NY, 1999

3. R. S. Kaplan, D. P. Norton, "The balanced scorecard: translating strategy into action”, Boston MA, Harvard Business School Press, 1996

4. M. Modarres, S. W. Cheon, "Function-centered modeling of engineering systems using the goal tree-success tree technique and functional primitives", Reliability Engineering and System Safety, Vol. 64, Issue 2, May 1999

5. T. L. Saaty, "The analytic hierarchy process", NY, Mc Graw-Hill, 1980

6. D. Mather, "The Maintenance Scorecard: Creating Strategic Advantage”, NY, Industrial Press, 2005

7. M. Modarres, M. Kaminsky, V. Kristov, "Reliability Engineering and Risk Analysis”, NY, Marcel Dekker Inc., 1999

8. R.D. Palmer, "Maintenance planning and scheduling handbook", NY, Mac GrawHill Handbooks, 1999

9. T. Wireman, "Developing performance indicators for managing maintenance", NY, Industrial Press Inc., 1998

10. B.W. Niebel, "Engineering maintenance management", Second edition, $N Y$, Marcel Dekker Inc., 1994 
11. R.F. Pagano, "An organization tool to enhance work motivation - part I - Job Satisfaction" Physician Executive, 1993

12. C. Ray Asfahl, "Industrial Safety and Health Management", NJ, Prentice Hall, 2003

13. T. L. Saaty, “The Analytic Network Process: Decision Making with Dependence and Feedback”, , Pittsburgh, PA, RWS Publications, June 2001

14. A. Ishizaka, D. Balkenborg, T. Kaplan, "AHP does not like compromises: the role of measurement scales", University of York publications, September 2005

15. C. D. Wickens, J. G. Hollands, "Engineering Psychology and Human Performance", NJ, Prentice Hall, 2000

16. M. Bevilacqua, M. Braglia, "The analytic hierarchy process applied to maintenance strategy selection”, Reliability Engineering \& System Safety, Issue 7, March 2000

17. A. W. Labib, R.F. O’Connor, G.B. Williams, “An effective maintenance system using the analytic hierarchy process", Integrated Manufacturing Systems, MCB University Press, 1998 